Maria Heloisa Massola Shimizu

\title{
A N-acetilcisteína Atenua a Progressão da Doença Renal Crônica
}

Tese apresentada à Faculdade de Medicina da Universidade de São Paulo para obtenção do título de Doutor em Ciências

Área de Concentração: Fisiopatologia Experimental

Orientador: Prof. Dr. Antonio Carlos Seguro

São Paulo

2005 
Este trabalho foi realizado no Laboratório de Pesquisa Básica, $\mathcal{L I M} 12$

Disciplina de Nefrologia

Hospital das Clínicas da Faculdade de Medicina da

Unive rsidade de $\mathcal{S}$ ão Paulo, $\mathcal{S P}$

Colaboração: Fundação Faculdade de Medicina e LI M-HCH.

FMUIS $P$ 


\title{
De dic atória
}

Ao grande gue rreiro

meu que rido e amado irmãa,

VICEN $\mathcal{T} \mathcal{E}$

\author{
Dentro de mim há um lugar \\ onde meus sonhos mais ternos residem \\ onde minhas esperanças mais caras permanecem vivas, \\ onde meus sentimentos mais profundos são sentidos \\ e onde minhas lembranças favoritas são \\ acalantadas com segurança e aconchego \\ Me u coração é uma fonte perene de felicidade \\ Apenas as coisas mais especiais em me u mundo \\ conseguem penetrar nesse lugar e lá \\ permanecem para sempre \\ Esempre que entro em contato \\ com as esperanças, sentimentos e le mbranças \\ e m meu coração, percebo a profundidade \\ Com que mintha vida foi tocada por você.
}


Ao Yu, me u compantie iro de todos os momentos e ao Diego, meu filho, minhaluz. 


\section{Agradecimento especial}

Ao Prof. Dr. Antonio Carlos Seguro, meu amigo Toninho, que admiro pelo seu caráter, de terminação, fumildade, coerência e pela sua inteligência impar. Acreditando e m meu potencial incentiva-me sempre, respeitando minha personalidade e modo de ser. $\mathcal{A}$ ele, meu reconfecimento e gratidão. 


\section{Agradecimentos}

À minha querida Ciça, pelo cuidado e atenção que de dica aos nossos animais e o carinho que tem comigo.

Ao Nivaldo, me u grande amigo, e a Eloá, que garantem a nossa infraestrutura no laboratório Ao Dr. Isac de Castro, pelo suporte em informática. 
"Nãa exis te oceano

\author{
maior que a \\ determinação fumana"
}

Lars Grael 


\section{Índice}

\section{Resumo \\ Summary}

1. Introdução 1

1.1. Geração de espécies reativas com oxigênio, nitrogênio e cloro na insuficiência renal crônica (DRC) e substâncias antioxidantes......

1.2. Antioxidantes.

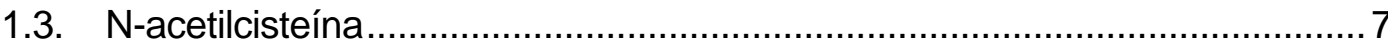

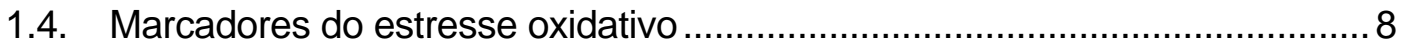

1.5. Doença Renal Crônica....................................................................... 11

1.6. Papel do sistema renina-angiotensina-aldosterona na doença renal.......... 13

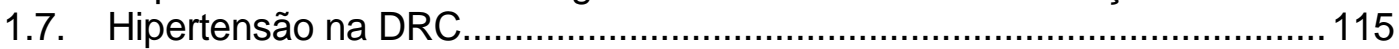

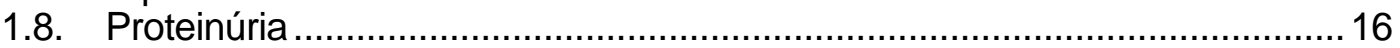

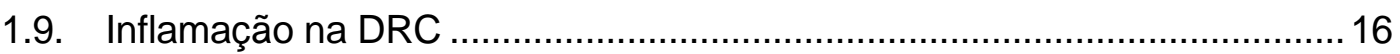

1.10. Aldosterona na doença renal e Espironolactona (Spi) ............................. 17

2. Objetivos ..............................................................................................20

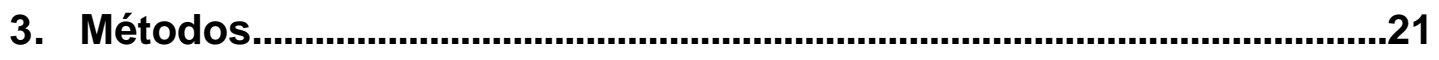

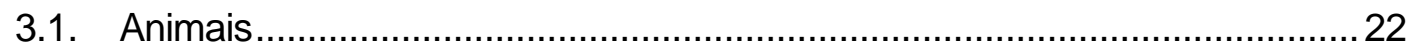

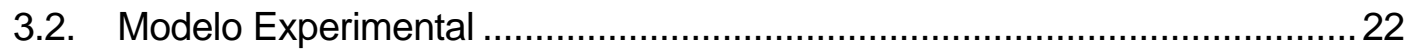

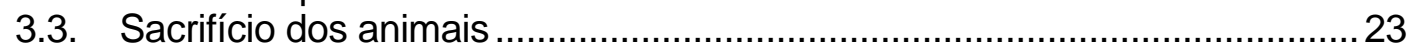

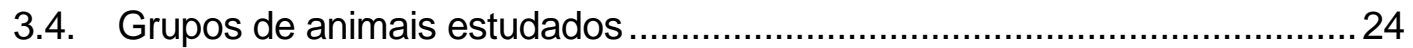

3.4.1. Grupos de animais sham e com insuficiência renal crônica $(\mathrm{Nx})$..........24

3.4.2. Grupos de animais sham e com Insuficiência renal crônica (Nx) tratado precocemente com N-acetilcisteína (NAC) ..........................................2 24

3.4.3. Grupos de animais com Insuficiência renal crônica $(\mathrm{Nx})$ tratados tardiamente com N-acetilcisteína (NAC) ....................................................... 225 3.4.4. Grupos de animais com Insuficiência renal crônica $(\mathrm{Nx})$ tratados ou não com NAC e com Espironolactona (Spi) ...................................................2225

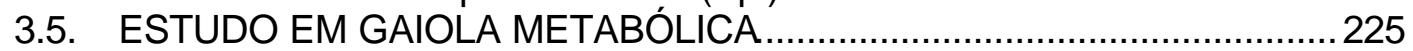

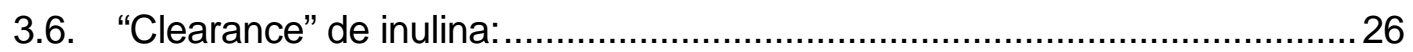

3.6.1. Dosagem e cálculo do clearance de inulina ........................................27

3.6.2. Relação potássio urinário/sódio urinário.............................................28

3.6.3. Medida da pressão arterial durante o experimento.............................. 28

3.6.4. Dosagem da proteinúria .................................................................. 28

3.6.5. Dosagem da aldosterona plasmática ............................................. 28

3.6.6. Dosagem das substâncias reativas com ácido tiobarbitúrico (TBARS) 28

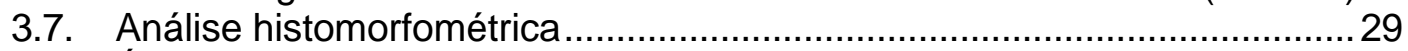

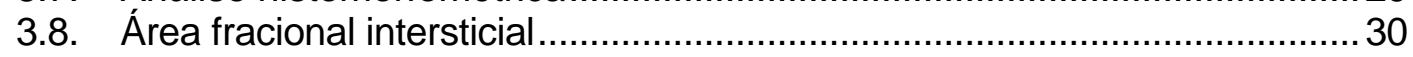

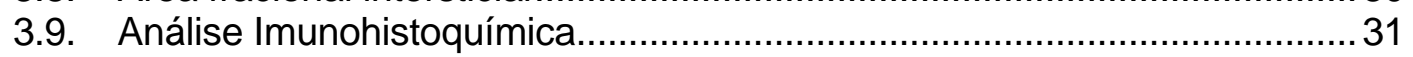

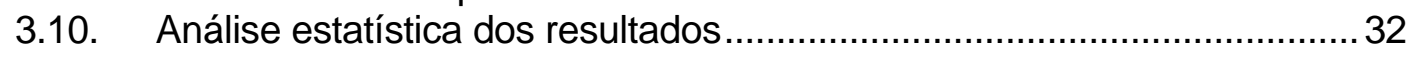

4. Resultados ............................................................................................33

4.1. Grupos de animais sham e após 21, 60 e 120 dias de nefrectomia (Nx), tratados ou não com com $\mathrm{N}$-acetilcisteína (NAC), iniciada no $7^{\circ}$ dia após cirurgia

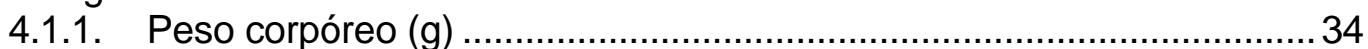

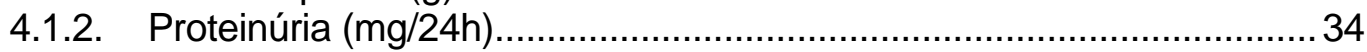


4.1.3. Ingestão de NAC (mg/100g PC/dia) .............................................. 35

4.1.4. Substâncias reativas com ácido tiobarbitúrico (TBARS) na urina (nmoles/24h)

4.2. Outros resultados dos grupos de animais sham e após 21, 60 e 120 dias de nefrectomia (Nx), tratados ou não com com $\mathrm{N}$-acetilcisteína (NAC), iniciada no $7^{\circ}$ dia após cirurgia :.....

4.2. Pressão arterial $(\mathrm{mmHg})$

4.2. "Clearance" de inulina (m//min/100g PC)

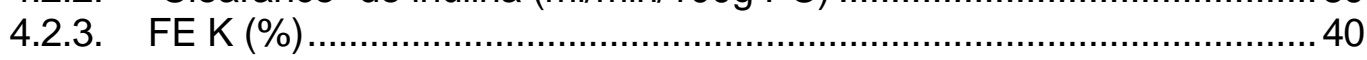

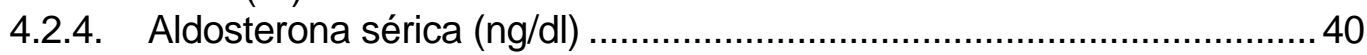

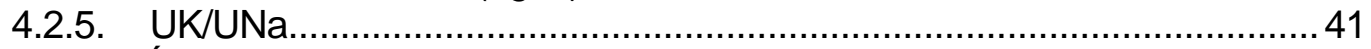

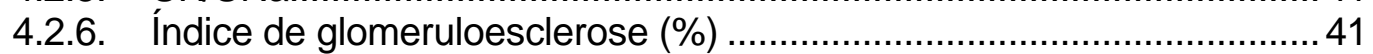

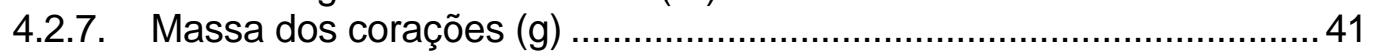

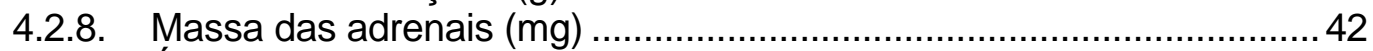

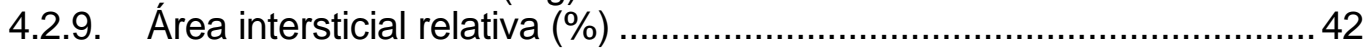

4.2.10. Imunohistoquímica para ED-1 (macrófagos/monócitos)...................... 43

4.2.11. Imunohistoquímica para CD-3 (linfócitos T) ....................................... 43

4.3. Grupos de animais sham e com Insuficiência renal crônica (Nx) tratados

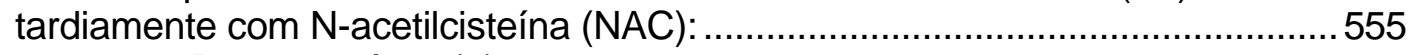

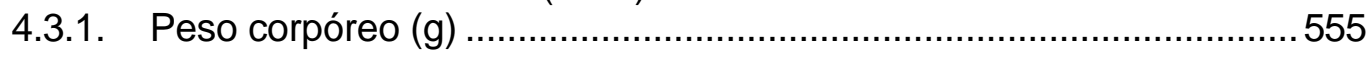

4.3.2. Ingestão de NAC (mg/100g PC/dia) ........................................... 555

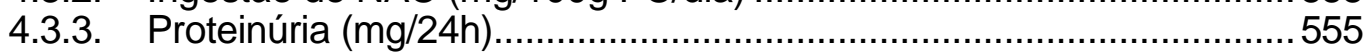

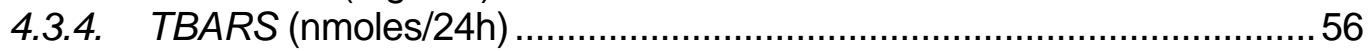

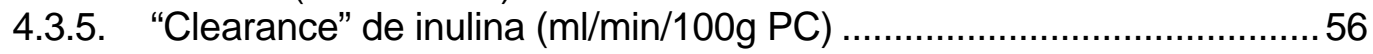

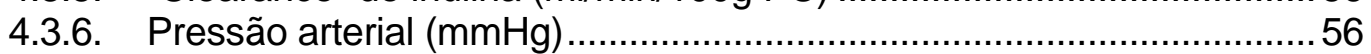

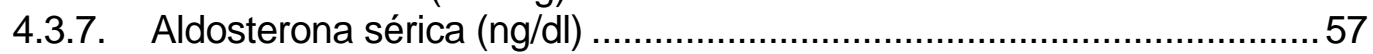

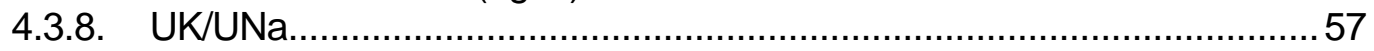

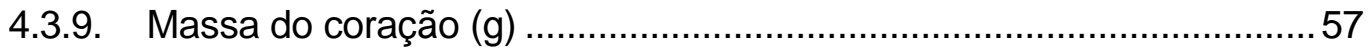

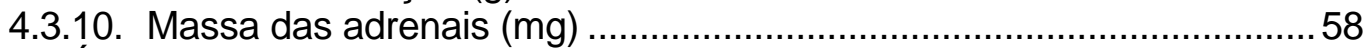

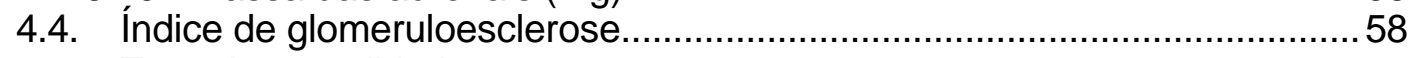

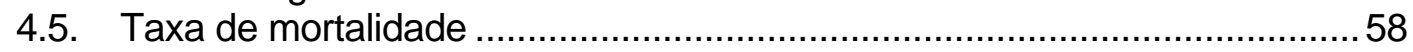

4.6. Grupo de animais sham e nefrectomizados ( $\mathrm{Nx}$ ) de 60 dias, tratados com

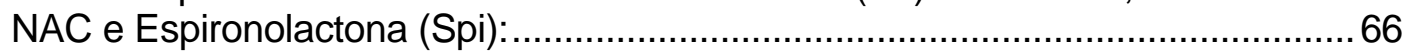

4.6.1. Ingestão de NAC (mg/dia/rato) .....................................................66

4.6.2. Ingestão de espironolactona (Spi) (mg/Kg PC/rato) .............................66 66

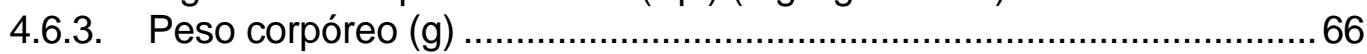

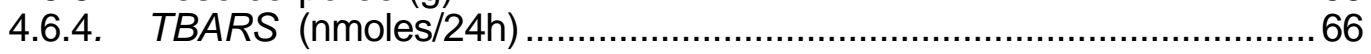

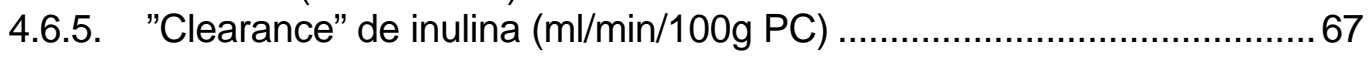

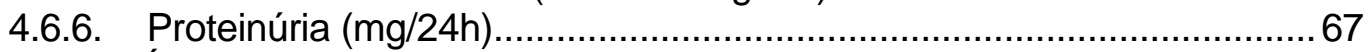

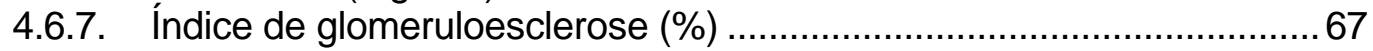

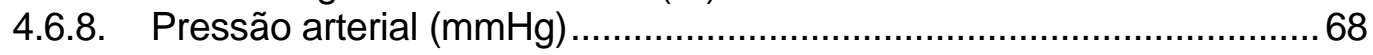

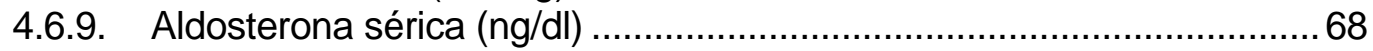

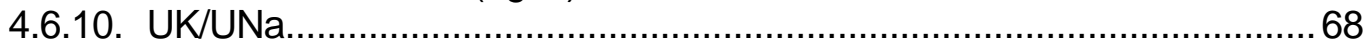

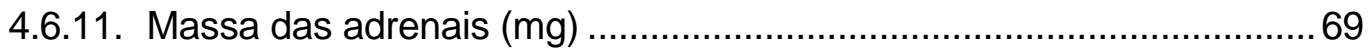

4.6.12. Massa dos corações $(\mathrm{g})$.................................................................69

4.6.13. Correlação (UV proteína/Cin/índice de glomeruloesclerose) log 10 .....69

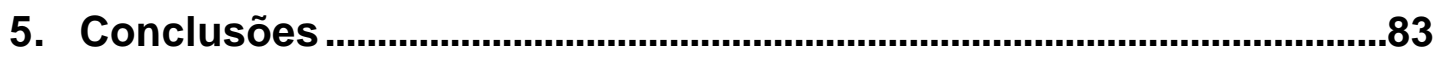

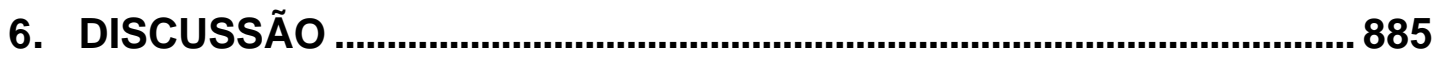

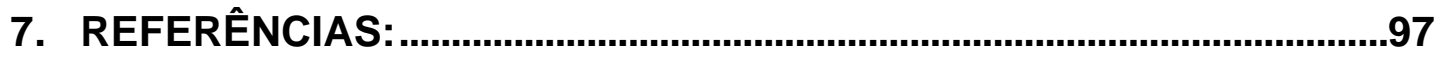




\section{RES ULMO}

SHIMIZU; M. H. M. - A N-acetilcisteína atenua a progressão da doença renal crônica. São Paulo, 2005. 105p. Tese (Doutorado) - Faculdade de Medicina da Universidade de São Paulo.

Os biomarcadores do estresse oxidativo encontram-se elevados na urina e no plasma dos pacientes renais crônicos. A aldosterona (ALD) contribui para a lesão renal no modelo de rins remanescentes.

Objetivos: 1-Determinar o efeito do antioxidante $\mathrm{N}$-acetilcisteína (NAC) sobre a função renal e a aldosterona plasmática de animais com IRC. 2Avaliar o efeito da NAC sobre a evolução da IRC, mesmo quando administrada tardiamente. 3 - Avaliar os efeitos da NAC associada a Espironolactona (Spi).

Material e Métodos: Ratos adultos Wistar machos foram submetidos a nefrectomia de 5/6 (Nx). No estudo 1: Animais foram tratados ou não com NAC na dose de (600mg/l na água de beber) iniciado 7dias após nefrectomia $(\mathrm{Nx})$. Estudos de clearance foram realizados em todos os grupos, 21, 60 e 120 dias após Nx. No estudo 2: 6 animais foram tratados com NAC após 60 dias de Nx e estudados 120 dias após NX. No estudo 3: Os ratos foram tratados com Spi (1.5g/kg de dieta) associados ou não com NAC, ambos iniciados a partir do $7^{\circ}$ dia da nefrectomia e estudados 60 dias após a Nx. Em todos os grupos foram avaliados: clearance de inulina (RFG, ml/min/100g peso); proteinúria (Uvpr., mg/24h); aldosterona plasmática $(\mathrm{ng} / \mathrm{dl})$; relação potássio/sódio urinário (UK/UNa), pressão arterial (mmHg), TBARS urinário (nmoles/24h) e 0 índice de glomeruloesclerose (\%).

Resultados: A ingestão média de NAC foi similar nos respectivos grupos tratados. Significante diminuição de TBARS (marcador de peroxidação lipídica), foi observada nos ratos Nx tratados com NAC (mesmo quando administrado tardiamente). O principal resultado deste estudo foi que a administração de NAC nos animais com nefrectomia de 5/6, protegeu a filtração glomerular (GFR) significativamente, com uma média de 
clearance de inulina de $0.45 \mathrm{ml} / \mathrm{min}$ ( $50 \%$ dos valores normais), mantendose estável 120 dias após a nefrectomia. $(0,51 \pm 0,03)$. Ao contrário, GFR diminuiu progressivamente nos animais não tratados $(0,16 \pm 0,03)$. Nos animais $\mathrm{Nx}+\mathrm{NAC}$, a proteinúria, o índice de glomeruloesclerose e a pressão arterial, apresentaram diminuição após 120 dias de $\mathrm{Nx}$ e hipertrofia dos corações e das adrenais foram atenuadas. Estes efeitos benéficos estão associados com uma significante redução da aldosterona plasmática e da razão UK/UNa (marcador indireto da ação tubular da aldosterona) e foram observados mesmo com a administração tardia de NAC (60 dias após Nx). A mortalidade foi de $33 \%$ no grupo de Nx120, 25\% no grupo Nx120+NAC e 10\% nos animais Nx120+60NAC.

No estudo 3: A espironolactona isoladamente diminuiu a proteinúria dos animais $\mathrm{Nx}$, entretanto, quando associada a NAC promoveu maior proteção da filtração glomerular (Nx60+NAC+Spi=0,59 $\pm 0,04$ vs. $\mathrm{Nx}+60+\mathrm{NAC}=0,47 \pm 0,05, \quad \mathrm{p}<0,001)$ e menor pressão arterial $(136 \pm 2 \mathrm{mmHg})$ do que nos animais tratados apenas com NAC $(154 \pm 2$ $\mathrm{mmHg})$.

\section{Conclusões:}

1. O antioxidante NAC exerceu efeito protetor sobre a filtração glomerular de ratos com insuficiência renal crônica, mesmo quando administrado tardiamente, além de diminuir as concentrações de aldosterona e TBARS, marcador de peroxidação lipídica.

2. A associação de NAC e espironolactona proporcionou efeito benéfico aditivo sobre a filtração glomerular, acompanhado de uma maior queda da pressão arterial.

Descritores: 1.Ratos Wistar 2.Insuficiência renal crônica 3.Acetilcisteína 4.Peroxidação de lipídeos 5.Substâncias reativas com ácido tiobarbitúrico 6.Testes de função renal 7.Inulina 8.Aldosterona 9.Espironolactona. 


\section{$S \mathcal{U M M A R Y}$}

SHIMIZU; M. H. M. - N-acetylcysteine attenuates the progression of chronic kidney disease. São Paulo, 2005. 105p. Tese (Doutorado) - Faculdade de Medicina da Universidade de São Paulo.

Oxidative stress biomarkers are increased in urine and plasma from renal chronic patients. Aldosterone (ALD) contributes to the kidney lesion in the remnant kidney model. Objectives: This studies was carried out to: 1Determine the effect of antioxidant $\mathrm{N}$-acetylcysteine (NAC) on kidney function and plasma aldosterone on animals with chronic renal failure (CRF); 2- Evaluate the effect of NAC on the CRF evolution, even when administered at a later stage; 3-Evaluate the effects of NAC associated with spironolactone (SPI).

Material and Methods: Adult male Wistar rats were submitted to $5 / 6$ nephrectomy (Nx). In study 1: Animals were treated or not with NAC (600 $\mathrm{mg} / \mathrm{l}$ in drinking water), started 7 days after Nx. Clearance studies were performed on all rats at 21, 60 and 120 days after Nx. In study 2: 6 rats were treated with NAC initiated 60 days after Nx and studied 120 days after Nx. In study 3: rats were treated with Spi (1.5 g/Kg diet) associated or not to $\mathrm{NAC}$, both initiated 7 days after $\mathrm{Nx}$-treated rats and studied 60 days after $N x$. In all experiments the following were measured: inulin clearance (GRF, $\mathrm{ml} / \mathrm{min} / 100 \mathrm{~g}$ body weight); proteinuria (Uvpr, $\mathrm{mg} / 24 \mathrm{~h}$ ); plasma aldosterone $(\mathrm{ng} / \mathrm{dl})$; urinary potassium/sodium ratio (UK/UNa); blood pressure $(\mathrm{mmHg})$; urinary TBARS (nmoles/24h) and glomerulosclerosis index (\%).

Results: Mean daily NAC ingestion was similar in respective treated groups. A significant decrease in urinary TBARS (an index of lipid peroxidation) was observed in the NAC treated rats even when administered at a later stage. The main new finding of this study is that NAC administration to $5 / 6-\mathrm{Nx}$ rats protects the glomerular filtration rate (GFR) significantly, with a mean inulin clearance of $0.45(50 \%$ of the normal values), remaining stable 120 days following nephrectomy $(0.51 \pm 0.03)$. 
Conversely, GFR fell progressively in untreated rats $(0.16 \pm 0.03)$. In $\mathrm{Nx}+\mathrm{NAC}$ rats, proteinuria, glomerulosclerosis index and blood pressure all decreased by day 120 , and heart and adrenal hypertrophy were attenuated. These beneficial effects were associated with a significant reduction in plasma aldosterone and urinary sodium/potassium (UK/UNa) ratio (indirect marker of aldosterone tubular action) and were observed even when NAC was administered later (60 days after Nx). Mortality was 33\% in the $\mathrm{Nx} 120$ group, $25 \%$ in the $\mathrm{Nx} 120+\mathrm{NAC}$ group and $14.3 \%$ in the $\mathrm{N} \times 120$ (Nx60+60NAC). In study 3: Spironolactone isolatedly decreased proteinuria in the Nx animals, however when associated with NAC it caused more

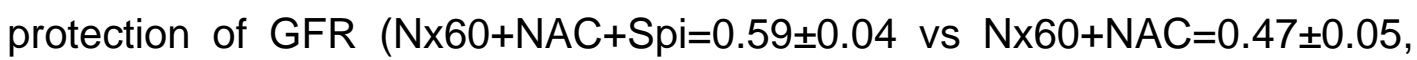
$p<0.001)$ and lower blood pressure $(136 \pm 2 \mathrm{mmHg})$ than in the animals treated only with NAC $(154 \pm 2 \mathrm{mmHg})$. The combination of Spi and NAC lowered blood pressure and improve GFR protection.

\section{Conclusion:}

1. In the remnant kidney model, NAC has a protective effect attributable to decreased plasma aldosterone and lower of lipid peroxidation indicative of thiobarbituric acid reactive substances (TBARS) lower levels, even in the later stages.

2. Combination of NAC and Spi showed an extra beneficial effect over glomerular filtration, and a higher decrease of blood pressure.

Descriptors: 1.Wistar rats 2.Chronic Kidney Failure 3.Acetylcysteine 4.Lipid peroxidation 5. Thiobarbituric acid reactive 6.Kidney function renal 7.Inulin 8.Aldosterone 9.Spironolactone 
1. Introduçãa 


\section{Introdução}

\subsection{Geração de espécies reativas com oxigênio, nitrogênio e cloro na insuficiência renal crônica (DRC) e substâncias antioxidantes.}

O oxigênio possui dupla face - provedor de vida, mas simultaneamente autor da degeneração e morte celular, o que resulta no aparecimento de substâncias reativas com o oxigênio que estão envolvidas na fisiopatologia de uma série de doenças.

Em condições normais, estas substâncias reativas têm importância como sinalizadores moleculares e são geradas pela ativação de leucócitos e macrófagos, desempenhando papel essencial na defesa do organismo contra microorganismos invasores e na manutenção da integridade das células.

O estresse oxidativo é definido como um "desbalanço" entre uma excessiva geração de compostos oxidantes e a insuficiência dos mecanismos de defesa antioxidantes que contribuem para a patogênese de diferentes doenças. Ambos, oxidantes e antioxidantes, exercem profundo impacto na expressão dos genes. ${ }^{1,2}$

O estresse oxidativo é um fator potencialmente importante na mortalidade dos pacientes com DRC e mediador de muitas complicações principalmente cardiovascular e neurológica ${ }^{3}$.Está envolvido na patogênese 
da hipertensão, disfunção endotelial, aterosclerose e inflamação. Encontrase tanto em pacientes com insuficiência renal leve a moderada, assim como naqueles que já necessitam de diálise. $\mathrm{Na} I R C$, o estresse oxidativo ocorre pelos efeitos das toxinas urêmicas, angiotensina II, citoquinas proinflamatórias, sobrecarga de ferro, infecções crônicas, desordens imunológica ou metabólica, assim como a diabetes ${ }^{3,4,5}$.

A cadeia respiratória mitocondrial representa a mais importante fonte de oxidantes no organismo como parte da fosforilação oxidativa. A primeira substância reativa com o oxigênio formada pelo organismo é o superóxido $\left(\mathrm{O}_{2}{ }^{-}\right)$. O sistema de enzimas NADPH-oxidase (nicotinamida adenina dinucleotídeo fosfato - forma reduzida), encontrado nas membranas das células reduz o oxigênio molecular $\mathrm{O}_{2}$, em ânion superóxido $\left(\mathrm{O}_{2}^{-}\right)$, altamente instável que logo a seguir é convertido a peróxido de hidrogênio $\left(\mathrm{H}_{2} \mathrm{O}_{2}\right)$ pela enzima superóxido dismutase ${ }^{3}$ (SOD)

$$
\begin{aligned}
& \mathbf{O}_{2}+\mathbf{e} \rightarrow \mathbf{O}_{2^{-}} \\
& \mathbf{O}_{2}^{-}+\mathbf{O}_{2}^{-}+2 \mathrm{H}^{+} \stackrel{S O D}{\longrightarrow} \mathbf{H}_{2} \mathbf{O}_{2}+\mathbf{O}_{2}
\end{aligned}
$$

Peróxido de hidrogênio é, por sua vez, reduzido em água e oxigênio moleculares ou pela catalase (CAT) ou glutationa peroxidase (GPX), a qual utiliza a glutationa (GSH) como doador de hidrogênio:

$$
\begin{aligned}
& \mathbf{2} \mathrm{H}_{2} \mathrm{O}_{2} \stackrel{C A T}{\longrightarrow} \mathbf{2} \mathrm{H}_{2} \mathrm{O}+\mathrm{O}_{2} \text { ou } \\
& \mathbf{H}_{\mathbf{2}} \mathrm{O}_{\mathbf{2}}+\mathbf{2} \mathbf{G S H} \stackrel{G P X}{\longrightarrow} \mathbf{2} \mathrm{H}_{\mathbf{2}} \mathrm{O}+\mathbf{G S}-\mathbf{S G}
\end{aligned}
$$


Entretanto, na presença de metais de transição (ferro ou cobre) ou excesso de $\mathrm{O}_{2}^{-}$, o $\mathrm{H}_{2} \mathrm{O}_{2}$ é convertido ao radical hidroxila $\left(\mathrm{OH}^{-}\right)$, sabidamente o radical mais citotóxico existente.

$$
\mathrm{H}_{2} \mathrm{O}_{2}+\mathrm{Fe}_{2} \rightarrow \mathrm{OH}+\mathrm{OH}^{-}+\mathrm{Fe}^{3+} \text { (Reação de Fenton) }
$$

ou

$$
\mathrm{H}_{2} \mathrm{O}_{2}+\mathrm{O}_{2}^{-} \rightarrow \mathrm{OH}+\mathrm{OH}^{-} \quad \text { (Reação de Haber-Weiss) }
$$

$\mathrm{Na}$ presença do cloro, a mieloperoxidase (MPO) oriunda dos neutrófilos, converte $\mathrm{H}_{2} \mathrm{O}_{2}$ em ácido hipocloroso $\left(\mathrm{HOCL}^{-}\right)$, um poderoso composto capaz de oxidar muitas moléculas como lipídeos, e outros constituintes intracelulares, particularmente proteínas de membrana do grupo dos tiois (estresse clorinativo) ${ }^{3}$

$$
\mathrm{H}_{2} \mathrm{O}_{2}+\mathrm{Cl}^{-}+\mathrm{H}^{+} \stackrel{M P O}{\longrightarrow} \mathrm{HOCL}+\mathrm{H}_{2} \mathbf{O}
$$

O óxido nítrico (NO) é um radical livre com potente efeito vasodilatador. Sua síntese é iniciada a partir do substrato L-arginina, pela ação da enzima óxido nítrico sintase (NOS). NO reage rapidamente com o oxigênio tanto na fase gasosa como em solução aquosa, formando o gás dióxido de nitrogênio. A forma induzível (iNOS) da enzima é ativada via elevação de cálcio intracelular, pela estimulação da acetilcolina, bradicinina. Esta forma induzível é também sintetizada quando da ocorrência de um estímulo específico, em geral, um processo inflamatório. As substâncias reativas com o oxigênio inativam o óxido nítrico NO, pelos superóxidos, promovendo sua deficiência funcional e formação de produtos citotóxicos como peróxido nitrito e ácido peróxido nitroso: ${ }^{3}$ 


\section{peróxido nitrito: $\left(\mathrm{NO}+\mathrm{O}_{2}^{-} \rightarrow \mathrm{ONOO}^{-}\right)$, e ácido peróxido nitroso $(\mathrm{ONOOH})$}

O peróxido nitrito é um gatilho para a peroxidação lipídica, podendo causar danos ao DNA e nitração de proteínas.

Com o aumento do estresse oxidativo, ocorre uma permanente formação de pontes disulfídicas (-S-S-) e, assim, alterações nas estruturas de proteínas. Esta situação é detectada pela redução da glutationa GSH, em glutationa oxidada GSSG. O aminoácido envolvido é a cisteína que é modificada tanto pelas substâncias reativas com o oxigênio como também com o nitrogênio. Uma única cisteína pode ser modificada em 4 diferentes formas: RSH reduzida, $\mathrm{RSOH}$ oxidada, RSNO S-nitrosilatada e RSSG glutationilatada. Por exemplo, a nitração de resíduos de tirosina e cisteína pelos peróxidos nitritos leva a formação de nitrotirosina e nitrocisteína, espécies reativas com nitrogênio (ERN), que podem modificar a função e estrutura de proteínas, interferindo com a fosforilação. ${ }^{5}$

O ânion superóxido e a hidroxila são os que realmente possuem estrutura de radical livre, sendo as demais consideradas espécies intermediárias que, através de diferentes reações, originam os radicais. Apesar de serem produtos menos reativos, podem produzir lesão celular através da peroxidação dos lipídeos das membranas mitocondriais, dos lisossomos e membrana plasmática, alterando não só sua estrutura como também sua fisiologia ${ }^{6,7}$. 


\subsection{Antioxidantes}

Frente à ação potencial lesiva destas substâncias reativas, torna-se vital um delicado controle de sua produção e consumo dentro das células, ou seja, um fino balanceamento de sua concentração intra e extra celular. Isto é possível graças à atividade dos antioxidantes que, removendo as substâncias reativas, as mantêm em baixas concentrações. ${ }^{8}$.

Estes podem ser enzimáticos (glutationa, superóxido dismutase, catalase), ou não enzimáticos, como flavonóides, as vitaminas C e E. Estas vitaminas encontram-se reduzidas nos pacientes renais crônicos, devido à restrição do consumo de frutas e vegetais para evitar hipercalemia. As terapias pelos antioxidantes podem contribuir para diminuir a pressão arterial, a ativação do fator nuclear Kappa B, amenizando desta maneira a inflamação tubulointersticial nos animais hipertensos ${ }^{4}$.

O mais ativo e importante antioxidante endógeno é a glutationa peroxidase $(\mathrm{GSH})$ forma reduzida que, ao reagir com os radicais, forma glutationa oxidada (GSSG) e água. Esse sistema constitui um ciclo redox (alternância de reações de oxidação e redução). A glutationa peroxidase atua tanto sobre os peróxidos de lipídeos como sobre a água oxigenada, reduzindo-os na presença da glutationa (fornecedora de hidrogênios). A degradação da $\mathrm{H}_{2}$ é um passo importantíssimo, pois, é a partir desta espécie que se origina o temido radical hidroxila $\left(\mathrm{OH}^{-}\right)$, iniciador da peroxidação lipídica. No estresse oxidativo ocorre redução da atividade do sistema da glutationa. A atividade da glutationa peroxidase é criticamente dependente de selênio, em cuja presença ocorre à transcrição regular do 
RNA mensageiro para formação da glutationa peroxidase. Dietas deficientes em selênio prejudicam a expressão do RNA mensageiro para formação daquela enzima. ${ }^{9}$ (FIGURA 1).

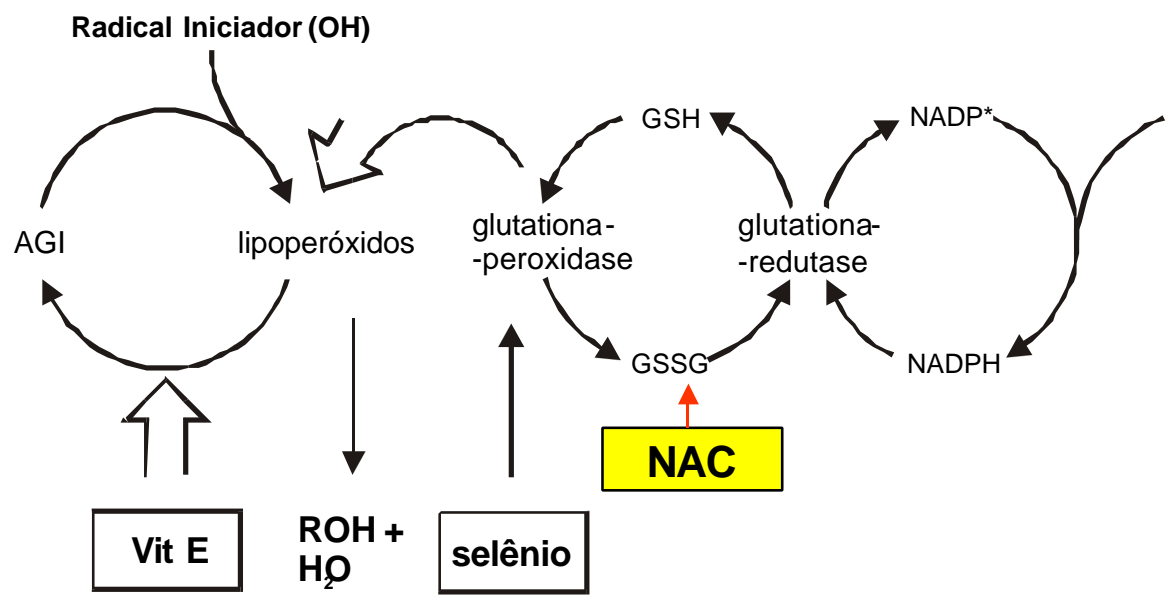

FIgURA 1: MECANISMO BIOQUÍMICO DA INTER-RELAÇÃO VITAMINA E / SELÊNIO. A VITAMINA E BLOQUEIA A SEQÜÊNCIA DE REAÇÕES EM CADEIA QUE PERPETUAM A LIPOPEROXIDAÇÃO SOBRE OS ÁCIDOS GRAXOS INSATURADOS (AGI) DAS MEMBRANAS. O SELÊNIO, COMPONDO PARTE FUNDAMENTAL DA GLUTATIONA-PEROXIDASE, POSSIBILITA A ATUAÇÃO ENZIMÁTICA DESTA NA INATIVAÇÃO DOS PERÓXIDOS, OU HIDROPERÓXIDOS JÁ FORMADOS, CONVERTENDO-OS EM ALCOÓIS PRIMÁRIOS OU SECUNDÁRIOS INÓCUOS. O EFEITO GLOBAL CONSEGUIDO POR ESTE SISTEMA É DEVIDO, ASSIM, À COMBINAÇÃO DO PODER REDUTOR ENZIMÁTICO E VITAMÍNICO (AÇÃO SINÉRGICA).

\subsection{N-acetilcisteína}

Outro antioxidante bastante eficiente é a N-acetilcisteína (NAC), que é um tiol, agente mucolítico e precursor da L-cisteína e glutationa reduzida nas células. É uma fonte de grupos sulfidril e removedores de substâncias 
reativas com o oxigênio $\left(\mathrm{OH}^{-}\right.$e $\left.\mathrm{H}_{2} \mathrm{O}_{2}\right)$, geradas pela reação dos peroxinitritos como NO e superóxidos ${ }^{10,11}$. A NAC tem demonstrado reduzir a disfunção endotelial, inflamação, fibrose, desintoxicação pelo paracetamol e diminuir a lesão provocada pelo tempo de isquemia do enxerto e os níveis de malondialdeído (MDA) em pacientes renais crônicos ${ }^{12,13}$.

A NAC inibe a ativação do c-Jun quinase $\mathrm{N}$-terminal (JNK), p38 MAP quinase, reduz a ativação do NF-kB, bloqueando o aparecimento do VCAM1 das células endoteliais e regulando a atividade de expressão de inúmeros outros genes $^{11,5}$. Também previne apoptose e promove a sobrevivência das células, ativando a sinalização de quinases extracelulares como tratamento de certas doenças degenerativas ${ }^{14,1}$.

A NAC pode melhorar a função endotelial e atenuar doença inflamatória vascular (aterosclerose), antagonizando os efeitos da geração de substâncias reativas intracelulares pelo aumento da viabilidade do óxido nítrico e pela redução da adesão de leucócitos do endotélio ${ }^{15,10 .}$

A N-acetilcisteína (NAC) é um antioxidante que também protege os animais da insuficiência renal aguda isquêmica ${ }^{16}$, por contraste radioiodados e outras drogas nefrotóxicas ${ }^{17,18,19,20,21,22,10}$ Entretanto, o efeito deste antioxidante na progressão da doença renal ainda não foi avaliado.

\subsection{Marcadores do estresse oxidativo}

Os compostos oxidantes são altamente reativos com meia vida de alguns segundos. Por este motivo sua determinação in vivo não é viável. Em 
contraste, os lipídeos, proteínas, ácidos nucléicos e carboidratos, após serem modificados pelos oxi-radicais, têm sua meia vida em torno de horas ou semanas, o que os torna marcadores ideais de estresse oxidativo. Estão incluídos nesta categoria, o malondialdeído (MDA), F2-isoprostano, entre muitos outros ${ }^{3}$.

O fenômeno da peroxidação de um ácido graxo polinsaturado dá-se justamente devido à existência de várias insaturações em sua molécula; é na dupla ligação que o radical peróxido se insere, formando, então, um lipoperóxido. A vitamina $\mathrm{E}$ atua neste passo, reduzindo novamente os carbonos da dupla ligação. A presença desta vitamina bloqueia a transferência de elétrons de uma molécula para outra, amenizando uma série de danos e impedindo o início da propagação da peroxidação dos lipídeos. Esta pode ser iniciada pelo hidrogênio e peróxidos orgânicos, metabólitos celulares que são inativados pela glutationa peroxidase ${ }^{9}$.

Existem duas vias de aparecimento de mais radicais livres, quando da lesão das membranas celulares e desencadeamento da propagação da peroxidação dos lipídeos. Uma delas é o caminho dos hidroperóxidos, resultando em produtos menores e mais estáveis, os aldeídos. O outro caminho, é a via dos endoperóxidos, resultando em malondialdeído e álcoois $^{23}$ (FIGURA 2). 


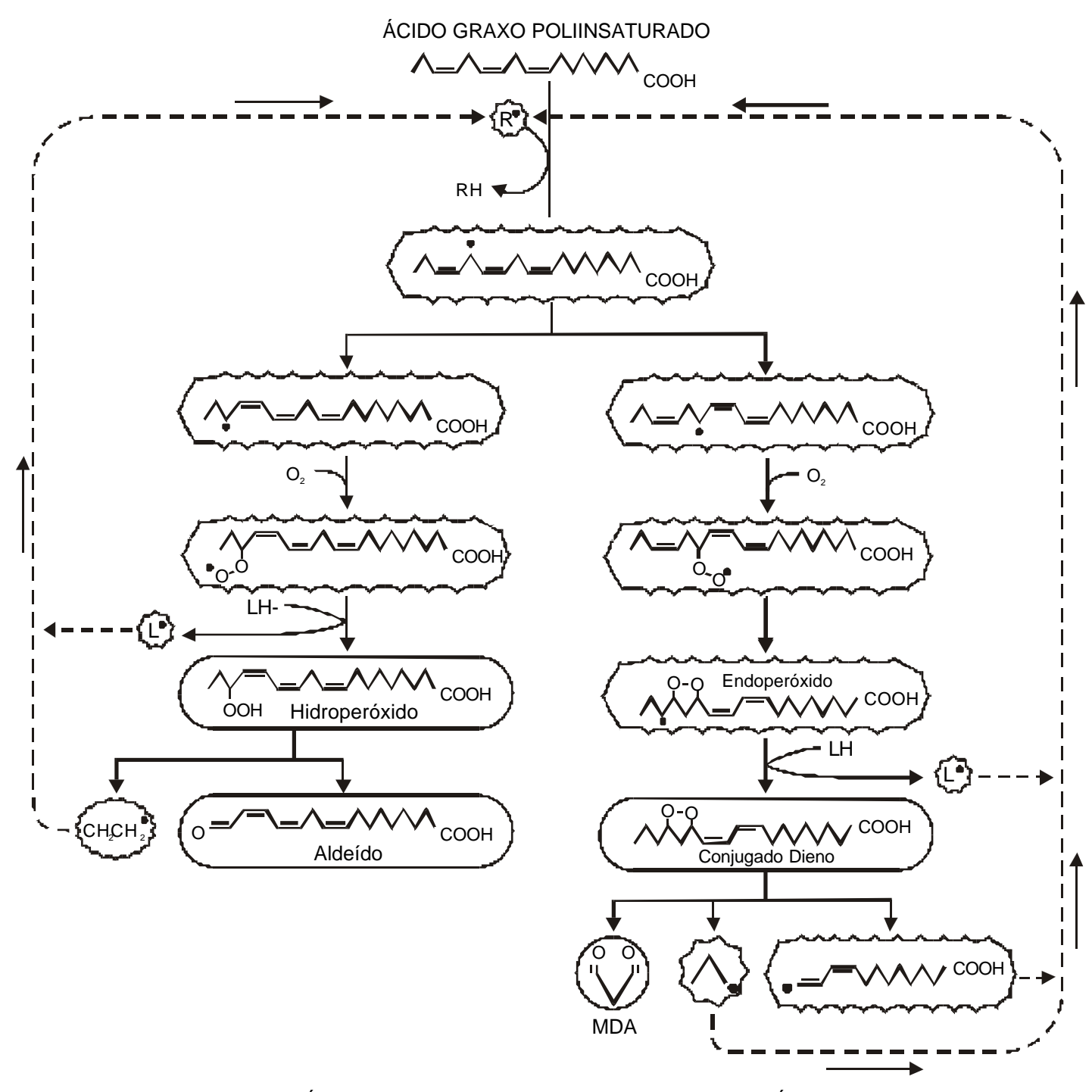

VIA - HIDROPERÓXIDO

VIA - ENDOPERÓXIDO

FIGURA 2: NA PRESENÇA DO OXIGÊNIO, O ATAQUE DOS RADICAIS LIVRES SOBRE OS ÁCIDOS GRAXOS POLINSATURADOS FORMAM HIDROPERÓXIDOS E ENDOPERÓXIDOS. ESTES COMPOSTOS PODEM SUBSEQÜENTEMENTE DECOMPOR-SE PRODUZINDO RADICAIS ADICIONAIS. O CAMINHO DOS HIDROPERÓXIDOS GERA DOIS RADICAIS DE UM ÚNICO ATAQUE A UM RADICAL E O CAMINHO DOS ENDOPERÓXIDOS GERA TRÊS RADICAIS. CADA RADICAL GERADO PODE POR SI INICIAR UMA NOVA PEROXIDAÇÃO LIPÍDICA, A CLÁSSICA REAÇÃO EM CADEIA, QUE RESULTA EM UMA INTENSA PEROXIDAÇÃO DE MUITAS MOLÉCULAS DE ÁCIDOS GRAXOS POLINSATURADOS PARTINDO-SE DE POUCOS RADICAIS, RESULTANDO EM DANO NA MEMBRANA OU ATÉ SUA DESTRUIÇÃO. A MEDIDA DESTES PRODUTOS REATIVOS, ESPECIALMENTE MALONDIALDEÍDO (MDA), ETANO E F-2 ISOPROSTANO PODEM SER UTILIZADOS COMO MARCADORES DE PEROXIDAÇÃO LIPÍDICA EM SISTEMAS BIOLÓGICOS. 
Os produtos finais gerados da peroxidação dos lipídeos são denominados, substâncias reativas. A medida destes produtos, como, malondialdeído, F2-isoprostano, entre outros, podem ser utilizados como marcadores desta peroxidação em sistemas biológicos.

\subsection{Doença Renal Crônica}

A característica fisiopatológica fundamental nos casos mais comuns de doença renal crônica é a perda dos néfrons, e não a lesão de qualquer de suas partes específicas.

As lesões morfológicas destrutivas que levam ao desaparecimento dos néfrons produzem uma queda da filtração glomerular e da capacidade de transporte tubular, evocando respostas compensatórias morfológicas e funcionais. Estas alterações são representadas em uma hipertrofia e hiperplasia dos néfrons remanescentes, que são capazes de adaptar-se à nova condição biológica, multiplicando em várias vezes seu ritmo de trabalho. Necessitam aumentar a taxa de filtração, a fim de atenuar a queda do RFG total.

Os rins são importantes para a manutenção da homeostase. Qualquer desvio deste rígido balanço implica a retenção de excretas e o acúmulo ou depleção de água, sódio, potássio e outros componentes essenciais do meio interno. Por essa razão, cada néfron remanescente deve adaptar-se de modo à, em conjunto com os demais, dar conta de cada um dos balanços que o organismo necessita manter.

Embora essa situação possa perdurar durante vários anos, infelizmente não é possível mantê-la indefinidamente. Com maior ou menor 
rapidez, a maioria dos pacientes com doença renal crônica progride inevitavelmente à fase terminal, quando passam a necessitar de terapêuticas como diálise crônica ou transplante renal. ${ }^{24}$.

Além da manutenção da homeostase, o rim também exerce importante papel endócrino, sendo capaz de sintetizar diversos hormônios e substâncias vasoativas com efeitos endócrinos, parácrinos e autócrinos, (angiotensina II, endotelinas, cininas, prostaglandinas, óxido nítrico, o PTH, a vasopressina, a aldosterona).

Os rins são alvos de hormônios como a angiotensina II e as mais importantes ações biológicas desta no rim são mediadas por dois tipos de receptores, $A T_{1}$ e $A T_{2}{ }^{24}$

Nos tecidos de adultos os receptores $A T_{1}$ estão distribuídos nos tecidos vasculares, rins, glândulas adrenais, coração, fígado e cérebro.

Em adultos saudáveis, os receptores $\mathrm{AT}_{2}$ estão presentes na medula da adrenal, útero, ovário, endotélio vascular, áreas distintas do cérebro, coração e rins. As formas dos receptores possuem várias similaridades. Ambos tem polipepitídeos $\mathrm{G}$ acoplados e possuem aproximadamente 360 aminoácidos. Entretanto seus genes residem em diferentes cromossomos; o gene para o $\mathrm{AT}_{1}$ está localizado no cromossoma 3 e para o $\mathrm{AT}_{2}$ é encontrado no cromossoma $X$. Ambos tem uma seqüência homóloga de $30 \%$. Como resultado, suas funções são distintas e possuem caminhos diferentes de sinalização. Por exemplo, os receptores $A T_{1}$ medeiam as ações hemodinâmicas, funções endócrinas e efeitos mitogênicos da angiotensina II no rim. Os receptores $A T_{2}$ regulam o desenvolvimento fetal e 
possuem ambos os efeitos, vasodilatador e antiproliferativo. Os receptores $A T_{2}$ interagem, modulando as ações dos $A T_{1}$, antagonizando muitos de seus efeitos. (FIGURA 3).

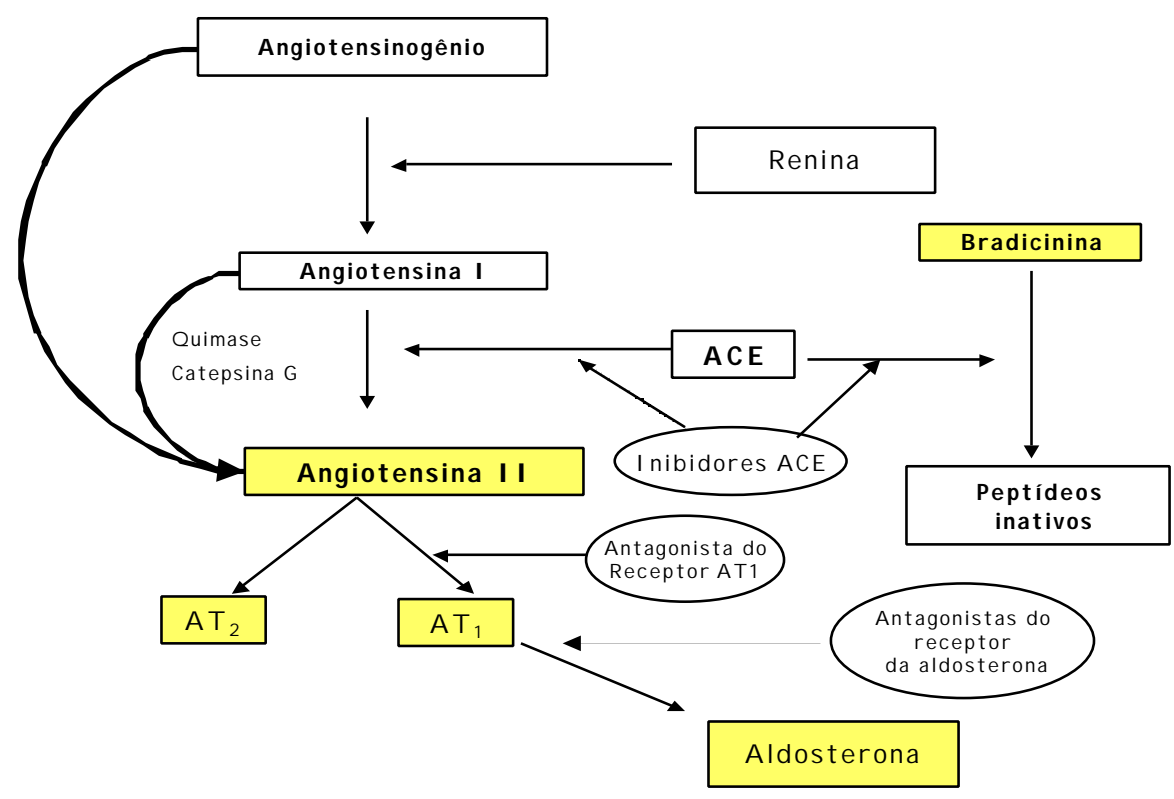

FIGURA 3: SISTEMA RENINA ANGIOTENSINA ALDOSTERONA E SEUS INIBIDORES. ACE $=$ ENZIMA CONVERSORA DE ANGIOTENSINA; AT1 = RECEPTOR DE ANGIOTENSINA TIPO I; AT2 = RECEPTOR DE ANGIOTENSINA TIPO II.

\subsection{Papel do sistema renina-angiotensina-aldosterona na doença renal}

O sistema renina-angiotensina-aldosterona desempenha papel importante na doença renal crônica. Além de sua ação vasoconstritora, a angiotensina II também possui efeito proliferativo, induzindo hipertrofia e hiperplasia. Estes efeitos inicialmente verificados em células musculares lisas e miócitos, favorecem o desenvolvimento de hipertrofia cardíaca na 
hipertensão arterial. A angiotensina II, bastante estimulada nesta doença, além de suas ações hemodinâmicas, (aumentando a pressão arterial), promove outros processos no rim, como a perpetuação de substâncias reativas com o oxigênio. (FIGURA 3). ${ }^{25}$

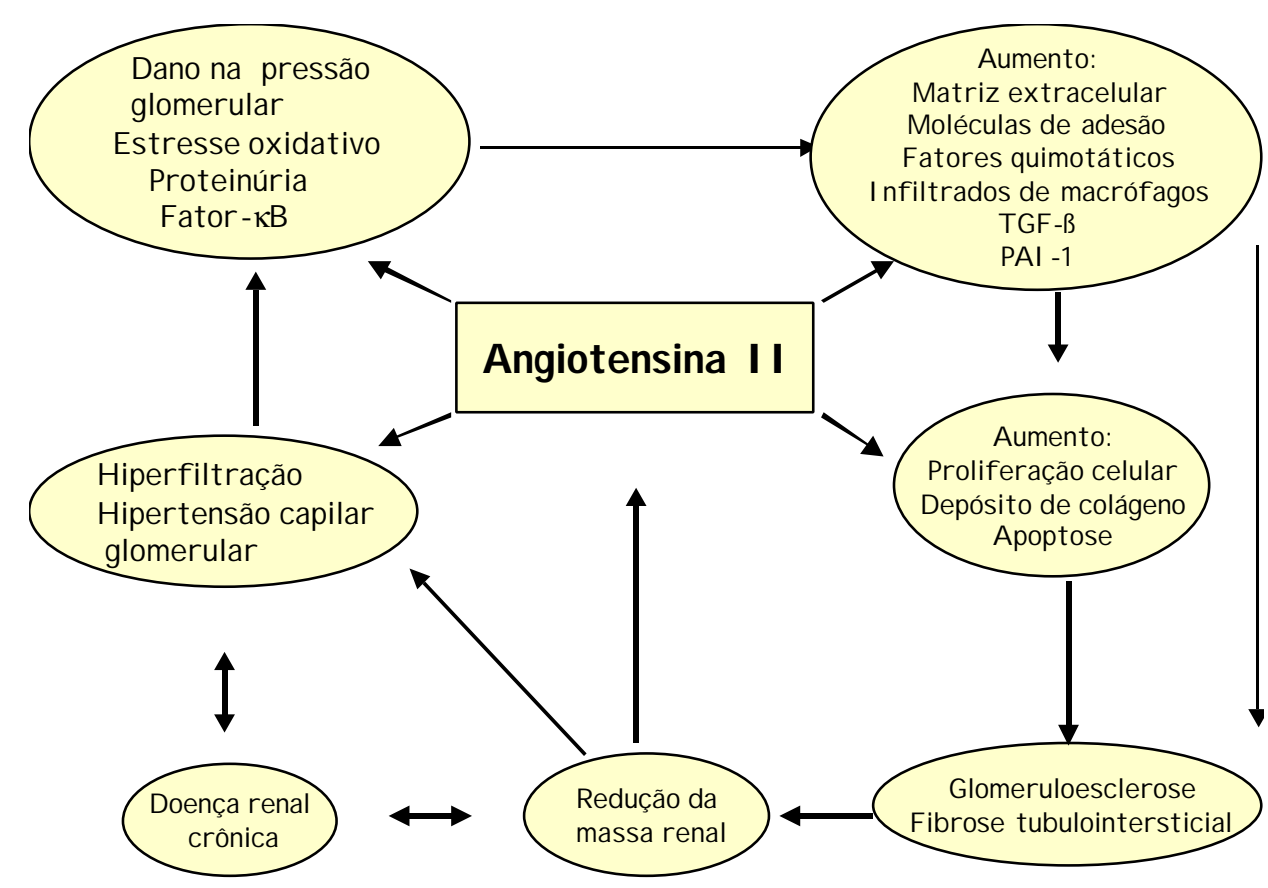

FIGURA 3: EFEITOS DA ANGIOTENSINA II

Baseado nos efeitos homeostáticos do sistema renina-angiotensinaaldosterona no rim, este quando alterado modifica o volume intracelular e proliferação de células nos néfrons. $A$ atuação dos receptores $A T_{1}$, contribui para a hipertensão pela retenção de sódio. A constrição da arteríola eferente reduz o fluxo sangüíneo renal, aumentando a filtração glomerular, pelo aumento da pressão capilar glomerular. A angiotensina II estimula a proliferação de células e reestruturação de tecidos pelo aumento da síntese 
de citoquinas fibróticas e fatores de crescimento. A ação da angio II pode causar apoptose nas células dos túbulos proximais pelo envolvimento com as espécies reativas com o oxigênio aumentando a expressão e a produção dos fatores de crescimento (fator $\beta)^{26,27,28}$.

\subsection{Hipertensão na DRC}

A hipertensão arterial contribui significativamente com a morbidade cardiovascular e mortalidade dos pacientes renais crônicos ${ }^{29}$. Está relacionada diretamente com o sistema renina-angiotensina-aldosterona e também com a peroxidação lipídica. As substâncias reativas geram nos vasos, inflamação, adesão de moléculas, depósito de proteínas na matriz extracelular, entre outros ${ }^{25}$.

Na DRC ocorre diminuição de óxido nítrico (NO) renal, vascular e cardíaco. Esta diminuição é devida ao hiperparatireoidismo, melhorando com a paratireoidectomia.

O NO, além de um potente vasodilatador, é também um mediador antinflamatório e neurotransmissor. Estudos crônicos com bloqueador de NO, o L-NAME, mostram vasoconstrição severa com surgimento de proteinúria provavelmente conseqüente a hipertensão glomerular mantida ${ }^{30}$.

Devido a potente ação vasoconstritora de um outro agente, a endotelina-1, sintetizada nos vasos e outros tecidos, muitos pesquisadores acreditam que esta, tenha participação ativa na patogênese da hipertensão. As espécies reativas com o oxigênio estimulam a síntese de endotelina-1. 
Muitos estudos demonstram a hipótese de que a angiotensina II estimula a produção e liberação de endotelina-1. ${ }^{31,6}$

\subsection{Proteinúria}

A ativação do sistema renina-angiotensina-aldosterona também provoca proteinúria. A hipertensão capilar glomerular leva a um aumento da permeabilidade glomerular e excessiva filtração de proteínas. Este sistema também pode causar proteinúria através da expressão de nefrina. Esta é uma proteína transmembrana localizada nos "slits" diafragmáticos dos podócitos glomerulares. Pela manutenção da integridade destes "slits", a nefrina limita a perda de proteínas pelo glomérulo. Quando sua expressão é alterada ocorre proteinúria. Proteínas presentes na urina são tóxicas para os túbulos e podem provocar inflamação tubulointersticial ${ }^{24}$. Animais com ablação renal, quando submetidos à dieta deficiente em vitamina $E$ e selênio, apresentam elevada excreção de proteína urinária ${ }^{32}$.

\subsection{Inflamação na DRC}

A inflamação pode ser a causa mais importante do aumento do estresse oxidativo em pacientes renais crônicos. As substâncias oxidantes inativam o NO, estimulando o aparecimento dos polimorfonucleares (PMNs) que, por sua vez, estimulam a mieloperoxidase (MPO). Este fato é um elo para a inflamação pelo aumento do estresse oxidativo e disfunção endotelial nos pacientes renais crônicos. O estresse oxidativo estimula a regulação do 
fator de transcrição $\mathrm{NF} \kappa \mathrm{B}$, que é também um gatilho para a inflamação. Esta, por sua vez, potencializa o estresse oxidativo pela geração de mais substâncias reativas pela ativação de leucócitos e macrófagos. A presença de inflamação em pacientes com DRC é evidenciada pela elevação da concentração de proteína C-reativa. ${ }^{4}$

O estresse oxidativo e a inflamação são importantes fatores para a doença cardíaca em pacientes renais crônicos. A NADPH oxidase é considerada a principal fonte de substâncias oxidantes no sistema cardiovascular $^{3,25}$. No coração, a inflamação induzida pela aldosterona (sintetizada pelas enzimas aldosterona sintetases - CYP11B2) é mediada pelo estresse oxidativo e atenuada pela NAC ${ }^{33,34}$. Dados experimentais e até mesmo em humanos, têm demonstrado efeitos renoprotetores e cardíacos quando da utilização de bloqueadores de receptores deste hormônio, como a espironolactona (Spi) ${ }^{35,26}$.

\subsection{Aldosterona na doença renal e Espironolactona (Spi)}

A aldosterona contribui para o dano cardiovascular. Porém, sua síntese não ocorre somente no córtex da adrenal, pelo conceito tradicional, mas também, o endotélio e células musculares lisas produzem aldosterona. A síntese da aldosterona encontra-se aumentada em modelo de ablação renal e está associada com aumento da fibrose e progressiva perda de função renal, por possuir propriedades mitogênica e profibrótica. Esta quando sintetizada nos vasos pode participar no desenvolvimento da 
hipertrofia vascular juntamente com a Angiotensina II. Estudos in vivo demonstraram que a aldosterona contribui com lesão cardiovascular em modelos de animais hipertensos. ${ }^{36}$

A espironolactona é um antagonista receptor mineralocorticóide, bloqueador da aldosterona, reduz a incidência de lesão vascular renal em animais espontaneamente hipertensos. ${ }^{37,38}$. Também contribui na melhora da hipertrofia cardíaca, inflamação e produção da matriz extracelular na lesão cardíaca induzida pela angiotensina II. A espironolactona melhora, porém, não normaliza a hipertrofia cardíaca e inflamação em ratos transgênicos (genes humanos de renina e angiotensina) ${ }^{39}$.

A espironolactona age inibindo os receptores mineralocorticóides, via genômica, portanto intracelular, e a ação não genômica da aldosterona não é inibida por esta droga. 29. 
2. OBJ $\mathcal{E} I$ I VOS 


\section{Os objetivos deste trabalho foram :}

- Determinar o efeito do antioxidante N-acetilcisteína (NAC) sobre a função renal e a aldosterona plasmática de animais com IRC, administrada tanto precoce como tardiamente.

- Avaliar os efeitos da NAC associada à Espironolactona (Spi). 
3. $\mathcal{M E} \mathcal{E} O D O S$ 


\section{Métodos}

\subsection{Animais}

Foram utilizados 79 ratos machos Wistar, cedidos pela Diretoria Técnica de Apoio ao Ensino e Pesquisa da Faculdade de Medicina da USP, pesando entre 150 e 180g, tratados ou não com NAC (600 mg/l - na água), e/ou com espironolactona (Spi) pela dieta $(1,5 \mathrm{~g} / \mathrm{Kg}$ de dieta), iniciando - se 7 dias após laparotomia e/ou ablação de 5/6.

\subsection{Modelo Experimental}

Para indução da insuficiência renal crônica os animais foram submetidos à ablação de 5/6 da massa renal: A anestesia foi realizada com pentobarbital sódico na dose de $50 \mathrm{mg} / \mathrm{Kg}$ de peso, via intraperitoneal. Após a laparotomia, foram expostos os pedículos renais e realizada nefrectomia direita A seguir realizada ligadura de 2 ramificações da artéria renal esquerda com fio mononylon 6-0. Estes animais foram chamados (Nx). (FIGURA 4).

Animais sham operados foram àqueles submetidos a laparotomia com procedimento idêntico ao anterior, com manipulação do pedículo e do rim esquerdo, porém sem destruição do tecido renal. 

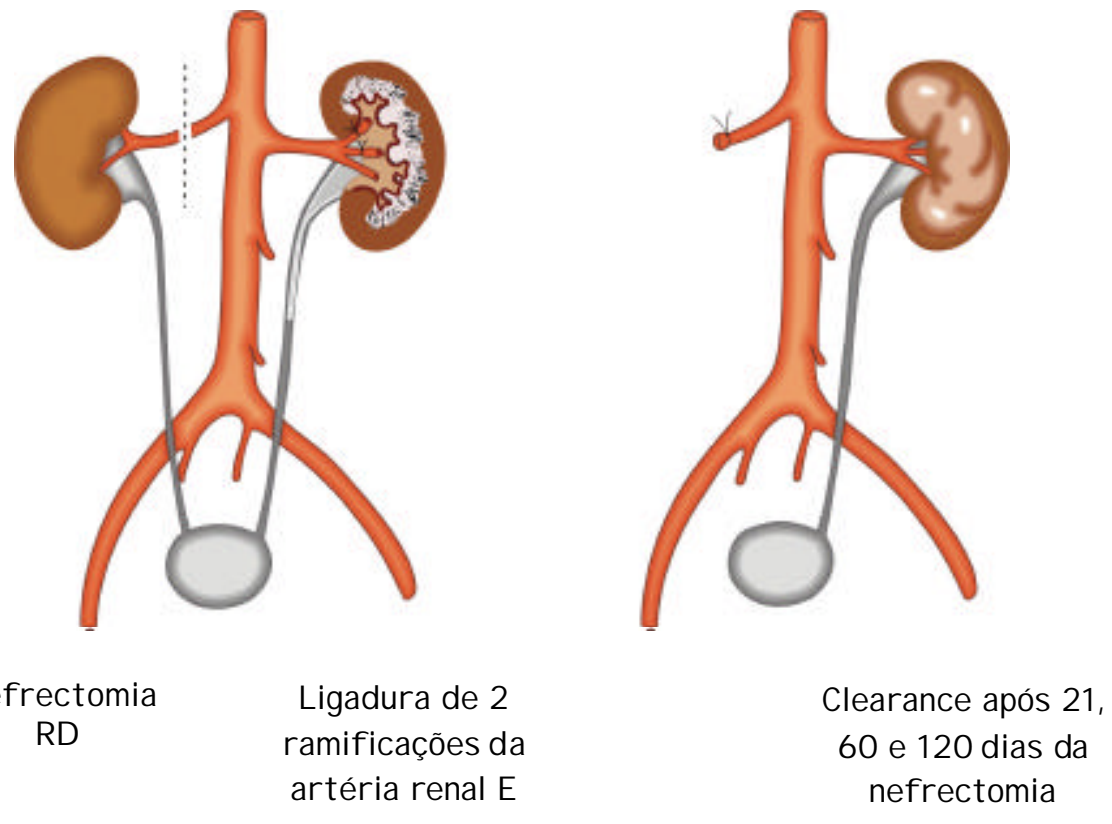

FIGURA 4: MODELO EXPERIMENTAL PARA INDUÇÃO DA INSUFICIÊNCIA RENAL CRÔNICA:

\subsection{Sacrifício dos animais}

Após a finalização dos experimentos propostos, os animais foram sacrificados pela injeção endovenosa de excesso de anestésico, pentobarbital sódico. 


\subsection{Grupos de animais estudados}

Foram estudados 11 grupos de animais, divididos entre os tratados ou não com NAC e espironolactona:

\subsubsection{Grupos de animais sham e com insuficiência renal crônica (Nx):}

- Sham - estudados após 21 dias da laparotomia - $(n=6)$

- $(\mathrm{N} \times 21)$ - estudados após 21 dias da nefrectomia - $(\mathrm{n}=6)$

- $(\mathrm{N} \times 60)$ - estudados após 60 dias da nefrectomia - $(\mathrm{n}=6)$

- (Nx120) - estudados após 120 dias da nefrectomia - $(n=6)$

\subsubsection{Grupos de animais sham e com Insuficiência renal crônica ( $\mathrm{Nx}$ ) tratado precocemente com $\mathrm{N}$-acetilcisteína (NAC):}

- Sham + NAC - (após 7 dias da cirurgia) Ingestão de NAC na água de beber por 14 dias e estudados no $21^{\circ}$ da nefrectomia - $(n=6)$

- (Nx21+NAC) - (após 7 dias da cirurgia) ingestão de NAC na água de beber por 14 dias e estudados no $21^{\circ}$ dia - $(n=6)$

- (Nx60+NAC) - (após 7 dias da cirurgia) - Ingestão de NAC na água de beber por 53 dias e estudados no $60^{\circ}$ dia - $(n=6)$

- (Nx 120 + NAC) - (após 7 dias da cirurgia) - Ingestão de NAC por 113 dias e estudados no $120^{\circ}$ dia - $(n=6)$ 


\subsubsection{Grupos de animais com Insuficiência renal crônica (Nx)} tratados tardiamente com $\mathrm{N}$-acetilcisteína (NAC):

- $(\mathrm{N} \times 120+\mathrm{NAC})-(\mathrm{N} \times 60+60 \mathrm{~d} \mathrm{NAC})-$ (após 60 dias da cirurgia) - Ingestão de NAC por + 60 dias e estudados no $120^{\circ}$ dia - $(n=6)$

\subsubsection{Grupos de animais com Insuficiência renal crônica (Nx)} tratados ou não com NAC e com Espironolactona (Spi)

Para realização destes grupos utilizamos dieta por nós
manufaturada sendo necessário este procedimento para podermos acrescentar a medicação espironolactona, cuja ingestão foi controlada em gaiola metabólica em mg de dieta ingerida/dia/rato.

- (Nx 60+ Spi) -(após 7 dias da cirurgia) - Ingestão de Spi pela dieta por 53 dias e estudados no $60^{\circ}$ dia $-(n=8)$

- (Nx $60+\mathrm{Spi}+\mathrm{NAC}$ ) - (após 7 dias da cirurgia) - Ingestão de Spi pela dieta + NAC na água de beber por 53 dias e estudados no $60^{\circ}$ dia - $(n=8)$.

\subsection{ESTUDO EM GAIOLA METABÓLICA}

Os animais foram colocados em gaiolas metabólicas para avaliarmos a quantidade da dieta e água consumidas diariamente dos grupos que receberam a medicação espironolactona (Spi) e a ingestão de NAC.

Para realização das dosagens da proteína urinária e de substâncias reativas com ácido tiobarbitúrico (TBARS). os animais de todos os grupos 
foram colocados em gaiolas metabólicas para coleta de urina de 24 horas, antes do experimento de "clearance" de inulina.

Os produtos finais gerados da peroxidação dos lipídeos das membranas celulares são denominados, substâncias reativas. Possuem baixo peso molecular e entre elas inclui-se o malondialdeído (MDA). São consideradas marcadoras da lipoperoxidação e algumas possuem afinidade com o ácido tiobarbitúrico e, por isso, são denominadas substâncias reativas com o ácido tiobarbitúrico (TBARS).

\section{6. "Clearance" de inulina:}

O estudo de "clearance" de inulina foi desenvolvido sob anestesia com pentobarbital sódico na dose de 50 mg/Kg de peso, via intraperitoneal. Para manutenção de boa ventilação, os animais foram entubados pela cateterização da traquéia com tubo de polietileno PE-240. A seguir, foram cateterizadas as veias jugulares, com PE-60, uma delas para infusão da solução de inulina a 10\%, primeiramente como dose inicial $(100 \mathrm{mg} / \mathrm{Kg})$ para elevar a concentração desta substância no sangue e, a seguir, foi mantida infusão da mesma solução durante todo o experimento, através de bomba de infusão "Harvard", numa velocidade constante de $0.04 \mathrm{ml} / \mathrm{min}$. A outra veia jugular cateterizada foi utilizada para controle da anestesia e posterior sacrifício dos animais. A artéria carótida também foi cateterizada com PE-60 para coleta das amostras de sangue, em diferentes intervalos e, também, para controle da pressão arterial monitorada através de manômetro de mercúrio. A bexiga urinária foi cateterizada com PE-240, 
para coleta de urina. No final do experimento, os rins foram perfundidos in situ com pressão controlada, lavados com solução salina e fixados em Duboscq-Brasil. Após esta fixação foram cortados em 4 secções e colocados em solução tamponada a 10\% de formaldeído.

\subsubsection{Dosagem e cálculo do clearance de inulina}

Para a dosagem da inulina urinária e plasmática utilizamos o método colorimétrico da Antrona, com leitura em espectrofotômetro CELM, comprimento de onda $620 \mathrm{~nm} .{ }^{40}$

$$
\begin{aligned}
& \mathbf{C}_{\text {in }}=\left(\mathbf{U}_{\text {in }} \mathbf{x} \mathbf{V}_{\mathbf{u}}\right) / \mathbf{P}_{\text {in: }} \text { onde: } \\
& U_{\text {in }}=(\text { concentração urinária de inulina em } \mathrm{mg} / \mathrm{dl}) \\
& P_{\text {in }}=(\text { concentração plasmática de inulina em } \mathrm{mg} / \mathrm{dl}) \\
& V_{\text {u }}=(\text { volume urinário em } \mathrm{ml} / \mathrm{min}) \\
& \mathrm{O} \text { "clearance" de inulina foi expresso corrigindo-se por } 100 \mathrm{~g}
\end{aligned}
$$
de peso corpóreo, ou seja:

$$
C_{\text {in }}=\mathrm{ml} / \mathrm{min} / 100 \mathrm{~g} \text { de peso corpóreo }
$$




\subsubsection{Relação potássio urinário/sódio urinário}

A dosagem de potássio e sódio urinário e plasmático foram realizadas em Fotômetro de Chama, marca Celm. A razão calculada pela fórmula - (UK/UNa) - é a medida indireta da ação da aldosterona no túbulo distal.

\subsubsection{Medida da pressão arterial durante o experimento}

Foram efetuadas medidas da pressão arterial $(\mathrm{mmHg})$ no dia do experimento de "clearance", através de cateterização da artéria carótida, com PE-60 e monitorada por manômetro de mercúrio.

\subsubsection{Dosagem da proteinúria}

A proteína na urina foi dosada por método colorimétrico, pelo kit Sensiprot da Labtest.

\subsubsection{Dosagem da aldosterona plasmática}

A aldosterona plasmática foi dosada por radioimunoensaio, pelo kit COAT-ACOUNT Aldosterone da DPC, Los Angeles, CA.

\subsubsection{Dosagem das substâncias reativas com ácido tiobarbitúrico (TBARS)}

As concentrações urinárias de TBARS foram determinadas utilizando-se o método colorimétrico do ácido tiobarbitúrico. Uma amostra de urina foi diluída em água destilada. Imediatamente, adicionou-se $1 \mathrm{ml}$ de ácido tricloroacético (TCA) 17.5\%. Em seguida foi adicionado $1 \mathrm{ml}$ de ácido 
tiobarbitúrico a $0,6 \%, \mathrm{pH}$ 2. As amostras foram colocadas em banho de água fervente por 15 minutos e a seguir resfriadas, sendo depois, adicionado a esta mistura $1 \mathrm{ml}$ de TCA a $70 \%$ e incubada por 20 minutos. As amostras foram centrifugadas por 15 minutos a 2000 RPM e a densidade óptica do sobrenadante lida em espectrofotômetro com comprimento de onda de $543 \mathrm{~nm}$ contra reagente branco. A concentração dos produtos da peroxidação lipídica foi calculada, utilizando-se coeficiente de extinção molar equivalente para malondialdeído (MDA-equivalente), de $1,56 \times 10^{5} \mathrm{M}^{-}$ ${ }^{1} \mathrm{~cm}^{-1}$ (utilizado para o complexo malondialdeído e ácido tiobarbitúrico) Os níveis de TBARS urinário foram expressos em nanomoles/24h. ${ }^{41,42,43,5,14}$

\subsection{Análise histomorfométrica}

Os tecidos renais foram parafinados e a seguir desparafinados utilizando técnica padrão seqüencial com cortes de 2 a $3 \mathrm{~mm}$ de espessura. A seguir, corados com o ácido periódico de Schiff (PAS), pela técnica do tricromo de Masson e pela hematoxilina-eosina. A extensão da esclerose glomerular (EG) foi avaliada em 6 animais após 60 dias da nefrectomia, e em 6 animais após 120 dias, tratados ou não com NAC e Spi. Um score foi atribuído para cada glomérulo de acordo com a extensão da lesão esclerótica:

0 = glomérulo intacto;

1 = lesão afetando 1 a 10 \% da área glomerular;

2 = lesão afetando 11 a 20 \% da área glomerular;

3 = lesão afetando 21 a 30 \% da área glomerular; 
4 = lesão afetando 31 a 40 \% da área glomerular;

5 = lesão afetando 41 a 50 \% da área glomerular;

6 = lesão afetando 51 a 60 \% da área glomerular;

7 = lesão afetando 61 a 70 \% da área glomerular;

8 = lesão afetando 71 a 80 \% da área glomerular;

9 = lesão afetando 81 a 90 \% da área glomerular;

10 = lesão afetando 91 a 100 \% da área glomerular.

O índice de glomeruloesclerose foi calculado para cada rato como a média ponderada de todos os glomérulos individualmente. Pelo menos 50 glomérulos foram examinados por animal.

\section{8. Área fracional intersticial}

Os cortes de $4 \mu \mathrm{m}$ de espessura do tecido renal obtidos dos animais experimentais foram corados com tricrômio de Masson para análise do comprimento túbulo-intersticial, avaliando-se também a área intersticial relativa do córtex renal desses animais.

Para o estudo de morfometria, as imagens obtidas pela microscopia óptica foram captadas por meio de vídeo-câmera de luz conectada a um analisador de imagens (Kontron Electronic System KS 300, Eching, Alemanha). Foram analisados 20 campos, medindo 0,174 $\mathrm{mm}^{2}$, determinadas as áreas do comprimento intersticial desses animais e avaliada a porcentagem dessas áreas em relação a cada campo, excluindose os glomérulos. ${ }^{44}$. 


\subsection{Análise Imunohistoquímica}

Secções de $4 \mu \mathrm{m}$ foram desparafinados e submetidos à análise imunohistoquímica de acordo com o seguinte protocolo: $\mathrm{O}$ tecido renal foi submetido à reação de imunohistoquímica para marcação de macrófagos e monócitos, utilizando anticorpo monoclonal anti-rato, anti-ED-1 (Serotec, Oxford, Reino Unido), para presença de antígeno citoplasmático, e um anticorpo monoclonal IgG para linfócitos de rato (CD3; Harlan Sera-Lab., Lougboruh, Inglaterra). Os cortes foram incubados durante $1 \mathrm{~h}$ em temperatura ambiente com 1/1000 anti-ED-1 (macrófagos) ou anticorpo CD3 (linfócitos). O produto da reação foi detectado pelo complexo avidina-biotinaperoxidase (Vector Laboratories, Burlingame, CA, EUA) e a cor desenvolvida com 3,3'-diaminobenzidina, incluindo ou não a adição de cloreto de níquel 8\% (Sigma, St. Louis, MO, EUA), na presença de água oxigenada. A contracoloração foi feita com Methyl Green para ED1, ou hematoxilina de Harris para CD3, desidratados e montados. As ligações inespecíficas foram bloqueadas pelas diluições dos anticorpos primários e secundários em solução de PBS contendo albumina bovina $20 \%$. Controle negativo consistiu na colocação de anticorpo primário com lgG de camundongo numa concentração equivalente. A avaliação dos resultados da imunorreação para ED-1 (monócitos/macrófagos) ou células positivas para linfócitos no córtex renal tubulointersticial e glomérulo, foi realizada em 30 glomérulos contandose o número de células ED-1 positivas, respectivamente por área de 0,245 $\mathrm{mm}^{2}$ de córtex renal (ED-1) e em seguida foi determinado o número médio de células por rim para cada animal. ${ }^{44}$ 
Estas análises foram determinadas nos grupos Nx120 e Nx120 tratado com NAC.

\subsection{Análise estatística dos resultados}

Os dados foram analisados utilizando-se análise de variância ANOVA e pós-teste Bonferroni, pelos programas de estatística, GraphPad (versão 3.0) e Stata (versão 8.0). Para avaliação da imunohistoquímica utilizamos teste $t$ não pareado com correção Welch.

Os resultados foram apresentados com média \pm erro padrão, sendo considerados significantes as diferenças quando, $p<0.05$. 
4. RES ULLT ADOS 


\section{Resultados}

4.1. Grupos de animais sham e após 21, 60 e 120 dias de nefrectomia (Nx), tratados ou não com com $\mathrm{N}$-acetilcisteína (NAC), iniciada no $7^{\circ}$ dia após cirurgia :

\subsubsection{Peso corpóreo (g)}

$\mathrm{Na}$ TABELA 1 observamos aumento progressivo na média do ganho de peso corpóreo (diferença entre peso final e inicial) entre os grupos de animais submetidos à ablação renal, Nx21 = $133 \pm 14 ; \mathrm{Nx60}=141 \pm 11 \mathrm{e}$ $N \times 120=248 \pm 20$. Entretanto os grupos nefrectomizados de 60 e 120 dias tratados com NAC, apresentaram maior ganho de peso do que os não tratados, $\mathrm{N} \times 60+\mathrm{NAC}=188 \pm 13$ vs $\mathrm{N} \times 60=141 \pm 11(\mathrm{p}<0,01)$ e $\mathrm{N} \times 120+\mathrm{NAC}$ $=308 \pm 16$ vs Nx120 = 248 $\pm 20(p<0,005)$.

\subsubsection{Proteinúria $(\mathrm{mg} / 24 \mathrm{~h})$}

A TABELA 1 mostra aumento significativo da proteinúria dos grupos não tratados com NAC se comparada a do grupo sham, Nx21 = $21 \pm 3$, $\mathrm{N} \times 60=27 \pm 3$ vs Sham $=5 \pm 1(p<0,05)$ e Nx120 = $208 \pm 10$ vs Sham $=5 \pm$ $1(p<0,001)$. Observamos diminuição da proteinúria nos grupos tratados em relação à dos não tratados, $\mathrm{Nx} 21+\mathrm{NAC}=15 \pm 2$ vs $\mathrm{Nx21}=21 \pm 3$; 
$\mathrm{N} \times 60+\mathrm{NAC}=16 \pm 3$ vs $\mathrm{N} \times 60=27 \pm 3(\mathrm{p}<0,01)$ e $\mathrm{N} \times 120+\mathrm{NAC}=159 \pm 10$ vs $N \times 120=208 \pm 10(p<0,005),($ FIGURA 5)

\subsubsection{Ingestão de NAC (mg/100g PC/dia)}

Não houve diferenças na ingestão de NAC entre os grupos, sham $+N A C=14,0 \pm 0,5 ; N x 21+N A C=13,7 \pm 0,6 ; N \times 60+N A C=14,5 \pm 0,3$ e $\mathrm{N} \times 120+\mathrm{NAC}=15,7 \pm 0,8,(\mathrm{NS})$

\subsubsection{Substâncias reativas com ácido tiobarbitúrico (TBARS) na urina (nmoles/24h)}

Observamos na TABELA 1, aumento da excreção de TBARS nos grupos Nx60 = $109 \pm 18$ e Nx120 = $254 \pm 51$, quando comparada aos valores do grupo sham $=18 \pm 2(p<0,001)$. Obtivemos diminuição significativa deste marcador nos grupos tratados precocemente quando

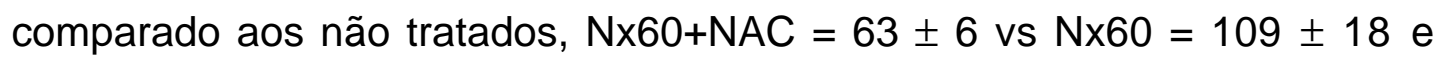
$\mathrm{N} \times 120+\mathrm{NAC}=92 \pm 6$ vs Nx120 = $254 \pm 51 \mathrm{p}<0,05$. Observamos diminuição da concentração de TBARS no grupo Nx21+NAC = 16 \pm 1 vs Nx21 = $29 \pm 3$ $(p<0,005)($ FIGURA 6). 
TABELA 1. Resultados dos animais sham e após 21,60 and 120 dias de Nx, tratados ou não com N-acetilcisteína (NAC), iniciada no $7^{\circ}$ dia da nefrectomia

\begin{tabular}{|c|c|c|c|c|}
\hline Grupos & $\begin{array}{l}\triangle \mathrm{PC} \\
(\mathrm{g})\end{array}$ & $\begin{array}{l}\text { Ingestão de NAC } \\
\text { (mg/100 g PC/dia) }\end{array}$ & $\begin{array}{l}\text { Proteinúria } \\
\text { (mg/24 h) }\end{array}$ & $\begin{array}{c}\text { TBARS } \\
\text { urinário } \\
(\mathrm{nmol} / 24 \mathrm{~h})\end{array}$ \\
\hline Sham $(n=6)$ & $106 \pm 10$ & - & $4,74 \pm 1,02$ & $18,22 \pm 2,41$ \\
\hline$N \times 21(n=6)$ & $133 \pm 14$ & - & $21,46 \pm 2,71^{* *}$ & $28,83 \pm 3,22$ \\
\hline$N \times 60(n=6)$ & $141 \pm 11$ & - & $26,57 \pm 2,99^{* *}$ & $109,0 \pm 17,95^{*}$ \\
\hline$N \times 120(n=6)$ & $248 \pm 20$ & - & $207,5 \pm 9,50$ * & $254,0 \pm 51,51^{*}$ \\
\hline Sham+NAC $(n=6)$ & $98 \pm 9$ & $14,0 \pm 0,5$ & $3,41 \pm 0,45$ & $14,85 \pm 1,64$ \\
\hline$N \times 21+N A C(n=6)$ & $146 \pm 16$ & $13,7 \pm 0,6$ & $14,78 \pm 1,93$ & $15,50 \pm 0,89^{b}$ \\
\hline Nx60+NAC $(n=6)$ & $188 \pm 13^{a}$ & $14,5 \pm 0,3$ & $15,62 \pm 2,64^{a}$ & $63,21 \pm 6,32^{\mathrm{c} *}$ \\
\hline$N x 120+N A C(n=6)$ & $308 \pm 16^{b}$ & $15,7 \pm 0,8$ & $158,6 \pm 9,82^{b *}$ & $91,69 \pm 6,03^{c *}$ \\
\hline
\end{tabular}

Os resultados estão expressos em média \pm EP

${ }^{a} p<0,01,{ }^{b} p<0,005,{ }^{c} p<0,05$; comparação entre grupos tratados e não tratados

${ }^{*} p<0,001,{ }^{* *} p<0,05$, vs. Sham

One way ANOVA - pós-teste Bonferroni 


\section{FIGURA 5}

Excreção urinária de Proteína

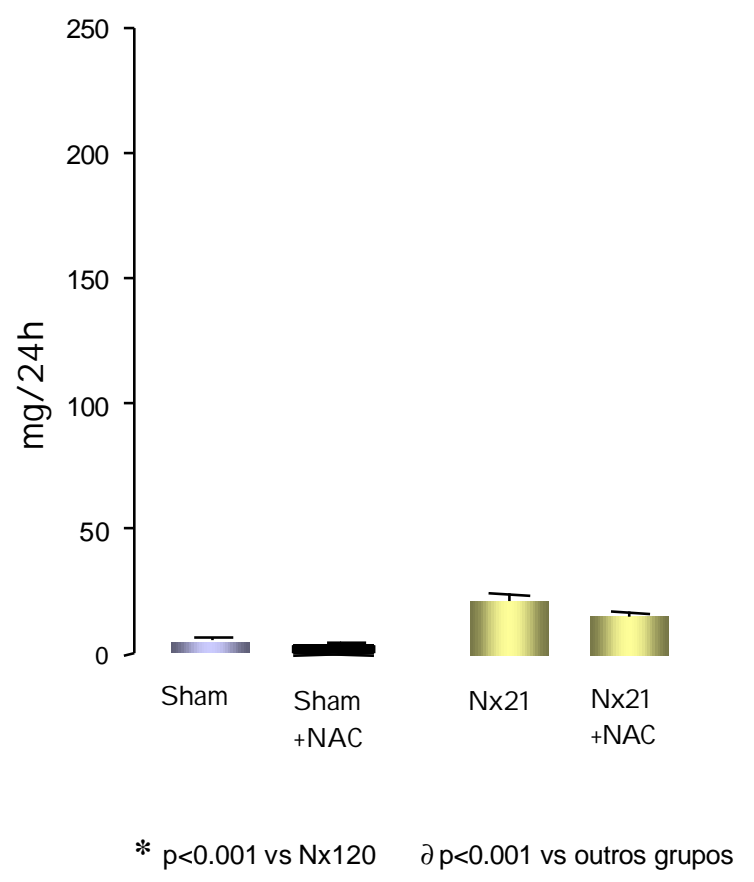

Nível de Significância entre os diversos Grupos

Teste estatístico de análise de variância ANOVA- pós-teste Bonferroni

\begin{tabular}{|c|c|c|c|c|c|c|c|}
\hline & Sham & $\begin{array}{c}\text { Sham } \\
\text { +NAC }\end{array}$ & $\mathbf{N x 2 1}$ & $\begin{array}{c}\text { Nx21 } \\
\text { +NAC }\end{array}$ & Nx60 & $\begin{array}{c}\text { Nx60 } \\
\text { +NAC }\end{array}$ & $\mathbf{N x 1 2 0}$ \\
\hline Sham+NAC & ns & - & & & & & \\
\hline $\mathbf{N x 2 1}$ & ns & ns & - & & & & \\
\hline Nx21+NAC & ns & ns & ns & - & & & \\
\hline Nx60 & ns & ns & ns & ns & - & & \\
\hline Nx60+NAC & ns & ns & ns & ns & ns & - & \\
\hline Nx120 & $<0,001$ & $<0,001$ & $<0,001$ & $<0,001$ & $<0,001$ & $<0,001$ & - \\
\hline Nx120+NAC & $<0,001$ & $<0,001$ & $<0,001$ & $<0,001$ & $<0,001$ & $<0,001$ & $<0,001$ \\
\hline
\end{tabular}




\section{FIGURA 6}

\section{Excreção urinária de $\mathcal{T} \mathcal{B A R S}$}

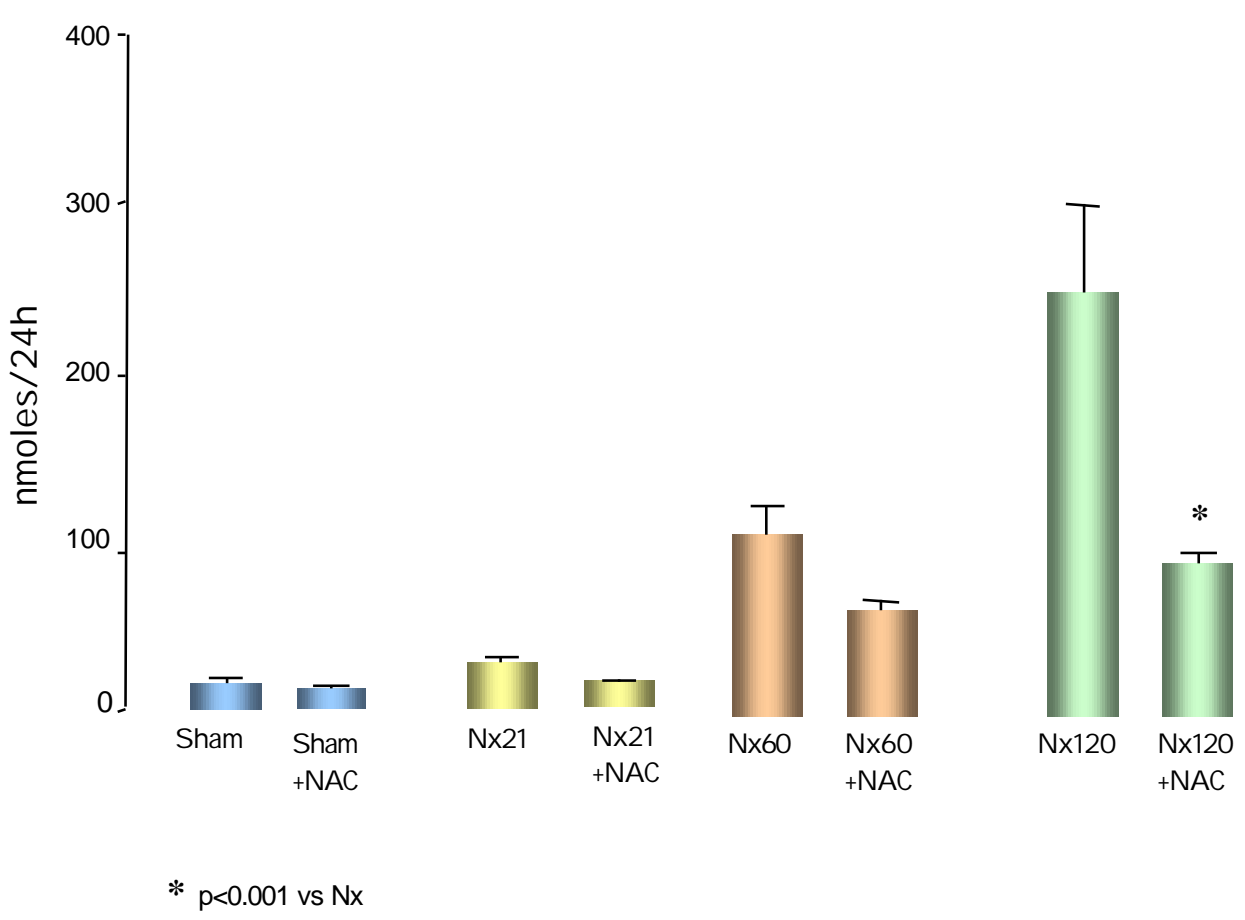

Nível de Significância entre os diversos Grupos

Teste estatístico de análise de variância ANOVA - pós-teste Bonferroni

\begin{tabular}{|c|c|c|c|c|c|c|c|}
\hline & Sham & $\begin{array}{c}\text { Sham } \\
\text { +NAC }\end{array}$ & Nx21 & $\begin{array}{c}\text { Nx21 } \\
\text { +NAC }\end{array}$ & Nx60 & $\begin{array}{c}\text { Nx60 } \\
\text { +NAC }\end{array}$ & Nx120 \\
\hline Sham+NAC & ns & - & & & & & \\
\hline Nx21 & ns & ns & - & & & & \\
\hline Nx21+NAC & ns & ns & ns & - & & & \\
\hline Nx60 & $<0,05$ & $<0,05$ & $<0,05$ & $<0,05$ & - & & \\
\hline Nx60+NAC & ns & ns & ns & ns & ns & - & \\
\hline Nx120 & $<0,001$ & $<0,001$ & $<0,001$ & $<0,001$ & $<0,001$ & $<0,001$ & - \\
\hline Nx120+NAC & ns & ns & ns & ns & ns & ns & $<0,001$ \\
\hline
\end{tabular}




\subsection{Outros resultados dos grupos de animais sham e após 21,} 60 e 120 dias de nefrectomia ( $\mathrm{Nx}$ ), tratados ou não com Nacetilcisteína (NAC), iniciada no $7^{\circ}$ dia após cirurgia :

\subsubsection{Pressão arterial ( $\mathrm{mmHg})$}

Na TABELA 2 observamos aumento da pressão arterial nos grupos dos animais nefrectomizados, quando comparada a do grupo sham $=109 \pm$ 3 vs, $N \times 21=138 \pm 4 ; N \times 60=158 \pm 3 ; N \times 120=174 \pm 5(p<0,001) . O$ mesmo observamos nos grupos nefrectomizados tratados precocemente com 0 antioxidante, $\mathrm{N} \times 21+\mathrm{NAC}=134 \pm 2 ; \mathrm{N} \times 60+\mathrm{NAC}=154 \pm 2$ e $\mathrm{N} \times 120+\mathrm{NAC}=$ $150 \pm 7$ ( $p<0,001)$. Somente houve diminuição da pressão arterial no grupo tratado $\mathrm{N} \times 120+\mathrm{NAC}=150 \pm 7$, se comparada a do grupo não tratado, $N \times 120=174 \pm 5(p<0,05)($ FIGURA 7$)$.

\subsection{2. "Clearance" de inulina ( $\mathrm{ml} / \mathrm{min} / 100 \mathrm{~g} \mathrm{PC})$}

Na TABELA 2 observamos que ao compararmos o "clearance" de inulina do grupo sham $=0,83 \pm 0,05$ (valor normal de filtração glomerular para ratos), com o dos grupos de animais nefrectomizados, obtivemos diminuição significativa deste valor, conforme a progressão da doença, $N \times 21=0,25 \pm$ 0,$06 ; \mathrm{N} \times 60=0,22 \pm 0,06$ e $\mathrm{N} \times 120=0,16 \pm 0,03(\mathrm{p}<0,001)$. Entretanto, proteção significativa e importante do "clearance" de inulina foi observada nos grupos tratados precocemente com NAC quando comparada a dos não tratados, $N \times 21+N A C=0,48 \pm 0,05$ vs $N \times 21=0,25 \pm 0,06 \quad(p<0,05)$; 
$\mathrm{N} \times 60+\mathrm{NAC}=0,47 \pm 0,05$ vs $\mathrm{Nx60}=0,22 \pm 0,06(\mathrm{p}<0,01) ; \mathrm{N} \times 120+\mathrm{NAC}=$ $0,45 \pm 0,04$ vs $N \times 120=0,16 \pm 0,03(p<0,0001)$ (FIGURA 8)

\subsubsection{FE K (\%)}

Aumento significativo na fração de excreção de potássio, observado (TABELA 2) nos grupos de animais nefrectomizados, Nx60 = 220 \pm 47 e $\mathrm{N} \times 120=100 \pm 22$ quando comparada ao sham $=28 \pm 2(\mathrm{p}<0,001, \mathrm{p}<0,05)$, respectivamente. Com a ingestão de NAC obtivemos diminuição significativa destas excreções em relação às dos grupos não tratados, Nx60+NAC = $46,7 \pm 4,6$ vs $\mathrm{Nx60}=220 \pm 47$ e $\mathrm{Nx} 120+\mathrm{NAC}=18,24 \pm 2,2$ vs $\mathrm{Nx} 120=100$ $\pm 22(p<0,05)$

\subsubsection{Aldosterona sérica ( $\mathrm{ng} / \mathrm{dl})$}

Observamos que os níveis de aldosterona encontraram-se elevados nos grupos de animais nefrectomizados, Nx21 = 288 $\pm 34 ; N \times 60=319 \pm 50$ Nx120 = $134 \pm 12$ em comparação aos do grupo sham $=11 \pm 27,(p<0,001$ $p<0,05)$, respectivamente. (TABELA 2). Diminuições importantes deste valor obtiveram os animais tratados precocemente quando comparados aos não tratados, Nx21+NAC = 54 \pm 16 vs Nx2 1= $288 \pm 34(p<0,0001) ; N \times 60+N A C$ $=125 \pm 4$ vs $\mathrm{N} \times 60=319 \pm 50(\mathrm{p}<0,005)$ e $\mathrm{Nx} 120+\mathrm{NAC}=59 \pm 2$ vs $\mathrm{Nx120}=$ $134 \pm 12(p<0,001)($ FIGURA 9) 


\subsubsection{UK/UNa}

A TABELA 2 mostra que a relação UK/UNa, que é um marcador indireto da ação da aldosterona no túbulo coletor, encontra-se elevada nos animais nefrectomizados comparada a do grupo Sham $=0,9 \pm 0,03$ vs $\mathrm{Nx} 21$ $=4,7 \pm 1,6 ; N \times 60=5,9 \pm 2,0$ e Nx120 = 5,1 \pm 0,7 $(p<0,05)$. Diminuição desta razão observou-se pós-tratamento precoce com o antioxidante, se comparada a dos grupos não tratados, $\mathrm{Nx} 21+\mathrm{NAC}=1,9 \pm 0,6$ vs $\mathrm{NX} 21=$ $4,7 \pm 1,6(\mathrm{NS}) ; \mathrm{N} \times 60+\mathrm{NAC}=1,6 \pm 0,3$ vs $\mathrm{Nx60}=5,9 \pm 2,0 \quad(\mathrm{p}<0,05)$ e $\mathrm{N} \times 120+\mathrm{NAC}=2,23 \pm 0,73$ vs $\mathrm{N} \times 120=5,1 \pm 0,7$ (NS); estando estes resultados coerentes com as dosagens de aldosterona. (FIGURA 10).

\subsection{6. Índice de glomeruloesclerose (\%)}

Apesar deste índice estar diminuído nos animais $\mathrm{N} \times 60+\mathrm{NAC}=28 \pm$ 2 em relação ao do grupo não tratado $\mathrm{Nx60}=102 \pm 33$, não encontramos diferença significativa. No entanto, houve diminuição no índice de glomeruloesclerose nos grupos tratados precocemente $\mathrm{Nx} 120+\mathrm{NAC}=31 \pm$ 7 quando comparado com dos animais sem tratamento $\mathrm{Nx120}=260 \pm 71$, $\mathrm{p}<0,01$ (FIGURA 11).

\subsubsection{Massa dos corações (g)}

Na TABELA 2 observamos que a massa dos corações dos grupos de animais nefrectomizados, foi maior em relação ao grupo Sham. Neste grupo obtivemos Sham =0,85 $\pm 0,04$ vs Nx $21=1,04 \pm 0,03(p<0,05) ; N \times 60$ 
$=1,37 \pm 0,06$ e Nx120 =1,51 $\pm 0,07$ vs Sham $=0,85 \pm 0,04(p<0,001)$. Ao tratarmos com NAC houve diminuição significativa da massa dos corações

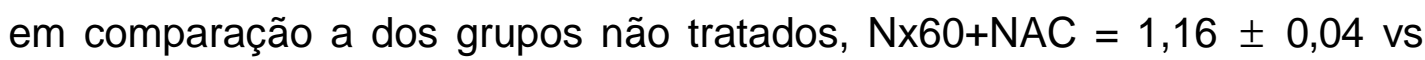
$\mathrm{N} \times 60=1,37 \pm 0,06(\mathrm{p}<0,001)$ e $\mathrm{Nx} 120+\mathrm{NAC}=1,35 \pm 0,05$ vs $\mathrm{Nx} 120=1,51 \pm$ $0,07(p<0,05)$. Entre os grupos de animais tratados houve diferença no grupo $\mathrm{Nx60}=1,37 \pm 0,06$ vs $\mathrm{Nx60+NAC}=1,16 \pm 0,04(\mathrm{p}<0,001)$ (FIGURA 12).

\subsubsection{Massa das adrenais (mg)}

Na TABELA 2 observamos aumento da massa das adrenais nos grupos de animais nefrectomizados $\mathrm{N} x 21=41 \pm 2.7 ; \mathrm{N} \times 60=59 \pm 0,8 \mathrm{e}$ $\mathrm{N} \times 120=59 \pm 2,0$ quando comparada ao do grupo sham $=29 \pm 0,5$ $(p<0,001)$. Ao tratarmos com NAC estes grupos apresentaram diminuição importante da massa das adrenais se comparada a dos grupos não

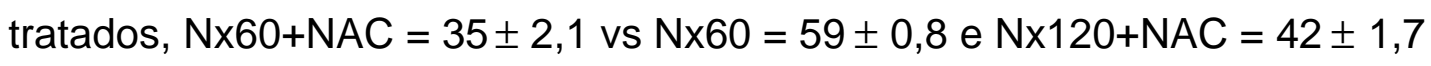
vs $\mathrm{Nx120}=59 \pm 2,0(\mathrm{p}<0,0001)$, respectivamente, . (FIGURA 13).

\subsection{9. Área intersticial relativa (\%)}

A área intersticial relativa nos animais Nx120 foi $22,47 \pm 3,66 \%$ com uma significativa redução no grupo Nx120 tratado com NAC de 10,17 \pm 0,66\% (p<0.03). (FIGURA 14). 


\subsubsection{Imunohistoquímica para ED-1 (macrófagos/monócitos)}

Nos glomérulos, o número de células coradas para ED-1 foi significativamente diminuído nos animais $\mathrm{N} \times 120+\mathrm{NAC}=1,46 \pm 0,25$ quando comparados com os não tratados $\mathrm{NX120}=4,16 \pm 0,70(\mathrm{p}<0,02)$. Na área intersticial tubular obtivemos em $\mathrm{Nx} 120=34.59 \pm 6.16$ e redução significativa nos animais Nx120+NAC = 13,26 $\pm 1,80(p<0,02)$ (FIGURA 15).

\subsubsection{Imunohistoquímica para CD-3 (linfócitos T)}

A análise imunohistoquímica também demonstrou nos glomérulos diminuição no infiltrado de linfócitos no grupo $\mathrm{Nx} 120+\mathrm{NAC}=1,19 \pm 0,26$ se comparado com $\mathrm{Nx} 120=2,10 \pm 0,30(\mathrm{p}<0,05)$; e na área tubulointersticial,

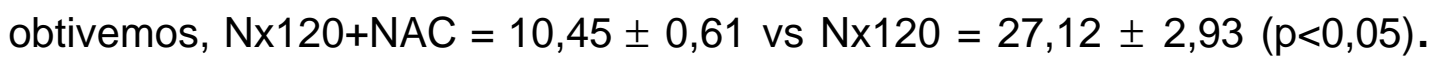
(FIGURA 16) 
Tabela 2 - Resultados dos grupos de animais sham e após 21, 60 e 120 dias de Nx, tratados ou não com Nacetilcisteína (NAC), iniciada no $7^{\circ}$ dia da nefrectomia

\begin{tabular}{|l|c|c|c|c|c|c|c|}
\hline GRUPOS & $\begin{array}{c}\text { P.A. } \\
(\mathbf{m m H g})\end{array}$ & $\begin{array}{c}\text { C.in. } \\
(\mathbf{m l} / \mathbf{m i n} / \\
\mathbf{1 0 0 g} \text { PC) }\end{array}$ & $\begin{array}{c}\text { FE K } \\
(\%)\end{array}$ & Uk/UNa & $\begin{array}{c}\text { Aldo } \\
(\mathbf{n g} / \mathbf{d}) \mathbf{I}\end{array}$ & $\begin{array}{c}\text { Massa do } \\
\text { Coração } \\
(\mathbf{g})\end{array}$ & $\begin{array}{c}\text { Massa da } \\
\text { Adrenal } \\
(\mathbf{m g})\end{array}$ \\
\hline 1-Sham (n=6) & $109 \pm 3$ & $0,83 \pm 0,05$ & $28 \pm 2$ & $0,9 \pm 0,03$ & $11 \pm 27$ & $0,85 \pm 0,04$ & $29 \pm 0,5$ \\
\hline 2.Nx21 (n=6) & $138 \pm 4^{*}$ & $0,25 \pm 0,06^{*}$ & $34 \pm 5$ & $4,7 \pm 1,6^{* *}$ & $288 \pm 34^{*}$ & $1,04 \pm 0,03^{* *}$ & $41 \pm 2,7^{*}$ \\
\hline 3.Nx60 (n=6) & $158 \pm 3^{*}$ & $0,22 \pm 0,06^{*}$ & $220 \pm 47^{*}$ & $5,9 \pm 2,0^{* *}$ & $319 \pm 50^{*}$ & $1,37 \pm 0,06^{*}$ & $59 \pm 0,8^{*}$ \\
\hline 4.Nx120 (n=6) & $174 \pm 5^{*}$ & $0,16 \pm 0,03^{*}$ & $100 \pm 22^{* *}$ & $5,1 \pm 0,7^{* *}$ & $134 \pm 12^{* *}$ & $1,51 \pm 0,07^{*}$ & $59 \pm 2,0^{*}$ \\
\hline
\end{tabular}

\begin{tabular}{|c|c|c|c|c|c|c|c|}
\hline $\begin{array}{l}\text { 5.Sham+NAC } \\
(n=6)\end{array}$ & $108 \pm 3$ & $0,93 \pm 0,02$ & $24,0 \pm 1,6$ & $1,8 \pm 0,3$ & $15 \pm 2$ & $0,81 \pm 0,05$ & $27 \pm 0,9$ \\
\hline $\begin{array}{l}\text { 6.Nx21+NAC } \\
(n=6)\end{array}$ & $134 \pm 2$ * & $0,48 \pm 0,05^{d *}$ & $28,3 \pm 4,5$ & $1,9 \pm 0,6$ & $54 \pm 16^{a *}$ & $1,04 \pm 0,06^{* *}$ & $45 \pm 4,2$ * \\
\hline $\begin{array}{l}\text { 7.Nx60+NAC } \\
(n=6)\end{array}$ & $154 \pm 2$ * & $0,47 \pm 0,05^{\mathrm{c} *}$ & $46,7 \pm 4 .{ }^{d}$ & $1,6 \pm 0,3^{* *}$ & $125 \pm 24^{b *}$ & $1,16 \pm 0,04^{d *}$ & $35 \pm 2,1^{a *}$ \\
\hline $\begin{array}{l}\text { 8.Nx120+NAC } \\
(n=6)\end{array}$ & $150 \pm 7^{d *}$ & $0,45 \pm 0,04^{a *}$ & $18,24 \pm 2,2^{\mathrm{d}}$ & $2,23 \pm 0,7^{d}$ & $59 \pm 2^{c *}$ & $1,35 \pm 0,05^{*}$ & $42 \pm 1,7^{a *}$ \\
\hline
\end{tabular}

Os resultados estão expressos em média \pm EP

${ }^{\mathrm{a}} p<0,0001,{ }^{\mathrm{b}} p<0,005,{ }^{\mathrm{c}} p<0,01,{ }^{\mathrm{d}} p<0,05$, comparação entre os grupos tratados e não tratados

${ }^{*} p<0,001,{ }^{* *} p<0,05$, vs. Sham

One way ANOVA - pós-teste Bonferroni 
FIGURA 7

Pressão arterial

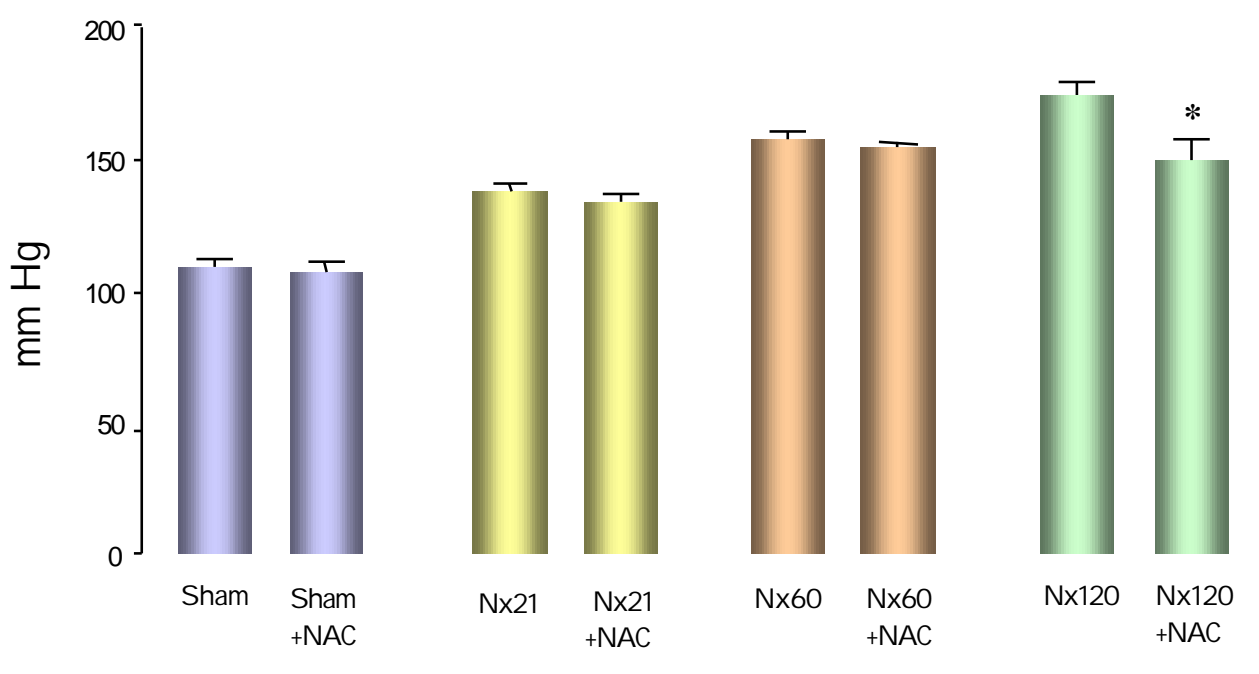

* p $<0.001$ vs Nx120

Nível de Significância entre os diversos Grupos

Teste estatístico de análise de variância ANOVA - pós-teste Bonferroni

\begin{tabular}{|c|c|c|c|c|c|c|c|}
\hline & Sham & $\begin{array}{c}\text { Sham } \\
\text { +NAC }\end{array}$ & Nx21 & $\begin{array}{c}\text { Nx21 } \\
\text { +NAC }\end{array}$ & Nx60 & $\begin{array}{c}\text { Nx60 } \\
\text { +NAC }\end{array}$ & Nx120 \\
\hline Sham+NAC & ns & - & & & & & \\
\hline Nx21 & $<0,001$ & $<0,001$ & - & & & & \\
\hline Nx21+NAC & $<0,001$ & $<0,001$ & ns & - & & & \\
\hline Nx60 & $<0,001$ & $<0,001$ & $<0,05$ & $<0,01$ & - & & \\
\hline Nx60+NAC & $<0,001$ & $<0,001$ & $<0,05$ & $<0,05$ & ns & - & \\
\hline Nx120 & $<0,001$ & $<0,001$ & $<0,001$ & $<0,001$ & $<0,05$ & $<0,05$ & - \\
\hline Nx120+NAC & $<0,001$ & $<0,001$ & $n s$ & $n s$ & $n s$ & $n s$ & $<0,01$ \\
\hline
\end{tabular}




\section{FIGURA 8}

\section{Cle arance de inulina}

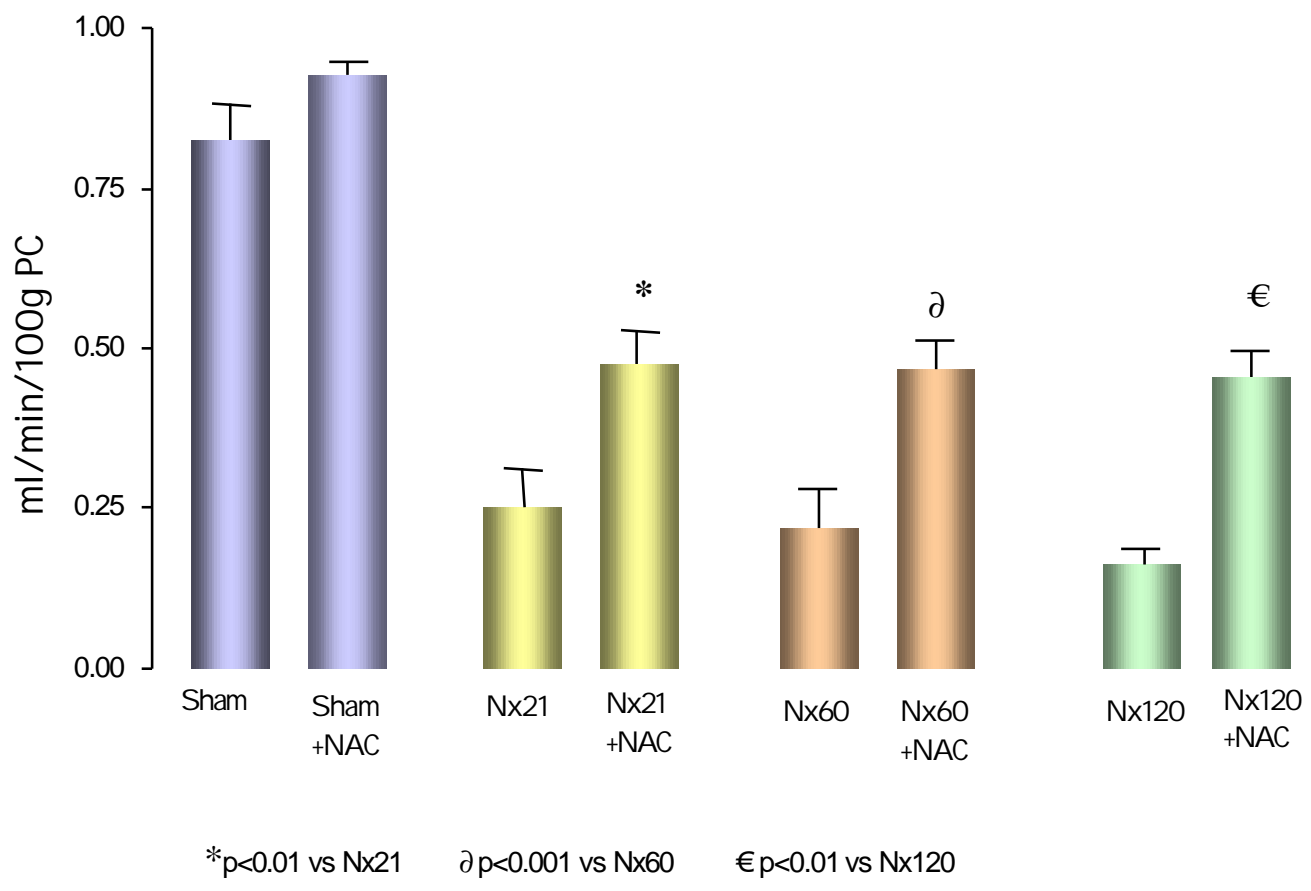

Grupos Nível de Significância entre os diversos

Teste estatístico de análise de variância ANOVA- pós teste Bonferroni

\begin{tabular}{|c|c|c|c|c|c|c|c|}
\hline & Sham & $\begin{array}{c}\text { Sham } \\
+\mathrm{NAC}\end{array}$ & $\mathrm{N} \times 21$ & $\begin{array}{c}\mathrm{N} \times 21 \\
+\mathrm{NAC}\end{array}$ & $\mathrm{N} \times 60$ & $\begin{array}{c}\text { Nx60 } \\
+\mathrm{NAC}\end{array}$ & $\mathrm{N} \times 120$ \\
\hline Sham+NAC & $\mathrm{ns}$ & - & & & & & \\
\hline $\mathrm{N} \times 21$ & $<0,001$ & $<0,001$ & - & & & & \\
\hline $\mathrm{N} \times 21+\mathrm{NAC}$ & $<0,001$ & $<0,001$ & $<0,01$ & - & & & \\
\hline $\mathrm{N} \times 60$ & $<0,001$ & $<0,001$ & $\mathrm{~ns}$ & $<0,01$ & - & & \\
\hline $\mathrm{N} \times 60+\mathrm{NAC}$ & $<0,001$ & $<0,001$ & $<0,01$ & $\mathrm{~ns}$ & $<0,01$ & - & \\
\hline $\mathrm{N} \times 120$ & $<0,001$ & $<0,001$ & $\mathrm{~ns}$ & $<0,001$ & $\mathrm{~ns}$ & $<0,001$ & - \\
\hline $\mathrm{N} 120+\mathrm{NAC}$ & $<0,001$ & $<0,001$ & $<0,01$ & $\mathrm{~ns}$ & $<0,01$ & $\mathrm{~ns}$ & $<0,001$ \\
\hline
\end{tabular}




\section{FIGURA 9}

\section{Aldosterona plasmática}

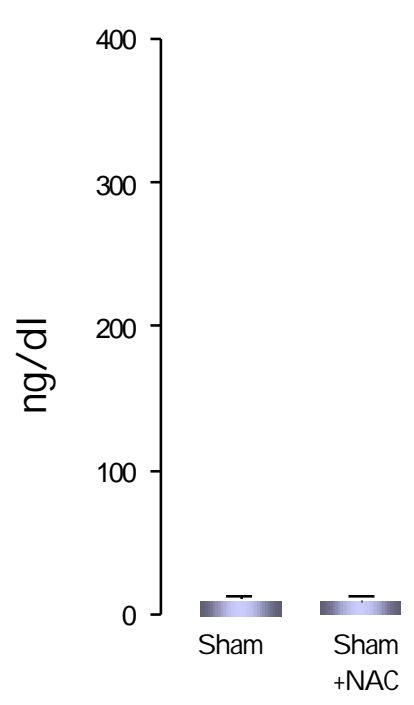

* $p<0.001$ vs Nx 21,60 e 120
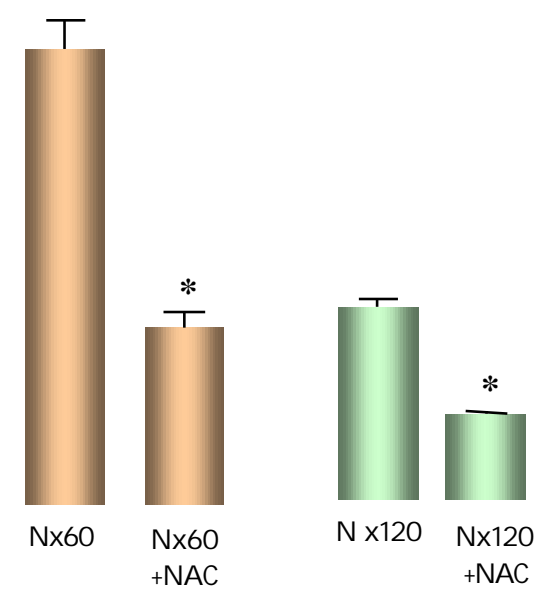

Nível de Significância entre os diversos Grupos

Teste estatístico de análise de variância ANOVA - pós-teste Bonferroni

\begin{tabular}{|c|c|c|c|c|c|c|c|}
\hline & Sham & $\begin{array}{c}\text { Sham } \\
\text { +NAC }\end{array}$ & Nx21 & $\begin{array}{c}\text { Nx21 } \\
\text { +NAC }\end{array}$ & Nx60 & $\begin{array}{c}\text { Nx60 } \\
\text { +NAC }\end{array}$ & Nx120 \\
\hline Sham+NAC & ns & - & & & & & \\
\hline Nx21 & $<0,001$ & $<0,001$ & - & & & & \\
\hline Nx21+NAC & $<0,05$ & $<0,05$ & $<0,001$ & - & & & \\
\hline Nx60 & $<0,001$ & $<0,001$ & $<0,05$ & $<0,001$ & - & & \\
\hline Nx60+NAC & $<0,001$ & $<0,001$ & $<0,001$ & $<0,001$ & $<0,001$ & - & \\
\hline Nx120 & $<0,001$ & $<0,001$ & $<0,001$ & $<0,001$ & $<0,001$ & ns & - \\
\hline Nx120+NAC & $<0,01$ & $<0,01$ & $<0,001$ & ns & $<0,001$ & $<0,001$ & $<0,001$ \\
\hline
\end{tabular}


FIGURA 10

\section{$\mathcal{U K} \mathcal{U L N a}$}

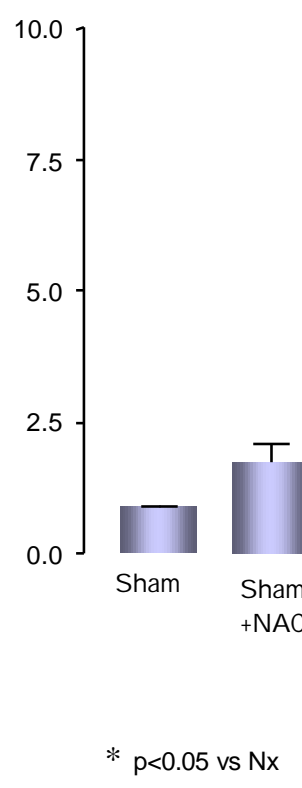

Nível de Significância entre os diversos Grupos

Teste estatístico de análise de variância ANOVA - pós-teste Bonferroni

\begin{tabular}{|c|c|c|c|c|c|c|c|}
\hline & Sham & $\begin{array}{c}\text { Sham } \\
\text { +NAC }\end{array}$ & Nx21 & $\begin{array}{c}\text { Nx21 } \\
\text { +NAC }\end{array}$ & Nx60 & $\begin{array}{c}\text { Nx60 } \\
\text { +NAC }\end{array}$ & Nx120 \\
\hline Sham+NAC & ns & - & & & & & \\
\hline Nx21 & ns & ns & - & & & & \\
\hline Nx21+NAC & ns & ns & ns & - & & & \\
\hline Nx60 & $<0,05$ & $<0,05$ & ns & $<0,05$ & - & & \\
\hline Nx60+NAC & ns & ns & ns & ns & $<0,05$ & - & \\
\hline Nx120 & ns & ns & ns & ns & ns & ns & - \\
\hline Nx120+NAC & ns & ns & ns & ns & $<0,05$ & ns & ns \\
\hline
\end{tabular}




\section{FIGURA 11}

\section{Indice de Glomeruloesclerose}

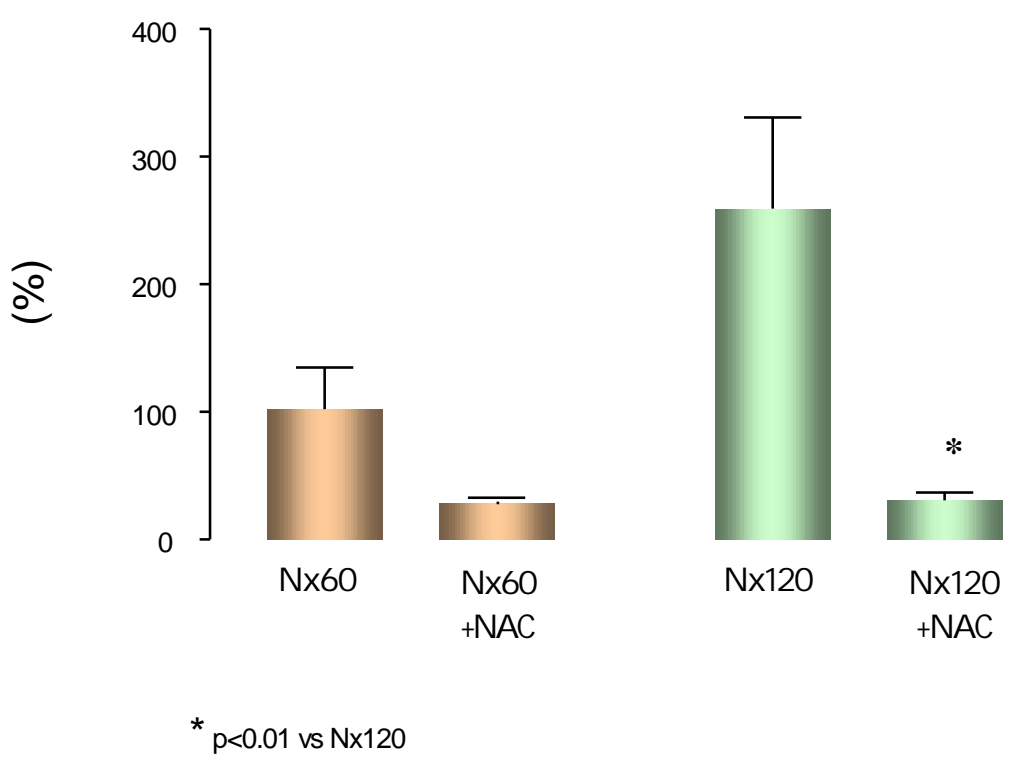

Nível de Significância entre os diversos Grupos

Teste estatístico de análise de variância ANOVA - pós-teste Bonferroni

\begin{tabular}{|c|c|c|c|}
\hline & Nx60 & $\begin{array}{c}\text { Nx60 } \\
\text { +NAC }\end{array}$ & Nx120 \\
\hline Nx60 & - & & \\
\hline Nx60+NAC & ns & - & \\
\hline Nx120 & ns & $<0,05$ & - \\
\hline Nx120+NAC & ns & ns & $<0,01$ \\
\hline
\end{tabular}




\section{FIGURA 12}

\section{Massa dos corações}

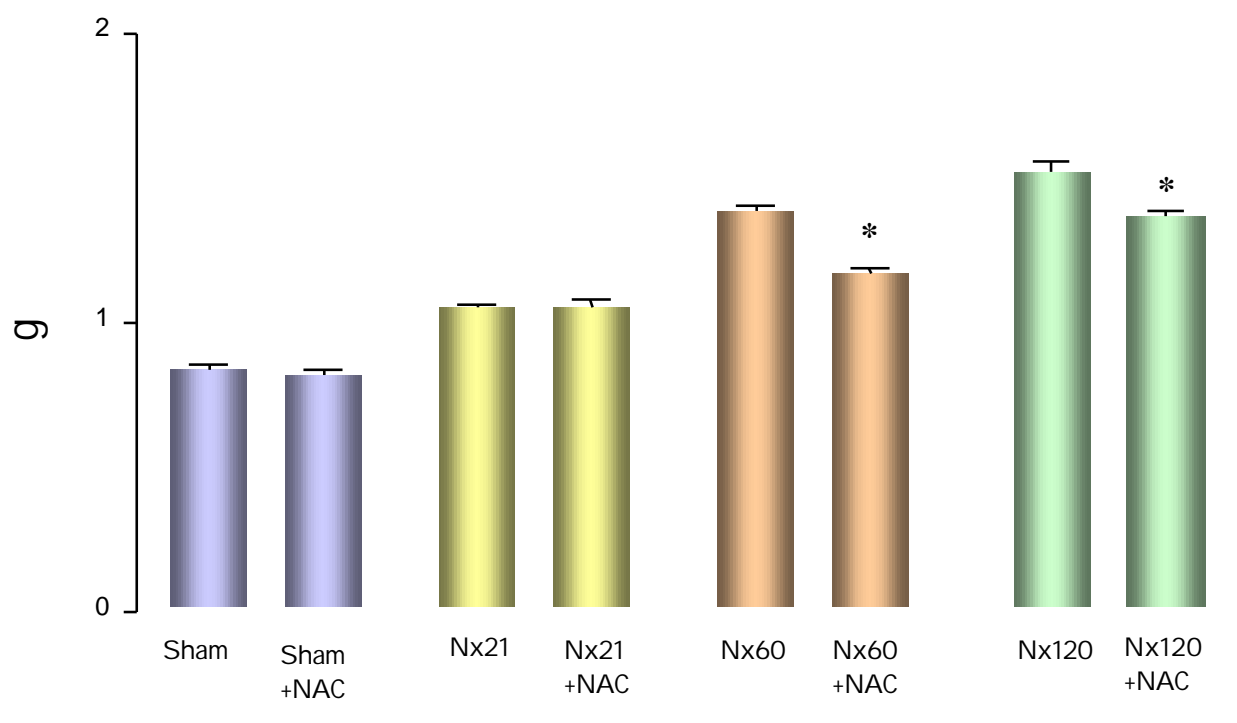

* $p<0.001$ vs $N \times 60$ e $N \times 120$

Nível de Significância entre os diversos Grupos

Teste estatístico de análise de variância ANOVA e pós-teste Bonferroni

\begin{tabular}{|c|c|c|c|c|c|c|c|}
\hline & Sham & $\begin{array}{c}\text { Sham } \\
\text { +NAC }\end{array}$ & Nx21 & $\begin{array}{c}\text { Nx21 } \\
\text { +NAC }\end{array}$ & Nx60 & $\begin{array}{c}\text { Nx60 } \\
\text { +NAC }\end{array}$ & Nx120 \\
\hline Sham+NAC & ns & - & & & & & \\
\hline Nx21 & $<0,001$ & $<0,001$ & - & & & & \\
\hline Nx21+NAC & $<0,001$ & $<0,001$ & $n s$ & - & & & \\
\hline Nx60 & $<0,001$ & $<0,001$ & $<0,001$ & $<0,001$ & - & & \\
\hline Nx60+NAC & $<0,001$ & $<0,001$ & $<0,01$ & $<0,001$ & $<0,001$ & - & \\
\hline Nx120 & $<0,001$ & $<0,001$ & $<0,001$ & $<0,001$ & $<0,001$ & $<0,001$ & - \\
\hline Nx120+NAC & $<0,001$ & $<0,001$ & $<0,001$ & $<0,001$ & ns & $<0,001$ & $<0,001$ \\
\hline
\end{tabular}




\section{FIGURA 13}

\section{Massa das adrenais}

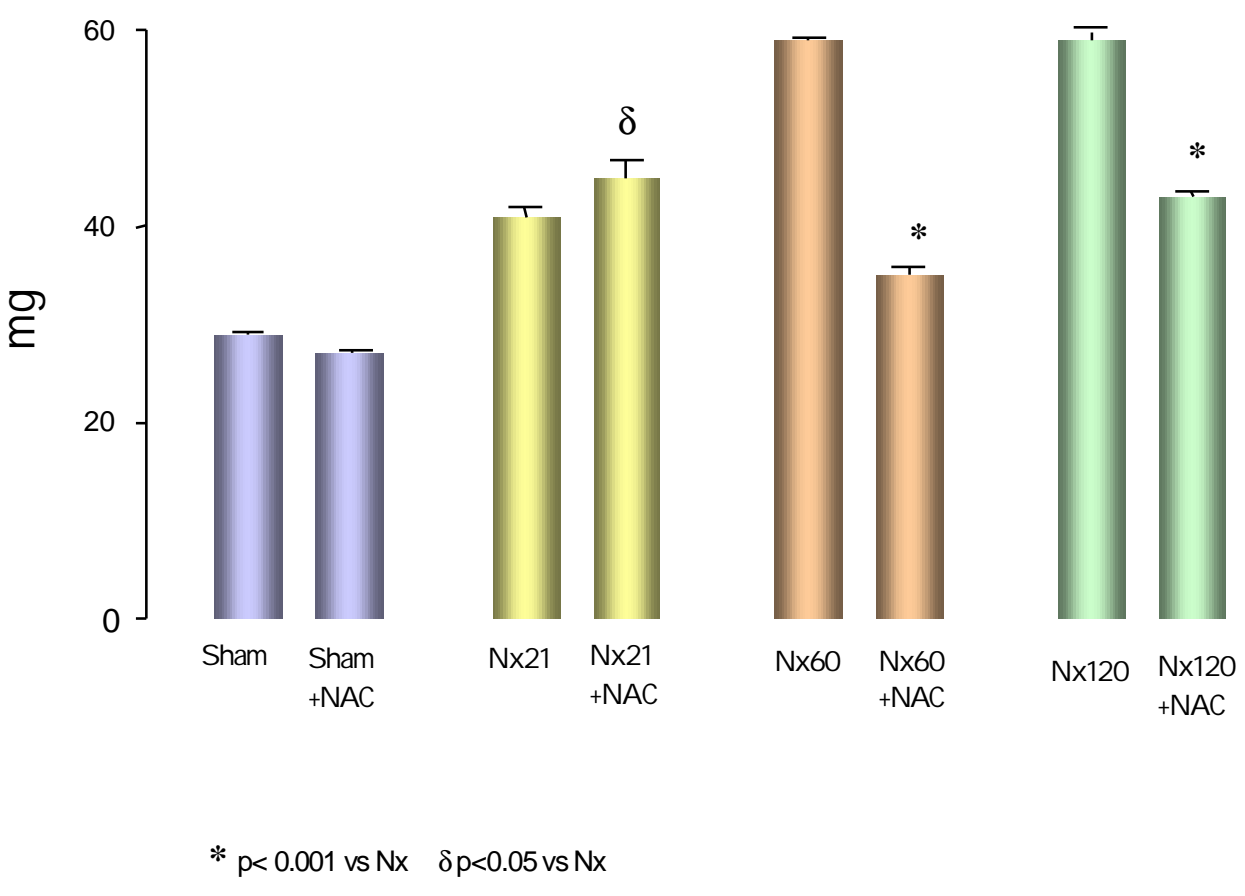

Nível de Significância entre os diversos Grupos

Teste estatístico de análise de variância ANOVA e pós-teste Bonferroni

\begin{tabular}{|c|c|c|c|c|c|c|c|}
\hline & Sham & $\begin{array}{l}\text { Sham } \\
+ \text { NAC }\end{array}$ & $\mathrm{Nx21}$ & $\begin{array}{r}\text { Nx21 } \\
+ \text { NAC } \\
\end{array}$ & Nx60 & $\begin{array}{r}\text { Nx60 } \\
+ \text { NAC } \\
\end{array}$ & Nx120 \\
\hline Sham+NAC & ns & 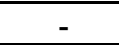 & & & & & \\
\hline Nx21 & $<0,001$ & $<0,001$ & - & & & & \\
\hline $\mathrm{N} \times 21+\mathrm{NAC}$ & $<0,001$ & $<0,001$ & $<0,05$ & - & & & \\
\hline Nx60 & $<0,001$ & $<0,001$ & $<0,001$ & $<0,001$ & - & & \\
\hline $\mathrm{N} \times 60+\mathrm{NAC}$ & $<0,001$ & $<0,001$ & $<0,001$ & $<0,001$ & $<0,001$ & - & \\
\hline Nx120 & $<0,001$ & $<0,001$ & $<0,001$ & $<0,001$ & $\mathrm{~ns}$ & $<0,001$ & - \\
\hline $\mathrm{Nx} 120+\mathrm{NAC}$ & $<0,001$ & $<0,001$ & ns & ns & $<0,001$ & $<0,001$ & $<0,001$ \\
\hline
\end{tabular}




\title{
FIGURA 14
}

\author{
Área intersticial \\ relativa
}

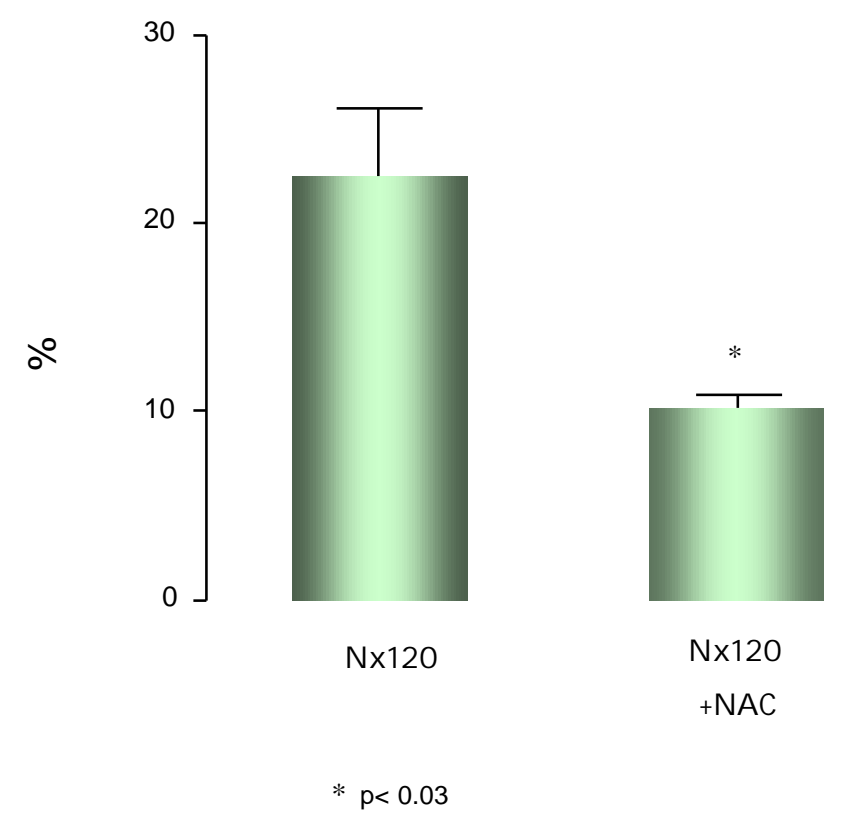




\section{FIGURA 15}

\section{ED-1 (macrófago/monócitos)}
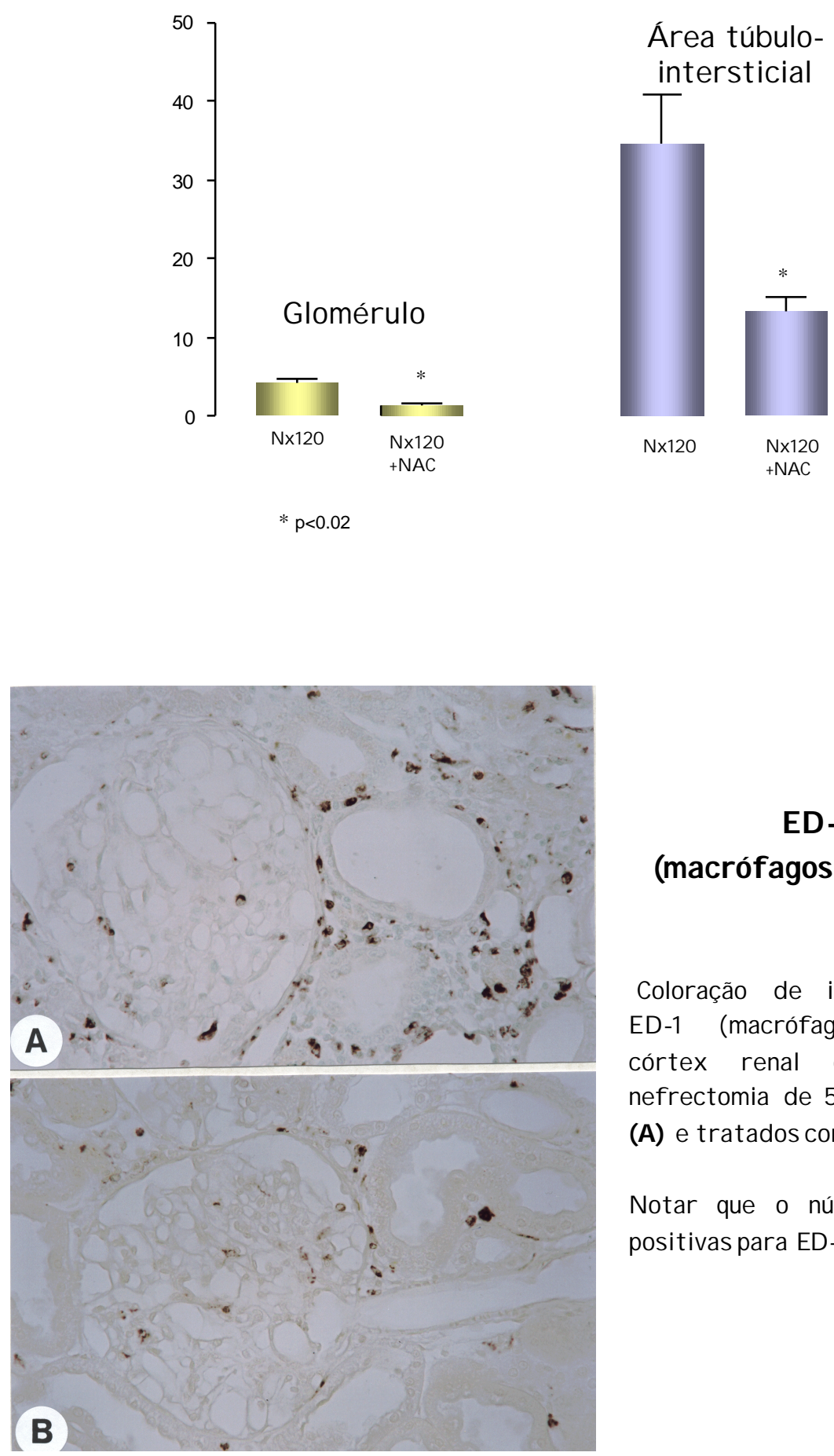

$\mathcal{E D}$ - 1

(macrófagos-monócitos)

Coloração de imunohistoquímica ED-1 (macrófago/monócito) na córtex renal de ratos com nefrectomia de 5/6 não tratados $(\mathcal{A})$ e tratados com $\mathcal{N} \mathcal{A C}(\mathcal{B})$.

Notar que o número de células positivas para $\mathcal{E D} \cdot 1$ é maior e m $\mathcal{A}$. 


\section{FIGURA16}

$$
C \mathcal{D}-3(\operatorname{Linf} \text { ćcitos })
$$
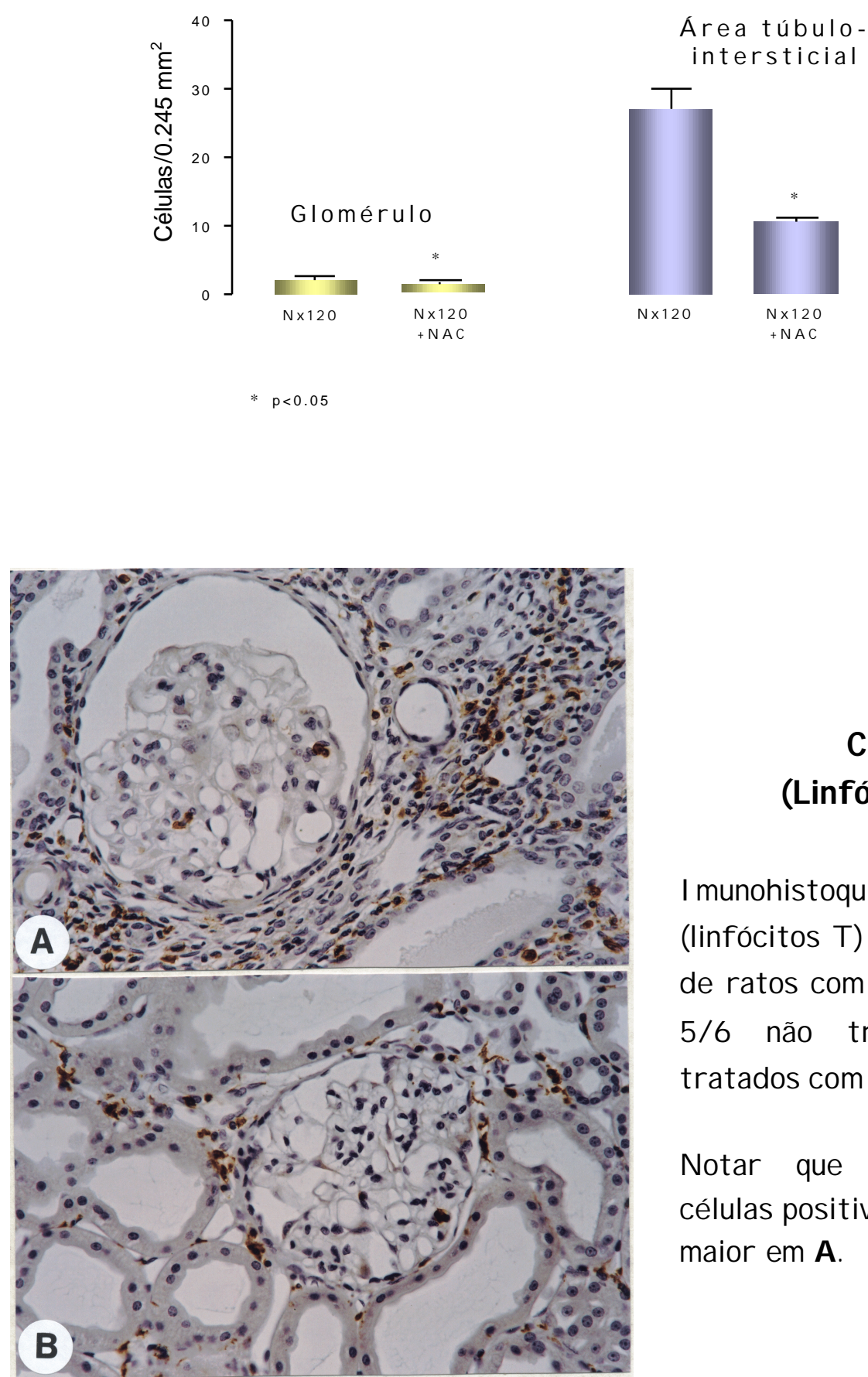

CD. 3

(Linfócitos $\mathcal{T}$ )

Imunofistoquimica para $C \mathcal{D}-3$ (linfócitos $\mathcal{T}$ ) na córtex renal de ratos com nefrectomia de $5 / 6$ não tratados (A) e tratados com $\mathcal{N A C}(\mathcal{B})$.

Notar que o número de células positivas para CD-3 é maior em $\mathcal{A}$. 


\subsection{Grupos de animais sham e com Insuficiência renal crônica (Nx) tratados tardiamente com $\mathrm{N}$-acetilcisteína (NAC):}

\subsubsection{Peso corpóreo (g)}

A média do ganho de peso corpóreo nos animais com ingestão tardia de NAC, após 60 dias da nefrectomia Nx120(Nx60+60NAC), foi de $337 \pm 10 \mathrm{~g}$, comparável ao dos animais com ingestão precoce, após 7 dias da nefrectomia Nx120 = $308 \pm 16(\mathrm{NS})$.

\subsubsection{Ingestão de $\mathrm{NAC}(\mathrm{mg} / 100 \mathrm{~g} \mathrm{PC} / \mathrm{dia})$}

Não houve diferenças na ingestão de NAC entre os grupos de animais tratados tanto precoce como tardiamente, $\mathrm{Nx} 120+\mathrm{NAC}=15,7 \pm 0,8$ vs $\mathrm{Nx} 120(\mathrm{~N} \times 60+60 \mathrm{NAC})=14,1 \pm 0.5(\mathrm{NS})$.

\subsubsection{Proteinúria $(\mathrm{mg} / 24 \mathrm{~h})$}

Na TABELA 3 observamos que os valores da proteinúria do grupo $\mathrm{N} x 120=208 \pm 10$, foi maior do que no grupo sham $=5 \pm 1(p<0,001)$. Nos animais tratados precocemente com NAC, observamos diminuição da proteinúria, $\mathrm{Nx} 120+\mathrm{NAC}=159 \pm 10$ vs $\mathrm{Nx} 120=208 \pm 10(\mathrm{p}<0,001)$ e vs Sham $=5 \pm 1(p<0,001)$. No grupo tratado tardiamente com NAC, o valor da proteinúria, foi menor, embora, elevada, em relação à do grupo não tratado, $\mathrm{N} \times 120(\mathrm{~N} \times 60+60 \mathrm{NAC})=134 \pm 22$ vs $\mathrm{Nx120}=208 \pm 10(\mathrm{p}<0,01)$ (FIGURA 17). 


\subsubsection{TBARS (nmoles/24h)}

Na TABELA 3 observamos diminuição significativa deste marcador de peroxidação lipídica tanto no grupo tratado precoce como tardiamente com NAC se comparada ao grupo sem tratamento, Nx120 = 254 \pm 52 vs $\mathrm{N} x 120+\mathrm{NAC}=92 \pm 6$ e $\mathrm{Nx} 120(\mathrm{~N} \times 60+60 \mathrm{NAC})=127 \pm 15$ vs $\mathrm{Nx120}=254 \pm$ $52(p<0,001)$ (FIGURA 18).

\subsection{5. "Clearance" de inulina ( $\mathrm{ml} / \mathrm{min} / 100 \mathrm{~g} \mathrm{PC})$}

Como observado na TABELA 3, após tratamento precoce com NAC, os animais nefrectomizados apresentaram, maior "clearance" de inulina, $\mathrm{N} \times 120+\mathrm{NAC}=0,45 \pm 0,04$, como no grupo de animais onde 0 antioxidante foi administrado tardiamente, $\mathrm{Nx} 120(\mathrm{~N} \times 60+60 \mathrm{NAC})=0.51 \pm 0.03$ (NS) (FIGURA 19).

\subsubsection{Pressão arterial $(\mathrm{mmHg})$}

A pressão arterial dos animais nefrectomizados $\mathrm{Nx120}=174 \pm 5$ foi maior quando comparada aos animais sham $=109 \pm 3(p<0,001) \cdot($ TABELA 3). Ao administrarmos NAC tanto precoce como tardiamente houve uma redução da pressão, embora, não tenha sido estatisticamente diferente da observada nos grupos de animais não tratados, Nx120+NAC = $150 \pm 7$; $\mathrm{N} \times 120(\mathrm{~N} \times 60+60 \mathrm{NAC})=159 \pm 8$ vs Nx120 = $174 \pm 5$ (NS) (FIGURA 20) 


\subsubsection{Aldosterona sérica (ng/dl)}

Na TABELA 3 notamos que o nível de aldosterona, encontra-se aumentado no grupo $\mathrm{Nx} 120=134 \pm 12$. Entretanto, quando comparado aos dos animais tratados precoce e tardiamente com NAC, observamos redução importante deste valor, $\mathrm{Nx} 120=134 \pm 12$ vs $\mathrm{Nx} 120+\mathrm{NAC}=59 \pm 2(\mathrm{p}<0,01)$ e Nx120(Nx60+60NAC) $=31 \pm .4(p<0,001)(F I G U R A 21)$

\subsubsection{UK/UNa}

De acordo com os resultados da dosagem de aldosterona o valor da razão UK/uma, demonstrado na TABELA 3, foi maior no grupo Nx120 =5,1 $\pm 0,7$, diminuindo após administração tanto precoce como tardia de NAC $\mathrm{N} x 120+\mathrm{NAC}=2,23 \pm 0,7, \mathrm{Nx} 120(\mathrm{Nx60+60NAC})=1,3 \pm 0,1 \quad(p<0,01 \mathrm{e}$ $\mathrm{p}<0,001)$, respectivamente (FIGURA 22).

\subsubsection{Massa do coração (g)}

A massa do coração demonstrada na TABELA 3, dos grupos Nx120 $=1,51 \pm .0,07, \mathrm{~N} \times 120+\mathrm{NAC}=1,35 \pm .0,05$ e $\mathrm{N} \times 120(\mathrm{~N} \times 60+60 \mathrm{NAC})=1,42$ $\pm .0,07$, foi maior do que obtivemos no grupo sham $=0,85 \pm .0,04 \quad(p<0,001)$. Com a ingestão precoce e tardia de NAC este valor encontrou-se diminuído porém sem diferença estatística (FIGURA 23). 


\subsubsection{Massa das adrenais $(\mathrm{mg})$}

$\mathrm{Na}$ TABELA 3 observamos diminuição significativa na massa da adrenal quando da ingestão precoce e tardia de NAC, Nx120+NAC $=42 \pm$ $1,7, \mathrm{~N} \times 120(\mathrm{~N} \times 60+60 \mathrm{NAC})=43 \pm 3$, quando comparada com a massa $\mathrm{da}$ adrenal do grupo Nx120 que foi de $59 \pm 2$ ( $p<0,001)$ (FIGURA 24).

\section{4. Índice de glomeruloesclerose}

Houve diminuição significativa quanto ao índice de glomeruloesclerose nos grupos tratados tanto precoce, como tardiamente $\mathrm{N} \times 120+\mathrm{NAC}=31 \pm 7, \mathrm{~N} \times 120(\mathrm{~N} \times 60+60 \mathrm{NAC}=21,7 \pm \cdot 5$, quando comparado com dos animais sem tratamento Nx120 = $260 \pm 71(p<0,01)$ (FIGURA 25)).

\subsection{Taxa de mortalidade}

Não houve análise estatística da taxa de mortalidade.

No grupo Nx120 foram operados 10 animais, sendo que obtivemos 1 óbito no $78^{\circ}$ dia, 1 óbito no $98^{\circ}$ dia e 2 óbitos no $103^{\circ}$ dia. Portanto, $33 \%$ de óbitos.

No grupo Nx120+NAC foram operados 8 animais, obtivemos 1 óbito no $96^{\circ}$ e 1 óbito no $110^{\circ}$ dia. Portanto, $25 \%$ de óbitos.

Neste grupo, Nx120 (Nx60+60d NAC), foram operados 7 animais. Obtivemos 1 óbito no $97^{\circ}$ dia após ingestão de NAC. Portanto, somente $14,3 \%$ de óbitos. 
Nossos resultados demonstram que o antioxidante NAC mesmo se administrado tardiamente, exerceu efeito protetor sobre a filtração glomerular de ratos com insuficiência renal crônica, com diminuição das concentrações de aldosterona, TBARS e proteinúria. 
Tabela 3- Resultados dos grupos sham e nefrectomizados após ablação renal de 120 dias e tratados precoces e tardiamente com $\mathrm{N}$-acetilcisteína (NAC):

\begin{tabular}{|c|c|c|c|c|c|c|c|c|}
\hline GRUPOS & $\begin{array}{c}\text { P.A. } \\
\text { (mmHg) }\end{array}$ & $\begin{array}{c}\text { C.in. } \\
\text { (ml/min/ } \\
100 \mathrm{~g} \mathrm{PC})\end{array}$ & TBARS & Proteinúria & Uk/UNa & $\begin{array}{l}\text { Aldo } \\
\text { (ng /d)I }\end{array}$ & $\begin{array}{l}\text { Massa do } \\
\text { Coração } \\
\text { (g) }\end{array}$ & $\begin{array}{c}\text { Massa da } \\
\text { Adrenal } \\
(\mathrm{mg})\end{array}$ \\
\hline $\begin{array}{l}\text { Sham } \\
(n=6)\end{array}$ & $109 \pm 3$ & $0,83 \pm 0,05$ & $18 \pm 2$ & $5 \pm 1$ & $0,9 \pm 0,03$ & $11 \pm 3$ & $0,85 \pm 0,04$ & $29 \pm 0,5$ \\
\hline $\begin{array}{l}N \times 120 \\
(n=6)\end{array}$ & $174 \pm 5^{*}$ & $0,16 \pm 0,03^{*}$ & $254 \pm 52$ * & $208 \pm 10^{*}$ & $5,1 \pm 0,7^{*}$ & $134 \pm 12^{* *}$ & $1,51 \pm 0,07^{*}$ & $59 \pm 2,0$ * \\
\hline $\begin{array}{l}\text { Nx120+NAC } \\
(n=6)\end{array}$ & $150 \pm 7^{*}$ & $0,45 \pm 0,04^{a *}$ & $92 \pm 6^{a}$ & $159 \pm 10^{a *}$ & $2,23 \pm 0,7^{c}$ & $59 \pm 2^{c *}$ & $1,35 \pm 0,05$ * & $42 \pm 1,7^{a \star *}$ \\
\hline $\begin{array}{l}\text { Nx120 } \\
(\mathrm{Nx60+60NA} \\
\mathrm{C}) \\
(\mathrm{n}=6)\end{array}$ & $159 \pm 8^{*}$ & $0,51 \pm 0,03^{a *}$ & $127 \pm 15^{a}$ & $134 \pm 22 * c$ & $1,3 \pm 0,1^{\mathrm{a}}$ & $31 \pm 4^{a}$ & $1,42 \pm 0,07^{*}$ & $43 \pm 3^{a *}$ \\
\hline \multicolumn{9}{|c|}{ Resultados estão expressos em média \pm SEM } \\
\hline \multicolumn{9}{|c|}{${ }^{*} p<0,001,{ }^{* *} p<0,01$ vs. Sham } \\
\hline \multicolumn{9}{|c|}{${ }^{a} p<0,001$ vs $N x 120 ;{ }^{b} p<0,05$ vs. $N x 120 ;{ }^{c} p<0,01$ vs $N \times 120$} \\
\hline \multicolumn{9}{|c|}{ One way ANOVA e pós-teste Bonferroni } \\
\hline
\end{tabular}


FIGURA 17 e 18

Excreção urinária de Proteína

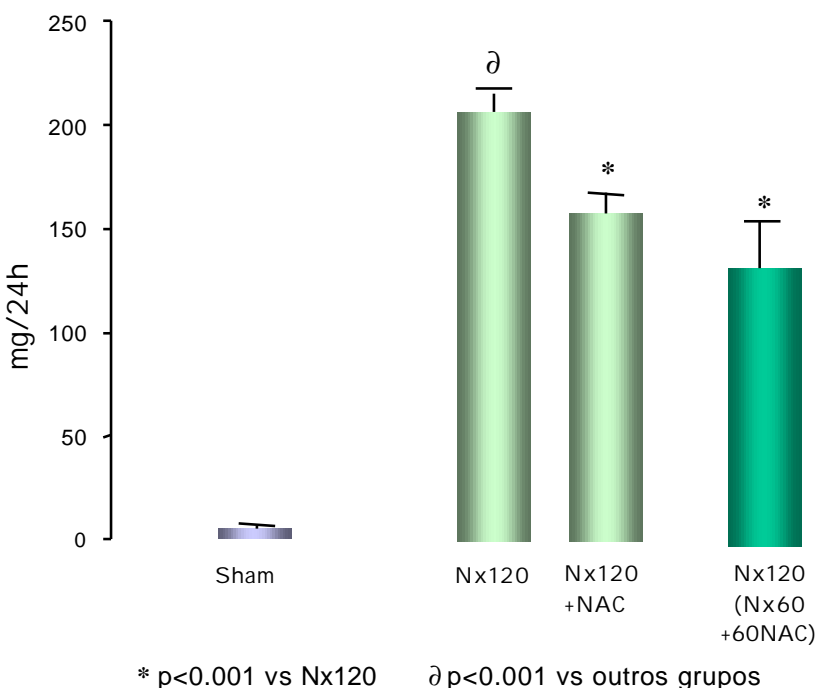

Excreção urináriaTBARS

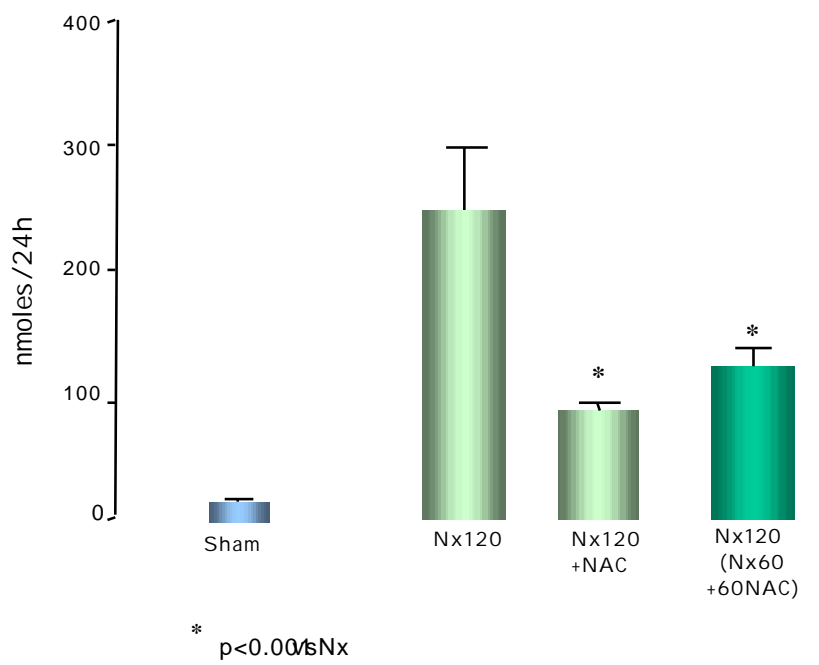


FIGURA 19 e 20

Cle arance de inulina

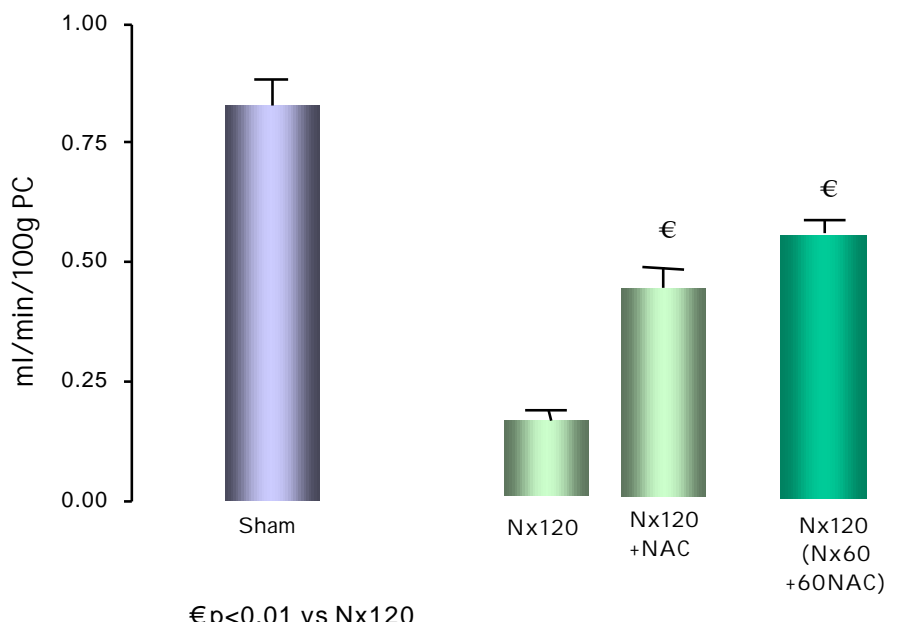

Pressão arterial

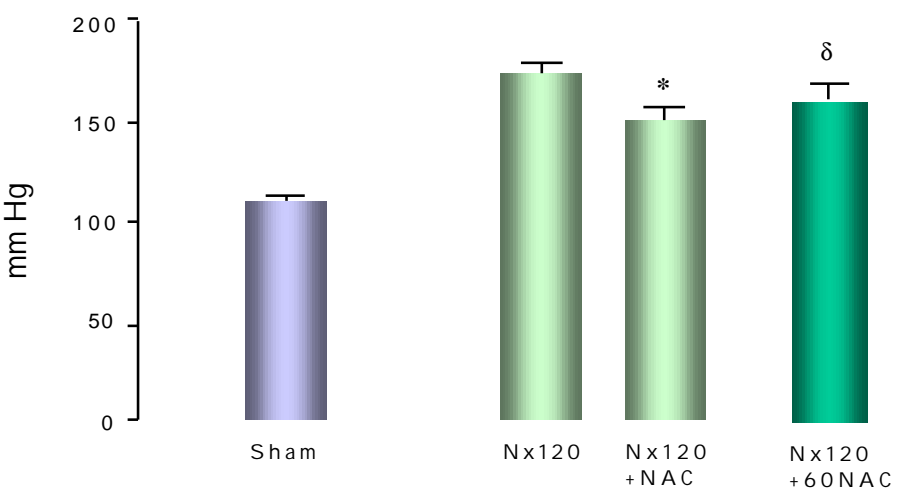

$* p<0.001$ vs $N \times 120 \quad \delta p<0.05$ vs $N \times 120$ 
FIGURA 21 e 22

Aldosterona plasmática

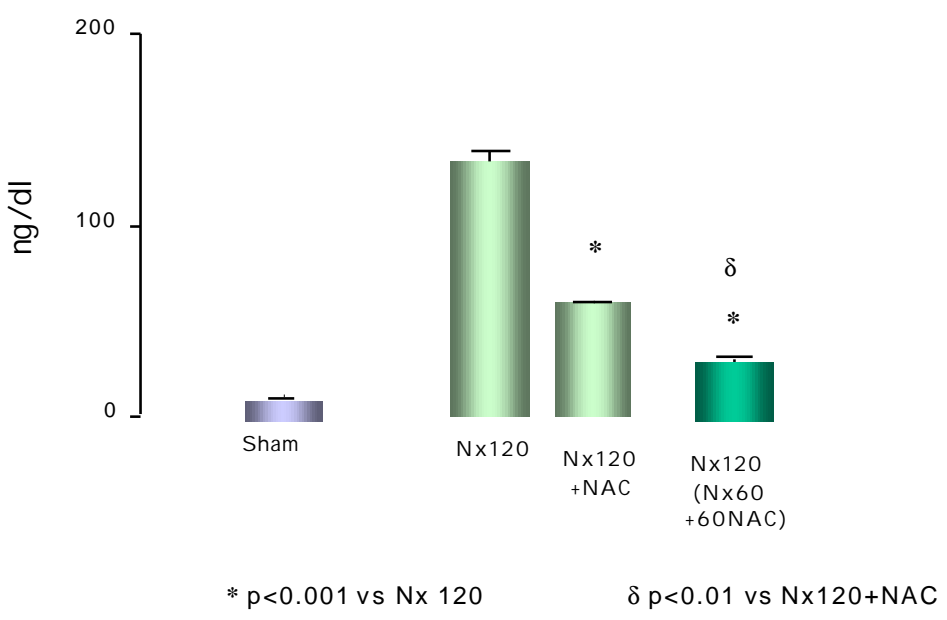

\section{$\mathcal{U K} / \mathcal{U N a}$}
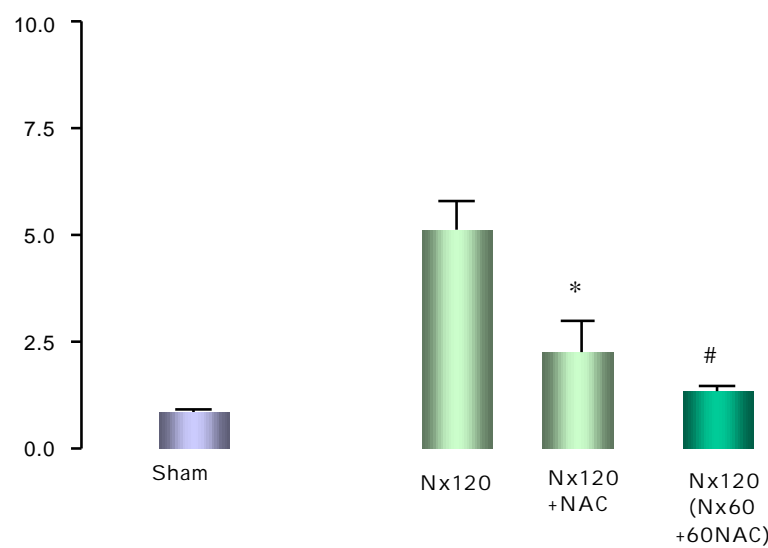

* $p<0,01$ vs $N \times 120$

$\# p<0,001$ vs $N \times 120$ 


\section{FIGURA 23 E 24}

Massa dos corações

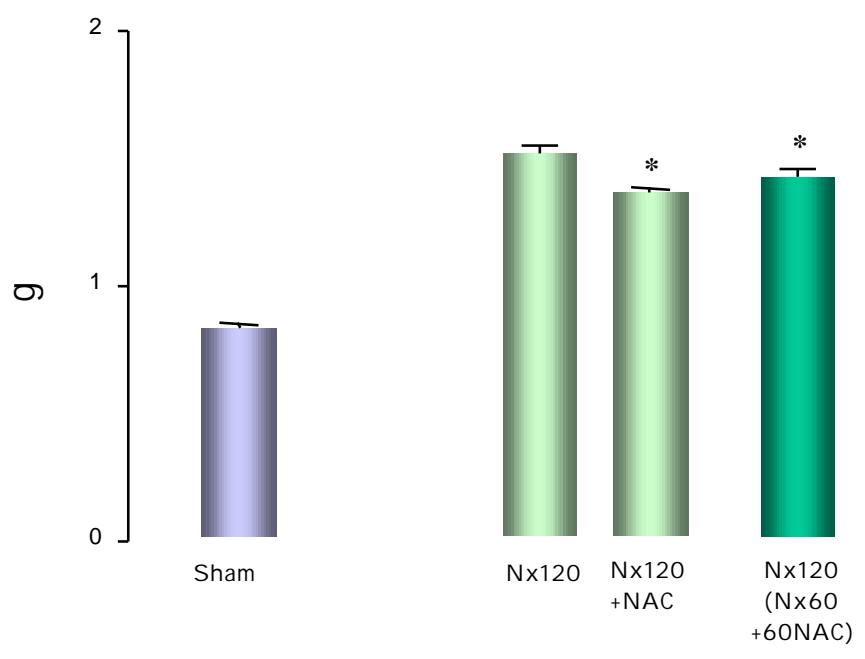

$* p<0.001$ vs $N \times 120$

Massa das adrenais

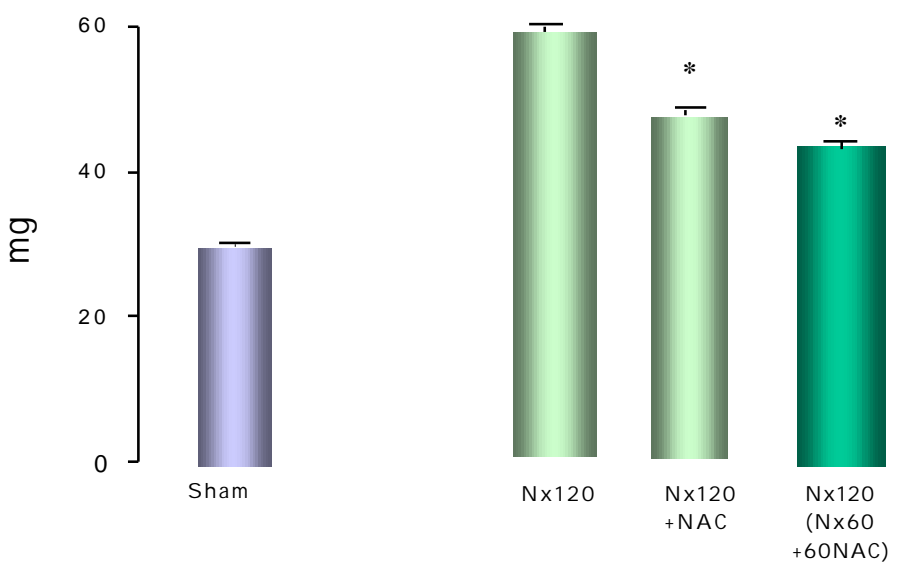

$* \mathrm{p}<0.001$ vs Nx 


\section{FIGURA 25}

\section{Indice de Glomeruloesclerose}

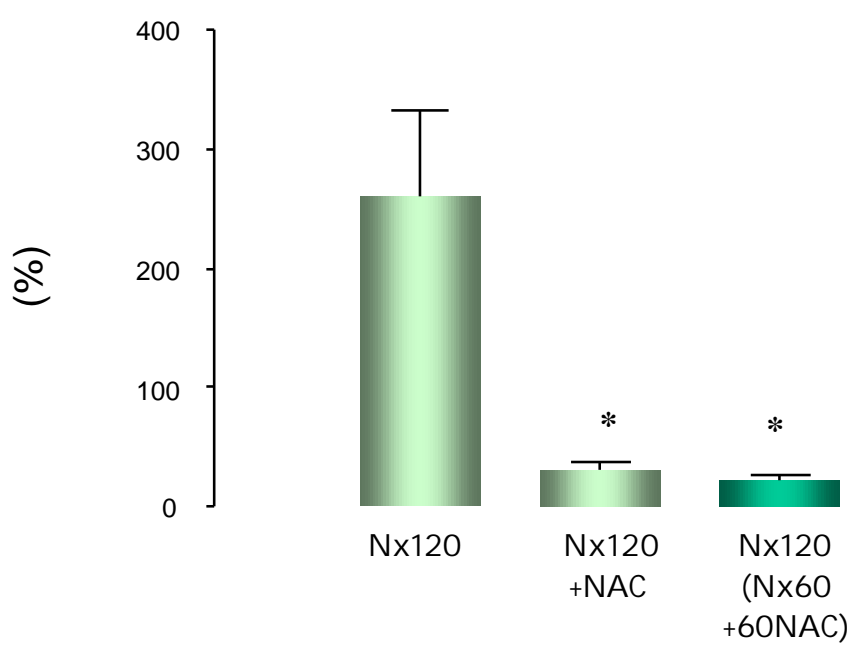

${ }^{*} p<0.01$ vs $N \times 120$ 
4.6. Grupo de animais sham e nefrectomizados ( $\mathrm{Nx}$ ) de 60 dias, tratados com NAC e Espironolactona (Spi):

\subsubsection{Ingestão de NAC (mg/dia/rato)}

A ingestão de NAC foi igual em todos os grupos, média de 14 $\mathrm{mg} / \mathrm{dia} /$ rato.

\subsubsection{Ingestão de espironolactona (Spi) (mg/Kg PC/rato)}

A ingestão de Spi foi igual nos grupos $\mathrm{Nx60+Spi}=134 \pm 7$ e

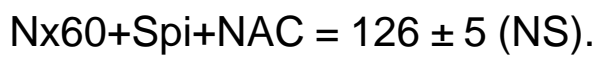

\subsubsection{Peso corpóreo (g)}

Houve aumento no ganho de peso nos grupos tratados com o antioxidante, Nx60+NAC e com Nx60+NAC+Spi, respectivamente, $188 \pm$ $13 \mathrm{~g}$ e $184 \pm 19 \mathrm{~g}$, quando comparado aos animais do grupo $\mathrm{Nx60}=141 \pm$ 11.

\subsubsection{TBARS (nmoles/24h)}

$\mathrm{Na}$ TABELA 4, observamos aumento da excreção urinária de TBARS tanto no grupo $\mathrm{Nx60}=109 \pm 18$ como no $\mathrm{Nx60+Spi}=116 \pm 16$. Diminuição significativa da excreção urinária deste marcador de peroxidação lipídica ocorreu nos grupos que foram tratados com o antioxidante, $\mathrm{Nx60+NAC}=63 \pm 6$ vs $\mathrm{Nx60}=109 \pm 18(\mathrm{p}<0,001)$ e no grupo 
da associação de ambas as drogas, Nx60+NAC+Spi = $83 \pm 5$ vs Nx60 $(p<0,05)$ (FIGURA 26).

\subsection{5. "Clearance" de inulina ( $\mathrm{ml} / \mathrm{min} / 100 \mathrm{~g} P C)$}

O "clearance" de inulina observado na TABELA 4, no grupo dos animais $\mathrm{Nx60}=0,22 \pm 0,06$ e no $\mathrm{Nx60+Spi}=0,28 \pm 0,04$. Aumento significativo deste parâmetro ocorreu, no grupo Nx60+NAC $=0,47 \pm 0,05$ vs $\mathrm{N} \times 60=0,22 \pm 0,06(\mathrm{p}<0,001)$ e no grupo da associação das drogas, $\mathrm{N} \times 60+\mathrm{NAC}+\mathrm{Spi}=0,59 \pm 0,04$ vs Nx60 =0,22 $\pm 0,06(\mathrm{p}<0,001)($ FIGURA 27)

\subsubsection{Proteinúria $(\mathrm{mg} / 24 \mathrm{~h})$}

Conforme mostrado na TABELA 4, obtivemos diminuição significativa da proteinúria nos grupos Nx60+NAC = $16 \pm 3 ; \mathrm{Nx60+Spi}=18 \pm$ 1 e $\mathrm{Nx} 60+\mathrm{Spi}+\mathrm{NAC}=14 \pm 1$, quando comparada com a do grupo $\mathrm{Nx60}=27$ $\pm 3(p<0,001)($ FIGURA 28).

\subsection{7. Índice de glomeruloesclerose (\%)}

$\mathrm{O}$ índice de glomeruloesclerose foi menor no grupo, Nx60+NAC = $28 \pm 2$ e no grupo com a associação das drogas, Nx60+NAC+Spi $=33 \pm 7$, se comparado com o respectivo grupo nefrectomizado, $\mathrm{Nx60}=110 \pm 31$ $(p<0,05)($ FIGURA 29). 


\subsubsection{Pressão arterial $(\mathrm{mmHg})$}

Observamos uma queda, embora pequena, significativa dos valores da pressão arterial no grupo $\mathrm{Nx60+NAC+Spi}=136 \pm 2$ em relação aos

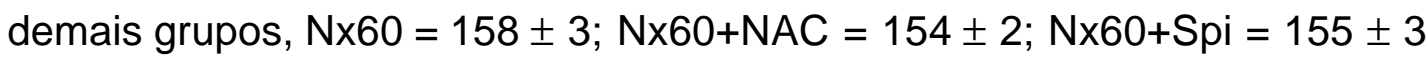
$(p<0,001)($ FIGURA 30).

\subsubsection{Aldosterona sérica ( $\mathrm{ng} / \mathrm{dl})$}

Os níveis de aldosterona observados na TABELA 4, encontraram-se elevados nos animais $\mathrm{Nx60}=318 \pm 50$ e nos tratados Nx60+Spi $=325 \pm 77$ Redução importante e significativa obteve no grupo Nx60+NAC = $125 \pm .24$ ou quando da associação de drogas Nx60+NAC+Spi = $183 \pm 20$ quando comparados aos do grupo Nx60 = $318 \pm 50(p<0,001)$ (FIGURA 31).

\subsubsection{UK/UNa}

De acordo com resultados da aldosterona, a razão UK/UNa, que é um marcador indireto da ação da aldosterona no túbulo coletor, foi maior nos animais $\mathrm{Nx60}=5,90 \pm 2,0$. Diminuição significativa obtivemos após tratamento com o antioxidante $\mathrm{Nx} 60+\mathrm{NAC}=1,63 \pm 0,27(\mathrm{p}<0,001)$, quando tratados apenas com bloqueador mineralocorticóide, Nx60+Spi = 0,90 \pm 0,1 $(p<0,001)$ e também com associação das drogas, Nx60+NAC+Spi = 0,66 \pm 0,1 se comparada ao grupo $\mathrm{Nx60}=5,90 \pm 2,0(\mathrm{p}<0,001)$ (FIGURA 32). 


\subsubsection{Massa das adrenais (mg)}

Observamos menor massa das adrenais nos grupos $\mathrm{Nx}+\mathrm{NAC}=35$

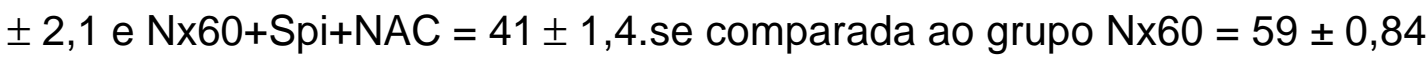
$(p<0,001)$ (FIGURA 33).

\subsubsection{Massa dos corações (g)}

O mesmo fato ocorreu com a massa dos corações quando administramos somente $\mathrm{Nx60+NAC}=1,16 \pm 0,4$ e quando da associação

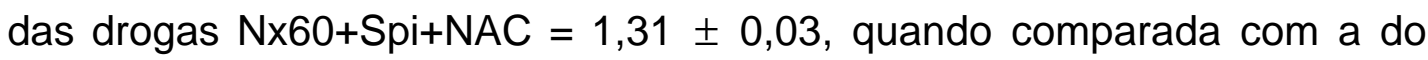
grupo Nx60 = 1,37 $\pm 0,1(p<0,001$ e 0,05), respectivamente (FIGURA 34).

\subsubsection{Correlação (UV proteína/Cin/índice de glomeruloesclerose)} $\log 10$

O efeito antiproteinúrico da NAC pareceu pequeno quando comparado ao índice de glomeruloesclerose. Entretanto, ao corrigirmos a excreção de proteína (UV prot) pelo respectivo clearance de inulina, os animais do grupo Nx120, apresentaram uma relação UV prot/Cin, 4 a 5 vezes maior quando comparados à dos grupos Nx120+NAC e Nx120(Nx60+60NAC). O mesmo ocorreu ao compararmos a relação UV prot/Cin dos animais Nx60 com Nx60+NAC+Spi. Ao colocarmos em gráfico a relação UV prot/Cin com o respectivo índice de glomeruloesclerose, obtivemos uma correlação positiva (FIGURA 35). 
Os animais nefrectomizados tratados com NAC apresentaram proteção importante da função renal com menor queda do "clearance" de inulina quando comparados aos não tratados. A associação de NAC com Spi proporcionou efeito protetor aditivo em relação à função renal, contribuindo com diminuição, embora pequena, mas significativa, da pressão arterial. 
Tabela 4- Resultados dos grupos com 60 dias de IRC tratados ou não com NAC e espironolactona (Spi)

\begin{tabular}{|c|c|c|c|c|c|c|c|c|}
\hline Grupos & $\begin{array}{l}\text { P.A. } \\
\text { mmHg }\end{array}$ & \begin{tabular}{|c|} 
C.in. \\
$\mathrm{ml} / \mathrm{min} / 100 \mathrm{~g} \mathrm{PC}$
\end{tabular} & $\begin{array}{l}\text { Proteinúria } \\
\text { mg\% }\end{array}$ & UK/UNa & $\begin{array}{c}\text { Aldosterona } \\
\text { sérica } \\
\text { ng/dl }\end{array}$ & \begin{tabular}{|l} 
TBARS \\
nmoles/24 \\
$\mathrm{h}$
\end{tabular} & $\begin{array}{c}\text { Massa do } \\
\text { coração } \\
\text { g }\end{array}$ & $\begin{array}{c}\text { Massa } \\
\text { da } \\
\text { adrenal } \\
\text { mg } \\
\end{array}$ \\
\hline $\begin{array}{c}\mathrm{N} \times 60 \\
(n=6)\end{array}$ & $158 \pm 3$ & $0,22 \pm 0,06$ & $27 \pm 3$ & $5,90 \pm 2,0$ & $318 \pm 50$ & $109 \pm 18$ & $1,37 \pm 0,1$ & $59 \pm 0,84$ \\
\hline $\begin{array}{l}\text { Nx60+NAC } \\
(n=6)\end{array}$ & $154 \pm 2^{d}$ & $0,47 \pm 0,05^{\mathrm{a}}$ & $16 \pm 3^{a}$ & $1,63 \pm 0,3^{\mathrm{a}}$ & $125 \pm 24^{\mathrm{a}}$ & $63 \pm 6^{a}$ & $1,16 \pm 0,4^{\text {ae }}$ & $35 \pm 2,1^{\mathrm{a}}$ \\
\hline $\begin{array}{l}\text { Nx60+Spi } \\
(\mathrm{n}=7)\end{array}$ & $155 \pm 3^{d}$ & $0,28 \pm 0,04$ & $18 \pm 1^{a}$ & $0,90 \pm 0,1^{a}$ & $325 \pm 77^{c}$ & $116 \pm 16^{d}$ & $1,38 \pm 0,03^{c}$ & $57 \pm 1,5^{c}$ \\
\hline $\begin{array}{l}\text { Nx60+NAC } \\
+ \text { Spi } 9 \\
(\mathrm{n}=6)\end{array}$ & $136 \pm 2^{a b c}$ & $0,59 \pm 0,04^{a b c}$ & $14 \pm 1^{a}$ & $0,66 \pm 0,1^{a}$ & $183 \pm 20^{a b c}$ & $83 \pm 5^{\mathrm{abd}}$ & $1,31 \pm 0,03^{\text {cd }}$ & $41+\frac{11,4}{a b c}$ \\
\hline \multicolumn{9}{|c|}{ Os resultados estão expressos em média \pm erro padrão } \\
\hline \multicolumn{9}{|c|}{${ }^{a} p<0,001$ vs $N x ;{ }^{b} p<0,001$ vs $N x+S p i ;{ }^{c} p<0,001$ vs $N x+N A C ;{ }^{d} p<0,05$ vs $N x 60 ;{ }^{e} p<0,05$ vs $N x+S p i-$} \\
\hline
\end{tabular}




\section{FIGURA 26}

Excreção urinária de $\mathcal{T} \mathcal{B} \mathcal{A} R$

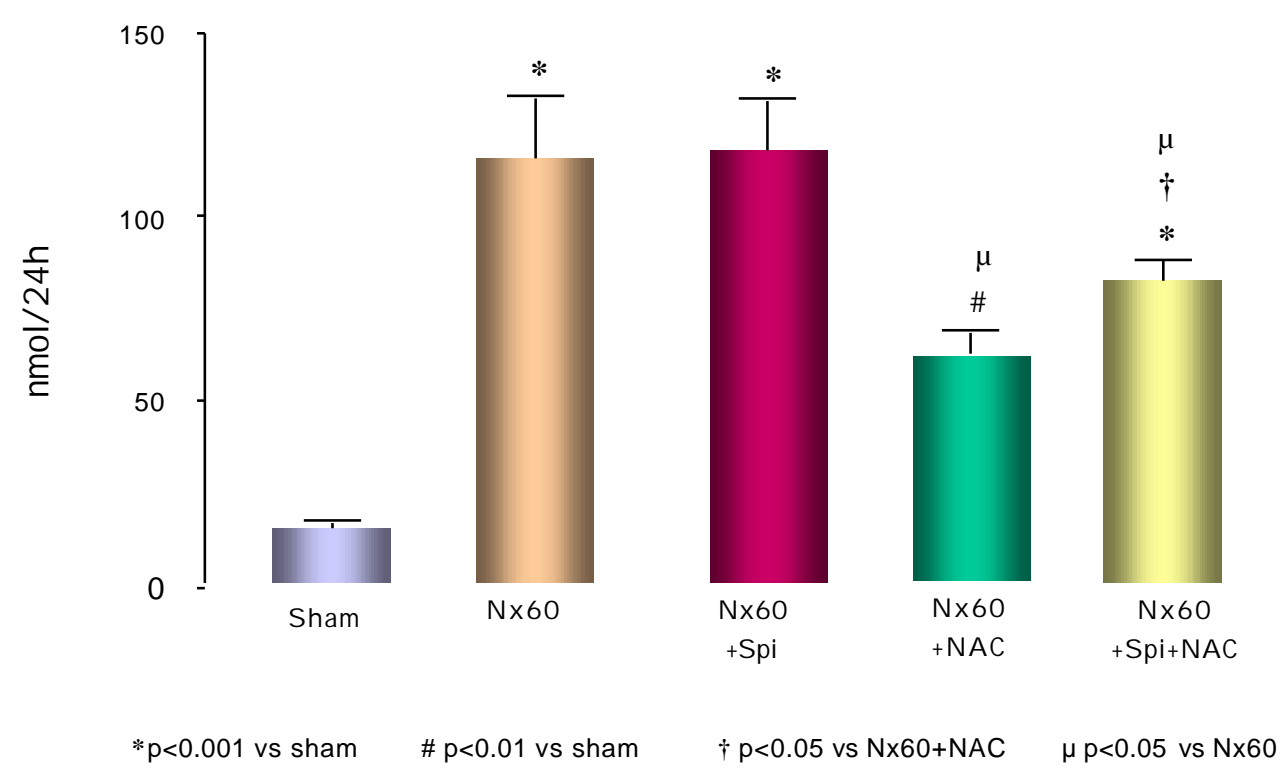




\section{FIGURA 27}

\section{Cle arance de inulina}

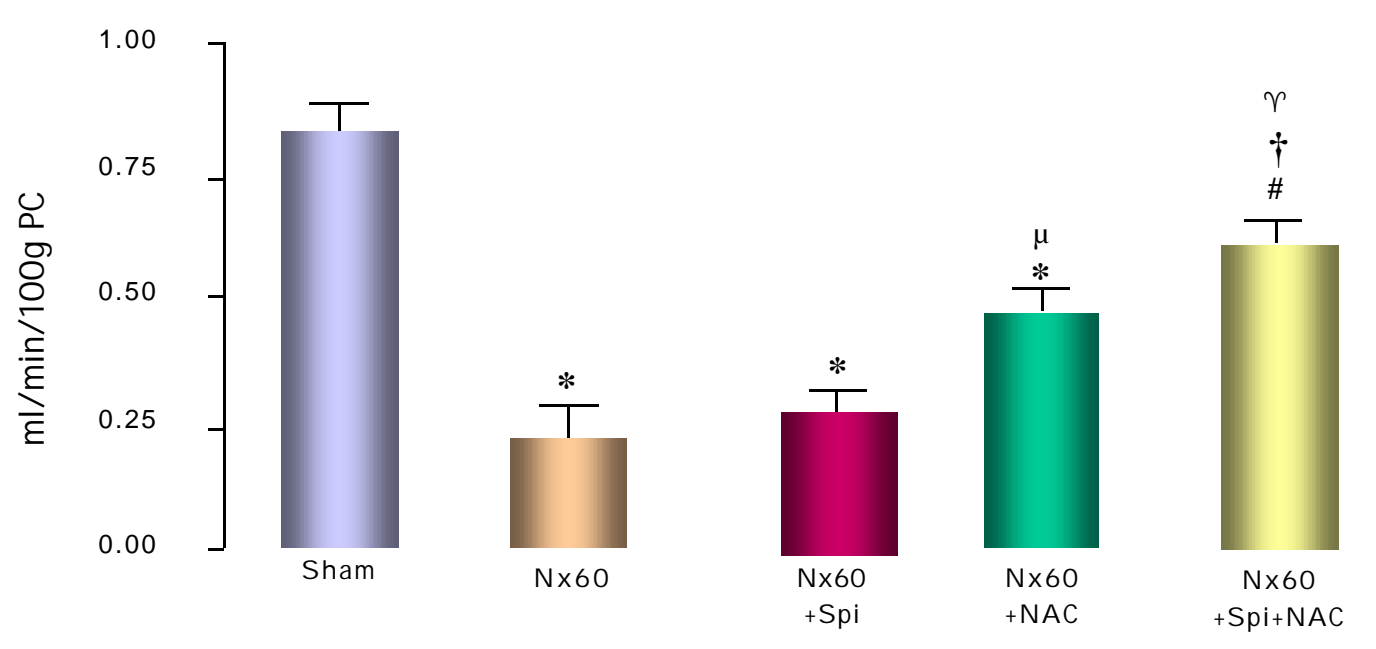

${ }^{*} p<0.001$ vs. Sham $\quad \# p<0.01$ vs. Sham $\quad \dagger p<0.001$ vs $N \times 60$

$\curlyvee p<0.001$ vs $\mathrm{N} \times 60+\mathrm{Spi} \quad \mu \mathrm{p}<0.05$ vs $\mathrm{N} \times 60+\mathrm{Spi}$ 
FIGURA 28

Excreção urinária de proteína

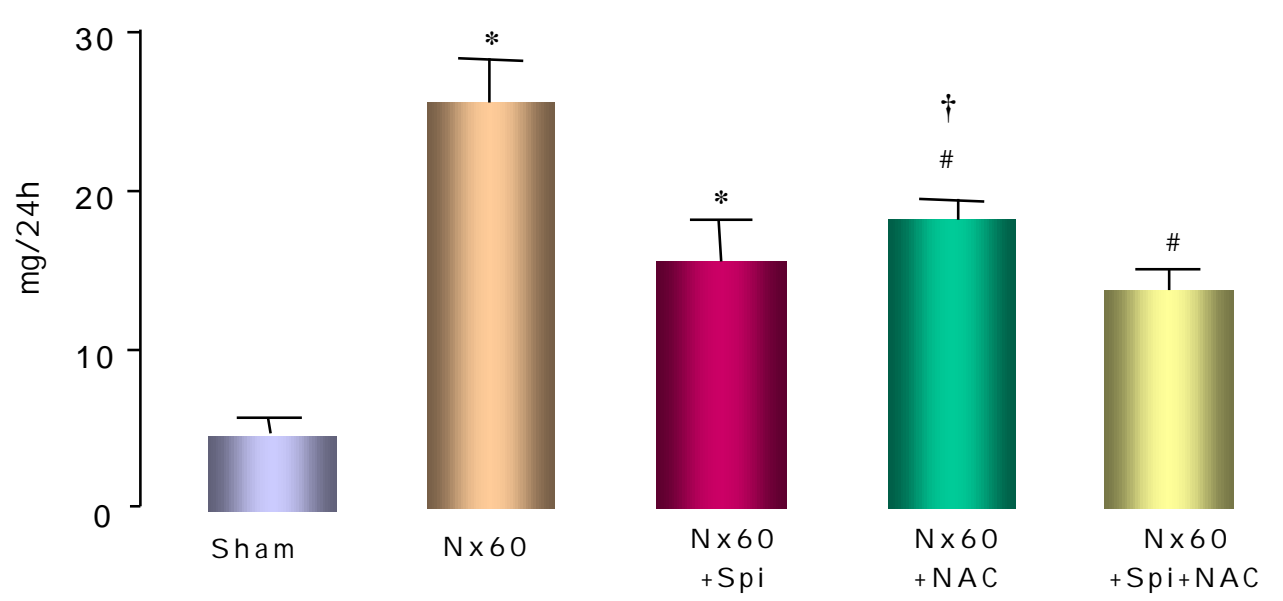

${ }^{*} p<0.001$ vs sham $\# p<0.01$ vs sham $\dagger p<0.01$ vs $N \times 60$ 
FIGURA 29

Índice de glomeruloesclerose

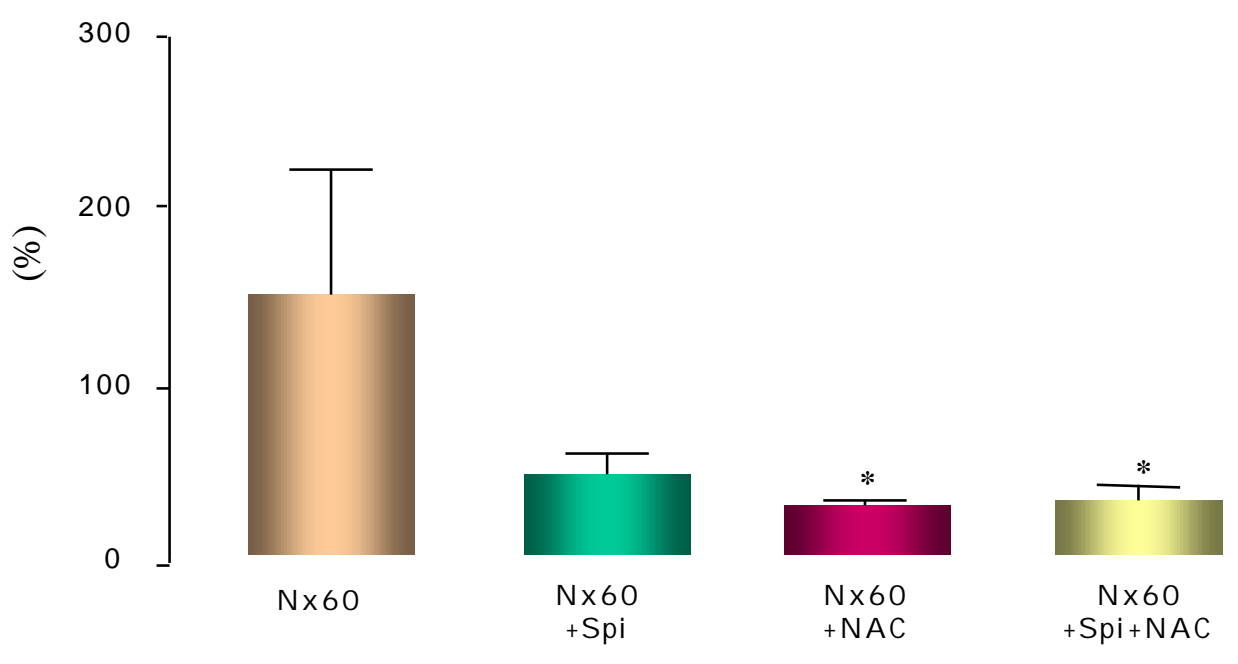

$*_{p}<0.05$ vs $N \times 60$ 
FIGURA 30

Pressão arterial

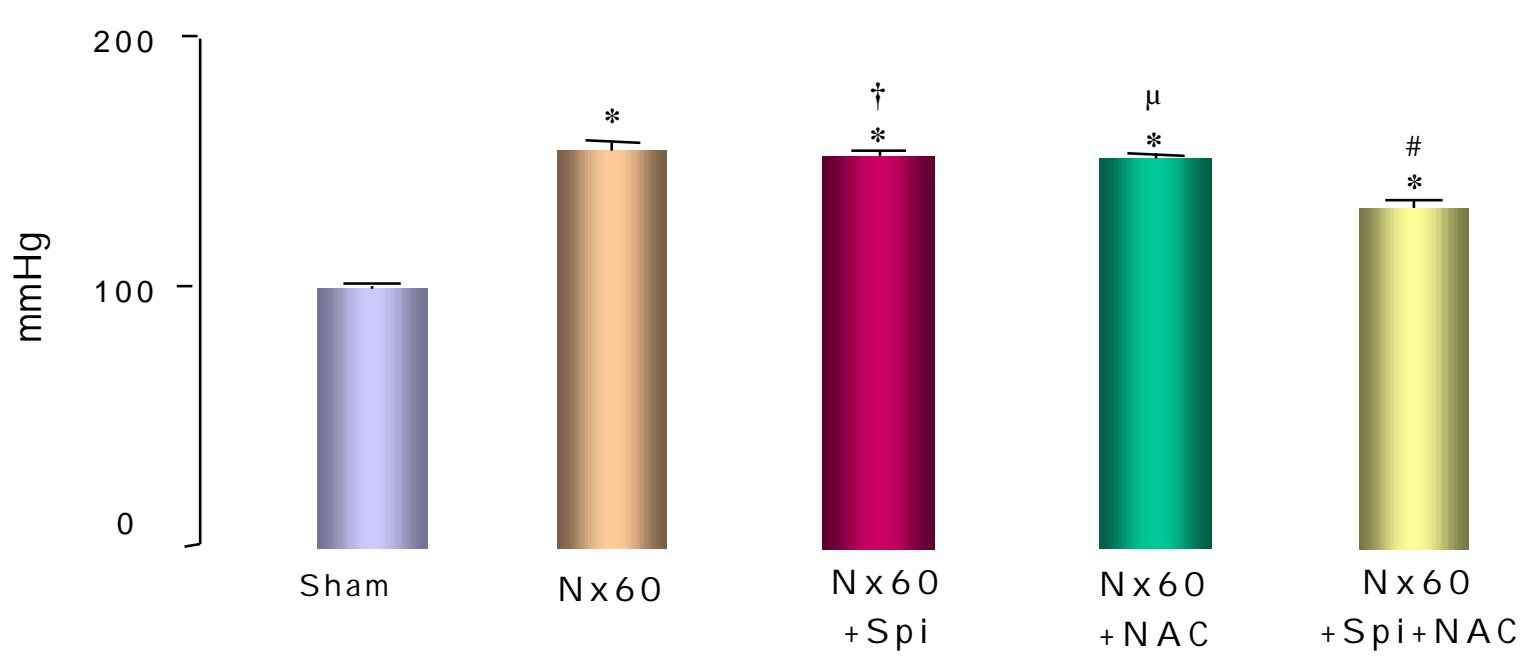

$* p<0.001$ vs sham $\# p<0.001$ vs $N \times 60 \dagger p<0.001$ vs Nx60+Spi+NAC $\mu \mathrm{p}<0.001$ vs $\mathrm{N} \times 60+\mathrm{Spi}+\mathrm{NAC}$ 


\section{FIGURA 31}

Aldosterona plasmática

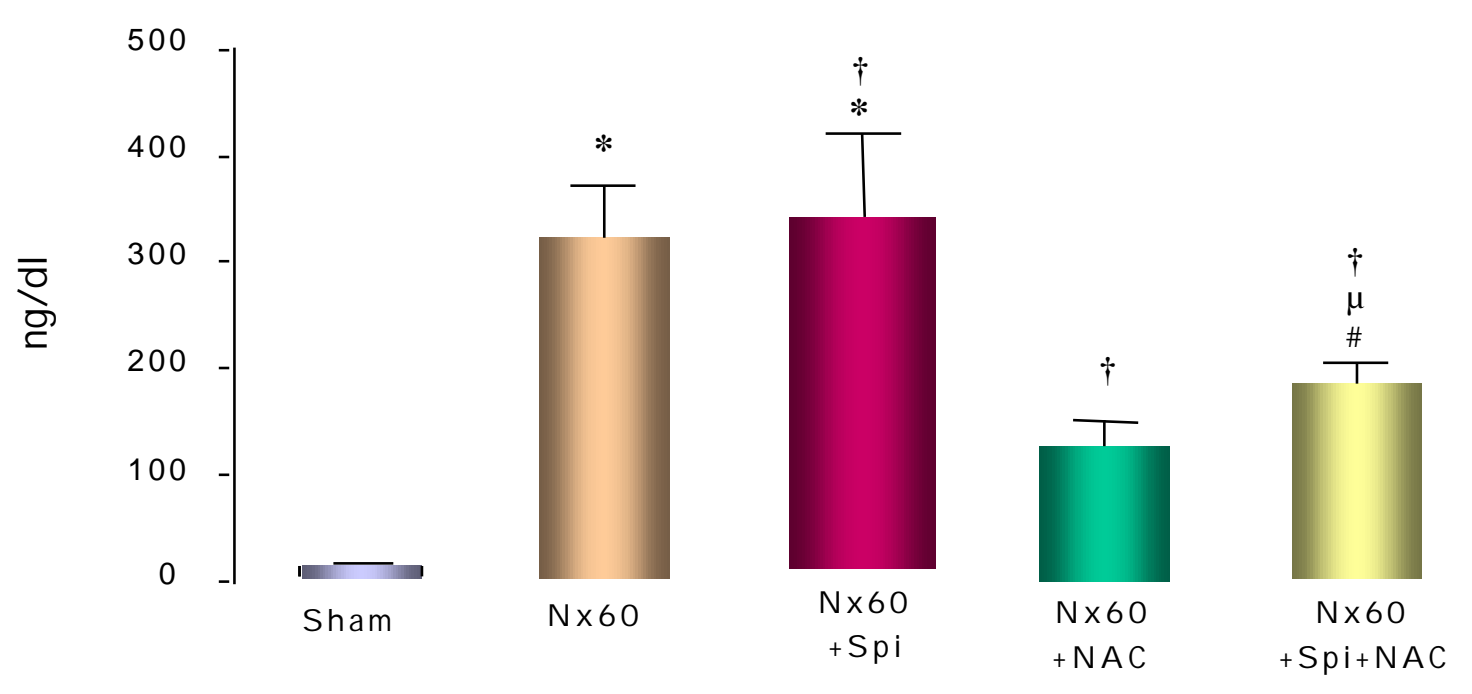


FIGURA 32

\section{$\mathcal{U K} \mathfrak{U} \mathfrak{N} a$}

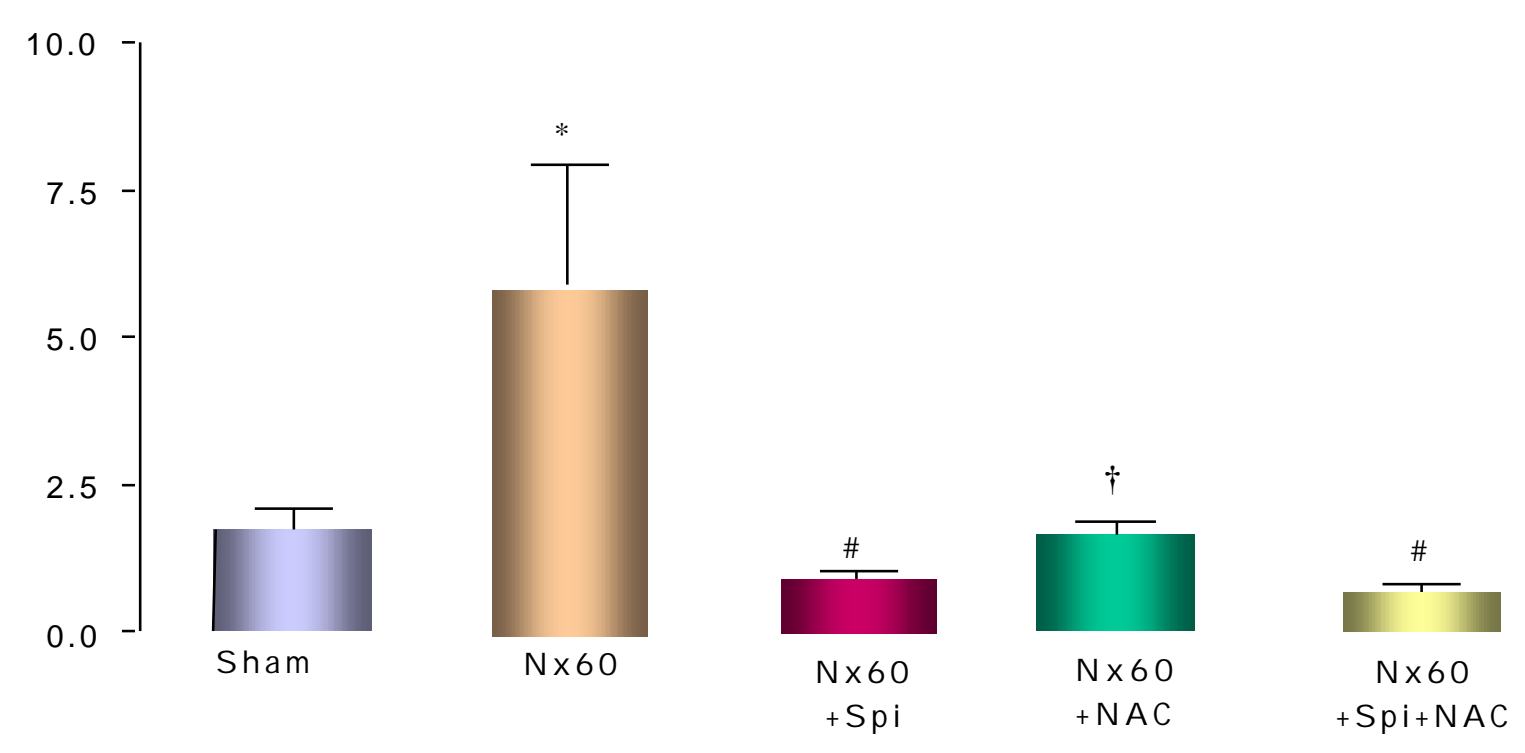

${ }^{*} p<0.01$ vs sham $\# p<0.001$ vs $N \times 60 \dagger p<0.01$ vs $N \times 60$ 
FIGURA 33

Massa das Adrenais

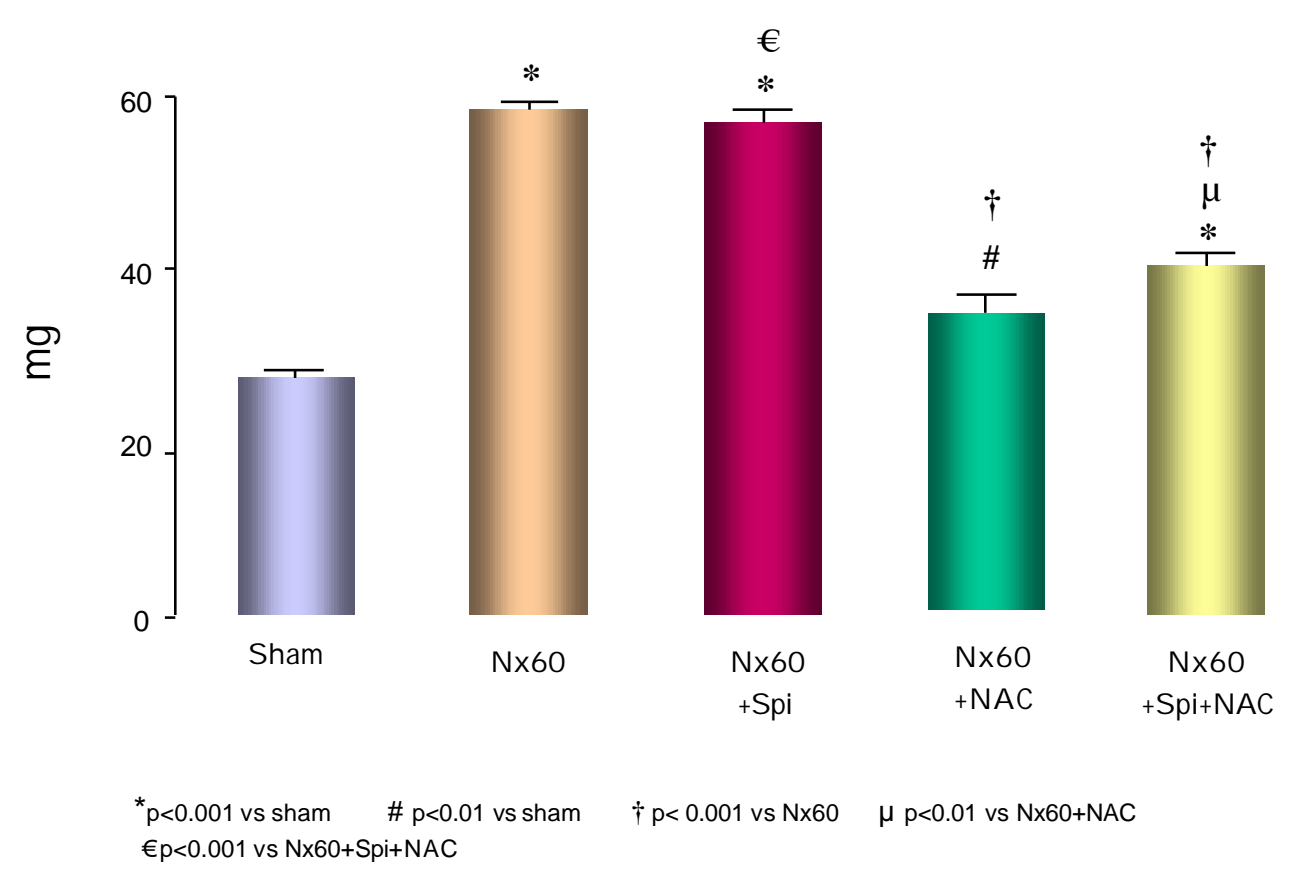


FIGURA 34

Massa dos corações

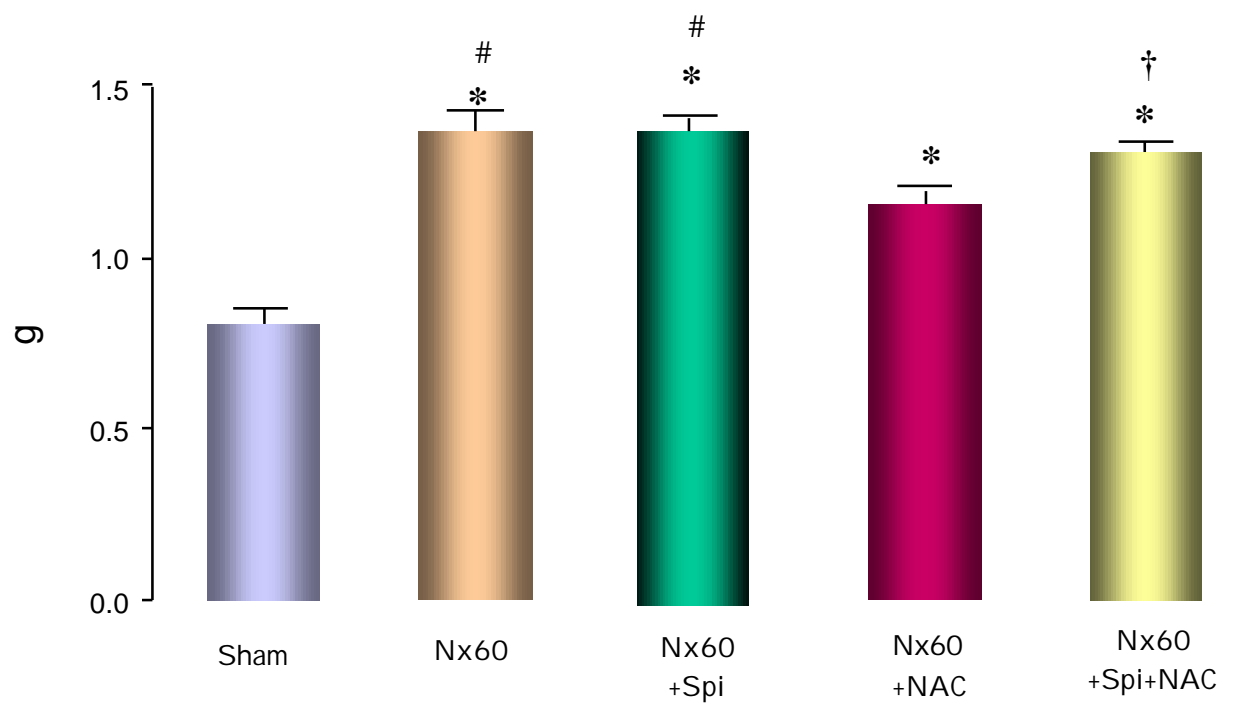

${ }^{*} p<0.001$ vs sham $\# p<0.01$ vs $N \times 60+N A C \quad \dagger p<0.05$ vs $N \times 60+N A C$ 


\section{FIGURA 35}

Correlação entre prote inúria corrigida pelo "clearance" de inulina (UV prot./Cin) - e o respectivo indice de glomeruloesclerose (GSI). Os dados estão expressos em logaritimo em base 10.

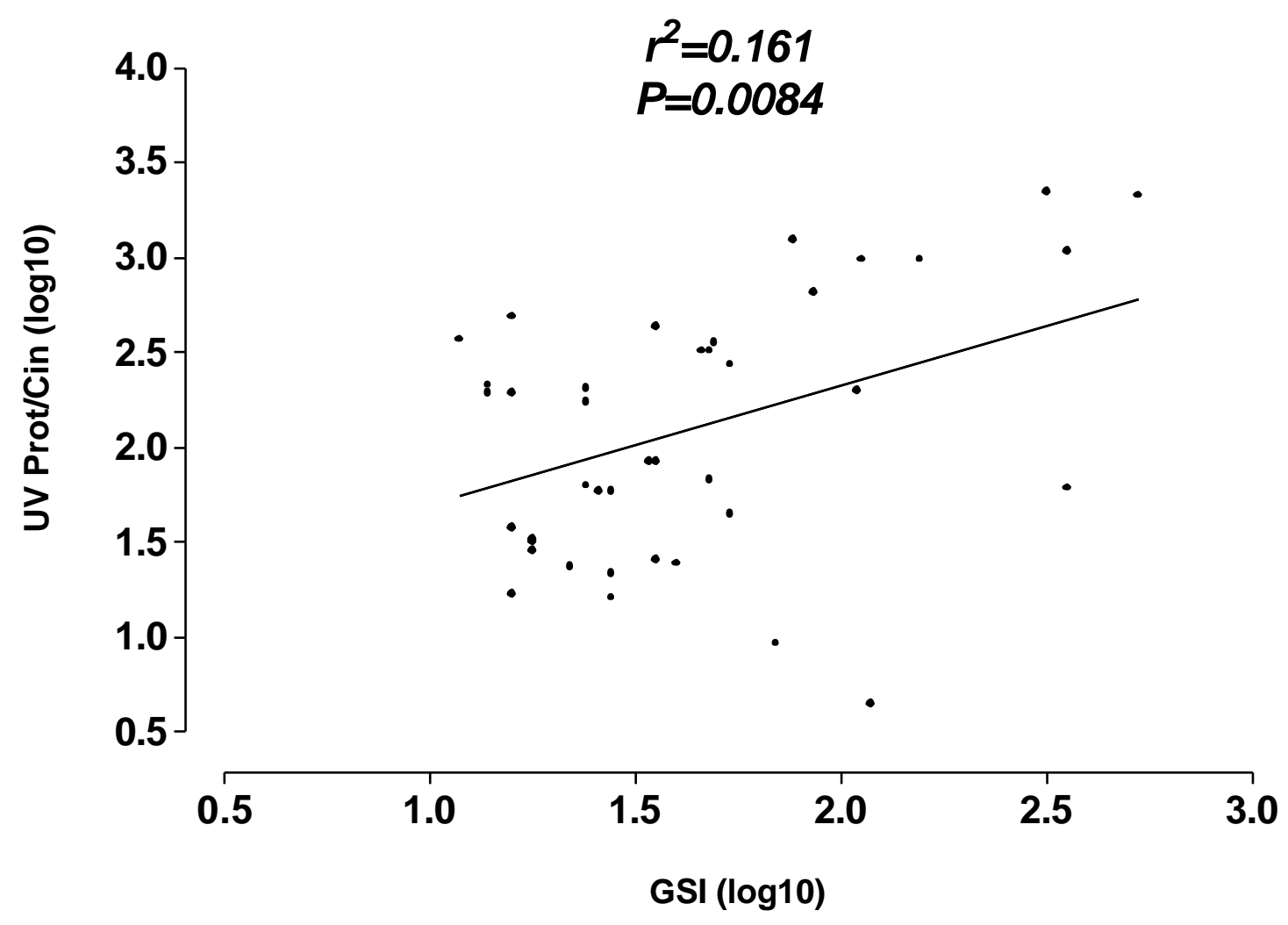


5. CONCLUS Õ ES 


\section{Conclusões}

1. O efeito protetor do antioxidante NAC nos ratos nefrectomizados refletiu-se na diminuição dos níveis de aldosterona, do estresse oxidativo e da pressão arterial.

2. Em modelos de rins remanescentes, mesmo em estágios tardios, NAC apresentou efeito protetor.

3. A associação de N-acetilcisteína (NAC) com Spironolactona (Spi) apresentou efeito aditivo protetor sobre a função renal. 
6. $\mathcal{D I S C U S S} \tilde{\mathcal{A} O}$ 


\section{DISCUSSÃO}

Pela limitação inerente aos estudos clínicos, como investigação profunda em relação às bases moleculares do estresse oxidativo e suas complicações e que necessitam acesso aos órgãos de interesse, torna-se quase impossível estudo em pacientes. O modelo experimental de ablação renal de 5/6 tem sido muito utilizado para estudo da nefropatia progressiva.

O estresse oxidativo é considerado um fator potencialmente importante na mortalidade dos pacientes com insuficiência renal crônica 45,46,47. Entretanto, a patogênese do estresse oxidativo nestes pacientes não está, ainda, totalmente definida. Na doença renal crônica, o aumento do estresse oxidativo se deve à redução do sistema de antioxidantes (vitamina C e selênio, dos níveis intracelulares de vitamina $\mathrm{E}$ e da atividade do sistema da glutationa). As espécies oxidantes nos renais crônicos são geradas em conseqüência da idade avançada, alta freqüência de diabetes, condições inflamatórias crônicas, síndrome urêmica, hipertensão e suas complicações, disfunção endotelial desordens neurológicas e aterosclerose ${ }^{4}$. Além destes produtos liberados pela peroxidação dos lipídeos, outros oxidantes oriundos do ataque às proteínas, carboidratos e ácidos nucléicos, como por exemplo, tiois oxidados, proteínas carbonilatadas entre outras substâncias encontram- 
se aumentadas tanto em ratos, após ablação renal de 5/6, como em pacientes com doença renal crônica ${ }^{3,4,41,48,49,50}$.

Nossos resultados demonstraram claramente que o estresse oxidativo desempenha papel importante na evolução da doença renal crônica, pelo aumento progressivo encontrado da excreção urinária de TBARS no modelo de ablação renal. O consumo de oxigênio é elevado nos néfrons sobreviventes quando comparado com dos néfrons de rins intactos $^{34}$. A concentração do MDA por néfron encontra-se aumentada no modelo de nefrectomia subtotal e está associada com valor absoluto da excreção urinária de MDA. Estudo recente demonstrou que dosagens urinárias de marcadores do dano oxidativo, como o MDA, são mais sensíveis do que as plasmáticas, em pacientes com doença renal crônica ${ }^{39}$.

Os valores por nós obtidos demonstraram significativa redução de TBARS urinário dos animais nefrectomizados com 120 dias, tanto quando tratados precoces como tardiamente com NAC, e dos animais com 60 dias de nefrectomia, se comparados aos não tratados. Esta é uma evidência de que o antioxidante $\mathrm{N}$-acetilcisteína proporciona significante diminuição do estresse oxidativo. Este efeito está associado com importante proteção da filtração glomerular e inflamação renal e com significante diminuição dos níveis de aldosterona.

Esta é a primeira demonstração da proteção da N-acetilcisteína na evolução da IRC experimental. 
O efeito da NAC tem sido verificado em pacientes renais crônicos em hemodiálise, principalmente quanto à redução do risco cardiovascular 3,50

Pelos efeitos iniciais da redução do número de néfrons que são hipertensão e hiperfiltração por unidade de néfrons remanescentes, muitos métodos têm sido estudados para contribuir com a redução da lesão dos ratos nefrectomizados, assim como inibidores da enzima de conversão, antagonistas da Angio II, imunosupressores como micofenolato mofetil, suplementação em $\alpha$-tocoferol ${ }^{51,52,53}$.

Terapias com a vitamina $E$ melhoraram a lesão renal, mas não normalizaram a pressão arterial, e restauraram o NO induzível nos animais submetidos à ablação renal de $5 / 6^{9}$. Em recente estudo, Vaziri et al. ${ }^{14}$ demonstraram que aumentos na pressão arterial e estresse oxidativo apresentaram um efeito paralelo com o declínio no NO induzível em ratos com ablação renal de 5/6. Quando animais foram tratados com vitamina $E$, houve melhora do estresse oxidativo, acompanhado do aumento da capacidade de produção de NO, diminuição de nitrotirosina no tecido e no plasma com a diminuição da hipertensão ${ }^{4}$.

Outro estudo em animais com ablação renal, demonstrou maior grau de lesão e hipertrofia do rim remanescente, submetidos à dieta deficiente em antioxidantes como vitamina $E$ e selênio, se comparados aos animais nefrectomizados com dieta normal ${ }^{53}$.

Com base nestes tratamentos, observamos diminuição da proteinúria e redução da inflamação avaliada pelo índice de 
glomeruloesclerose e "scores" de lesão tubular intersticial

54. Porém, a proteção da filtração glomerular medida pelo "clearance" de inulina, ainda não havia sido descrita.

Pelos resultados deste nosso estudo demonstramos que a administração de NAC em ratos nefrectomizados produziu significante e importante proteção da filtração glomerular, com média do "clearance" de inulina de $(0.47 \pm 0.05)$ nos animais de 60 dias após ablação, que se manteve estável nos animais, após 120 dias da nefrectomia. Em contraste, a razão de filtração glomerular diminuiu progressivamente nos animais não tratados $(0.16 \pm 0.03)$. O efeito protetor da NAC foi mais expressivo na filtração glomerular que na redução da proteinúria e da queda da pressão arterial.

Não observamos redução significativa da pressão arterial nos ratos tratados com NAC com 120 dias de nefrectomia. Resultados similares foram obtidos em ratos com inibição crônica da enzima óxido nítrico sintetase e tratados com vitamina E. Houve redução da lesão renal, porém, sem melhora da hipertensão nestes animais. ${ }^{53}$.

Tratamento com bloqueador de receptores da angiotensina II melhorou a função renal de ratos espontaneamente diabéticos com dieta com muito sal, sem afetar a pressão sangüínea.

A proteinúria e a pressão elevada são prognósticos de lesão renal. Alguns estudos sugerem que a albumina pode estimular a produção de citoquinas proinflamatórias nas células do túbulo proximal pela ativação do NF-kB ${ }^{55,56}$. Porém, pouco se sabe se estados proinflamatórios e estresse 
oxidativo no rim podem ser reduzidos sem uma significativa redução da proteinúria e pressão arterial.

Um recente estudo, em pacientes com insuficiência renal crônica tomando inibidor de enzima de conversão, além de outros, foram submetidos a um bloqueio adicional da angiotensina II com losartan ${ }^{57}$. Os resultados mostraram uma melhora na filtração glomerular, sem alterações na pressão arterial e na proteinúria. O bloqueio da angiotensina II nesses pacientes induziu a uma redução de $35 \%$ na albumina oxidada excretada na urina, associada a uma redução na excreção urinária da proteína quimiotática para monócitos (MCP-1) a qual se correlaciona com a extensão da inflamação. Em outro grupo de pacientes com insuficiência renal crônica, o mesmo autor e colaboradores mostraram que o bloqueio da angiotensina II reduziu de $38 \%$ a excreção urinária de TGF-ß, uma citoquina fibrogênica ${ }^{58}$.

Assim, tratamentos com bloqueadores da angiotensina II melhoraram parâmetros do estresse oxidativo em pacientes proteinúricos com doença renal crônica sem afetar a pressão arterial.

As substâncias reativas com ácido tiobarbitúrico (TBARS) plasmáticas são marcadores de peroxidação lipídica e conseqüentemente de estresse oxidativo. Ambas, atividade da NADPH oxidase e TBARS plasmáticas, encontraram-se elevadas em ratos que foram infundidos com Angio II quando comparados com o controle, porém, ocorreu redução destas substâncias pela espironolactona. Estes resultados reforçam a possibilidade de que o aumento do estresse oxidativo exercido pela angiotensina II seja mediado parcialmente pela aldosterona. Estudos em humanos 
demonstraram que a espironolactona melhorou a vasodilatação endotelial na microcirculação de pacientes com IRC, provavelmente melhorando a viabilidade do óxido nítrico. A angio II aumentou o $\mathrm{O}_{2}^{-}$basal e a geração de $\mathrm{O}_{2}^{-}$pela ativação da NADPH. Estes efeitos foram abolidos pela espironolactona. ${ }^{39}$

A associação de NAC com espironolactona (grupo 11) indicou que a diminuição da pressão arterial e a redução do estresse oxidativo produziram proteção aditiva na filtração glomerular, sugerindo que estudos futuros com a associação de antioxidantes com drogas anti-hipertensivas são promissores em modelos de insuficiência renal crônica.

Em estudos com o uso de NAC houve proteção da nefropatia por contraste radioiodados, e estes pacientes apresentaram menor concentração de creatinina plasmática, o que sugere mais que uma proteção do radiocontraste, um efeito próprio da NAC ${ }^{59,20,21 .}$

O estresse oxidativo e inflamação provocam disfunção endotelial e o endotélio sendo ao mesmo tempo fonte e alvo dos produtos oxidantes participam da resposta inflamatória ${ }^{60,61}$.

A aldosterona tem papel importante na progressão da lesão renal crônica. Seus efeitos cardiovasculares parecem ser mediados em parte pelo aumento do estresse oxidativo. Provoca hipertrofia das células do músculo liso, resultando em grave doença cardíaca ${ }^{62,63,26,35}$

Danos celulares induzidos pela Angio II são mediados, em parte, pelas substâncias reativas com o oxigênio que, por sua vez, estão envolvidas na ativação das proteínas mitogênicas (MAP) quinases ${ }^{22,64}$. 
Somado a outros efeitos, acontece 0 desenvolvimento de glomeruloesclerose e fibrose intersticial. Angiotensina II, estimula a ativação das $\mathrm{NAD}(\mathrm{P}) \mathrm{H}$ oxidases e induzem produção de substâncias reativas em culturas de células de músculo liso vasculares, células endoteliais, fibroblastos. Estes efeitos são mediados via receptores AT1. As substâncias reativas regulam os receptores AT1 para a expressão dos genes os quais por sua vez modulam a formação das espécies reativas ${ }^{65}$.

O efeito benéfico da NAC sobre o estresse oxidativo por nós documentado pode estar associado também à menor concentração de aldosterona encontrada nesses animais o que pode contribuir ainda mais para a proteção renal.

Atualmente sabe-se que a produção da aldosterona está expressa em locais não clássicos, como coração, cérebro e vasos sangüíneos. Pela ação da aldosterona nos cardiomiócitos, fibroblastos cardíacos e células endoteliais, este hormônio desempenha papel importante no desenvolvimento da insuficiência cardíaca, fibrose do miocárdio e disfunção endotelial. Em estudo recente observou-se que a supressão farmacológica da Angio II não necessariamente reduz os níveis de aldosterona plasmática e, caso isto aconteça, é por tempo limitado ${ }^{66}$.

Estudos anteriores demonstraram que a aldosterona induziu inflamação nos corações de ratos ${ }^{33}$. Este efeito foi mediado pelo estresse oxidativo e atenuado pelo tratamento com NAC.

Em nosso trabalho a hipertrofia cardíaca, avaliada indiretamente pela massa dos corações, aumentou progressivamente após nefrectomia. 
Nos animais tratados com NAC a massa dos corações após 60 e 120 dias da nefrectomia foi significantemente menor que a dos animais não tratados. Podemos sugerir que os níveis de aldosterona dos ratos tratados com NAC podem ser responsáveis por este efeito.

Desde que altos níveis de aldosterona são necessários para manter o balanço de potássio na doença renal crônica, podemos inferir que os baixos níveis de aldosterona observados nos animais tratados com NAC são conseqüência de um menor grau de lesão renal.

Como previamente demonstrado em nosso estudo, também obtivemos hipertrofia da adrenal e hiperaldosteronismo ${ }^{28}$. Estas alterações estão associadas com um aumento na razão potássio/sódio (UK/UNa), medida indireta da ação da aldosterona no túbulo coletor. A aldosterona, além de aumentar a absorção de sódio, aumenta também a secreção de potássio.

Quando tratamos os animais com NAC, observamos diminuição dos níveis de aldosterona. Com 120 dias após nefrectomia, os valores de aldosterona persistiram elevados, porém, menores do que nos animais de 60 dias. Estudo prévio em nosso laboratório demonstrou valores baixos de aldosterona em ratos de 8 meses quando comparados a ratos jovens ${ }^{67}$. As concentrações diminuídas de aldosterona após 120 dias da nefrectomia são devidas, provavelmente à idade dos animais e estão de acordo com a baixa fração de excreção de potássio neles encontrada. Nossos dados sugerem que a aldosterona contribui para a hipertensão arterial neste modelo de rins 
remanescentes e uma pequena diminuição de seus valores foi encontrada nos animais tratados com NAC.

É importante também salientar que a ativação dos receptores $A T_{1}$ pela angio II, resulta numa super ativação da NADPH oxidase. Conseqüentemente, drogas que bloqueiam o sistema renina-angiotensinaaldosterona, como a espironolactona, podem servir como antioxidantes altamente específicos na doença renal crônica. ${ }^{3 .}$ Entretanto, no organismo existem caminhos alternativos para a produção de angiotensina II, ou diretamente do angiotensinogênio ou da angiotensina I. A angiotensina II e aldosterona podem continuar sendo sintetizadas mesmo na presença de inibidores da enzima de conversão (ACE) ${ }^{26}$. Ambas, atividade da NADPH oxidase e TBARS plasmáticas, encontram-se elevadas em ratos que foram infundidos com Angio II quando comparados com o controle, ocorrendo, porém, redução destas substâncias pela espironolactona. Estes resultados reforçam a possibilidade de que o aumento do estresse oxidativo exercido pela angio II seja mediado parcialmente pela aldosterona. ${ }^{35}$

Ao associarmos NAC e espironolactona, obtivemos efeito protetor aditivo com significante diminuição da pressão arterial, embora seus valores continuem elevados, sugerindo que o bloqueio da ação da aldosterona pode ser por tempo limitado ou, até mesmo, uma ação incompleta adicional da aldosterona nos sítios da membrana plasmática. A administração da espironolactona exerceu, além do efeito anti-hipertensivo, um efeito na proteinúria minimizando também a hipertrofia cardíaca. 
Ação não hemodinâmica da aldosterona pode participar na glomeruloesclerose. Estudos in vitro demonstraram que incubação de células mesangiais com aldosterona aumentou a produção de colágeno tipo IV 68,69,70. Transcritos para receptores mineralocorticóides têm sido detectados nos glomérulos que podem mediar a ação dos hormônios nestes sítios $^{64}$. É possível que o efeito benéfico da NAC na filtração glomerular seja em parte mediado pela aldosterona. Após tratamento com antioxidante, mesmo se administrado precoce ou tardiamente, ocorreu importante diminuição do índice de glomeruloesclerose associado com melhora da filtração glomerular.

O receptor AT1 contém quatro resíduos de cisteína e duas pontes dissulfídicas em sua região extracelular: C18-C274 e C101-C180 ${ }^{\mathbf{7 1 , 7 2}}$. NAC e o ácido dihidrolipólico, podem inibir essas pontes, sendo que a vitamina $E$ não possui essa capacidade. Um estudo recente, em cultura de células de músculo liso, demonstrou que NAC inibe a ligação da angiotensina II aos seus receptores AT1, diminuindo sua ação ${ }^{72}$ Esta característica da NAC confere além de sua ação antioxidante, outro efeito que é o de inibir as ações da angiotensina II, potencialmente prejudiciais à doença renal crônica. Por este fato a NAC pode ser considerada substância preferencial entre os outros antioxidantes que não possuem esta característica.

Outro importante efeito da NAC é sua capacidade de aumentar as concentrações de glutationa. Sabe-se que, em condições de depleção desta enzima, como encontrada na doença renal crônica, promovem a retirada do citocromo c das mitocondrias, levando as células a apoptose. 
Em resumo, nossos resultados demonstraram que NAC atenuou a queda da filtração glomerular, assim como diminuiu a proteinúria e pressões arteriais nos ratos nefrectomizados. Estes efeitos foram acompanhados por uma significante redução nas concentrações de aldosterona. Nossos achados indicam que as substâncias reativas com o oxigênio têm papel importante na progressão da doença renal crônica. Este fato comprova que NAC é potencialmente útil na prevenção da glomeruloesclerose e perda da função renal em pacientes com esta doença.

Estes resultados, demonstrando que NAC atenuou a queda da filtração glomerular e diminuiu a proteinúria mesmo em estágios tardios da insuficiência renal crônica e que a associação de NAC com espironolactona melhorou a função renal mais do que quando somente NAC foi administrada, tem implicação clínica importante. 
7. REFERÊEN $(C I \mathcal{A S}$ 


\section{REFERÊNCIAS:}

01. PAHL, H.L.; AND BAEUERLE, P.A. Oxygen and the control of gene expression. Bioessays, v.16, p.497-502, 1994.

02. ARRIGO, A.P. Gene expression and the thiol redox state. Free Radic. Biol. Med., v.27, p.936-944, 1999.

03. LOCATELLI, F.; CANAUD, B.; ECKARDT, K.U.; STENVINKEL, P.; WANNER, C.; ZOCCALI, C. Oxidative stress in end-stage renal disease: an emerging threat to patient outcome. Nephrol Dial Transplant. , v.18, p.1272-1280, 2003.

04. VAZIRI, N.D. Roles of oxidative stress and antioxidant therapy in chronic kidney disease and hypertension. Current Opinion in Nephrology and Hypertension, v.13, p.93-99, 2004.

05. WARDLE, E.N. Cellular oxidative processes in relation to renal disease. Am J Nephrol., v.25, p.13-22, 2005.

06. POLLOCK, D.M. Renal endothelin in hypertension. Hypertension, v.9(2), p.157-64, 2000.

07. MILLER, W.L.; THOMAS, R.A.; BERNE, R.M.; RUBIO, R. Adenosine production in the ischemic kidney. Circ. Res., v.43, p.390-397, 1978.

08. REILLY, P.M.; SCHILLER, H.J.; BULKLEY, G.B. Reactive oxygen metabolites in shock. Scientific American Inc., chapter 8, v.8, p.1-28, 1991.

09. SIGNORINI, J.L.; SIGNORINI, S.L. Atividade física e radicais livres: 
(aspectos biológicos, químicos, fisiológicos e preventivos). São Paulo, Editora da Universidade de São Paulo - Ícone, 1993.

10. ZAFARULLAH, M.; LI, W.Q.; SYLVESTER, J.; AHMAD, M: Molecular mechanisms of $\mathrm{N}$-acetylcysteine actions. Cell. Mol. Life Sci., v.60, p.620, 2003.

11. ARUOMA, O.I, HALLIWELL, B.; HOEY, B.M.; BUTLER, J. - The antioxidant action of $\mathrm{N}$-acetylcysteine: its reaction with hydrogen peroxide, hydroxyl radical, superoxide, and hypochlorous acid. Free Radic. Biol. Med., v.6, p.593-597, 1989.

12. MASSY, Z.A.; NGUYEN-KHOA, T. Oxidative stress and chronic renal failure: markers and management. J Nephrol., v.15(4), p.336-341, 2002.

13. TRIMARCHI, H.; MONGITORE, M.R.; BAGLIONI, P.; FORRESTER, B.; FREIXAS, M.; SCHROPP, M.; PEREIRA, H.; ALONSO, M. Nacetylcysteine reduces malondialdehyde levels in chronic hemodialysis patients - a pilot study. Clin Nephrol., v.59, p.441-446, 2003.

14. VAZIRI, N.D.; NI, Z.; OVEISI, F.; LIANG, K.; PANDIAN, R. Enhanced nitric oxide inactivation and protein nitration by reactive oxygen species in renal insufficiency. Hypertension, v.39, p.135-141, 2002.

15. IVANOVSKI, O.; SZUMLILAK, D.; NGUYEN-KHOA, T.; The antioxidant $\mathrm{N}$-acetylcysteine prevents accelerated atherosclerosis in uremic apoliprotein E knockout mice. Kidney International, v.67, p.22882294, 2005.

16. DI MARI, J.; MEGYESI, J.; UDVARHELYI, N.; N-acetylcysteine ameliorates ischemic renal failure. Am J. Physiol., v. 272, p.F292F298, 1997.

17. EPSTEIN, M. Aldosterone as a mediator of progressive renal disease: 
Pathogenetic and clinical implications. American Journal of Kidney Diseases, v.37(4), 2001.

18. SALOM; M.G.; RAMIREZ, P.; CARBONELL, L.F.; CONESA, E.L.; CARTAGENA, J.; QUESADA, T.; PARRILA, P.; FENOY, F.J. Protective effect of $\mathrm{N}$-acetyl-I-cysteine on the renal failure induced by inferior vena cava occlusion. Transplantation, v.65 (10), p.1315-1321, 1998.

19. MAZZON, E. Effect of $N$-acetylcysteine on gentamicin-mediated nephropathy in rats. Eur J Pharmacol., v.13, 424(1), p.75-83, 2001.

20. TEPEL, M. Prevention of radiographic-contrast-agent-induced reductions in renal function by acetylcysteine. $\mathbf{N}$ Engl $\mathbf{J}$ Med., v.20 343(3), p.180-4, 2000.

21. DRAGER, L.F.; ANDRADE, L.; TOLEDO, J.F.B.; LAURINDO, F.R.M.; CESAR, L.A .M.; SEGURO, A .C. Renal effects of N-acetylcysteine in patients at risk for contrast nephropathy: decrease in oxidant stressmediated renal tubular injury. Nephrol Dial Transplant., v.4, p.1-5, 2004.

22. MEHTA, A.; SEKHON, C.P.; GIRI, S.; ORAK, J.K.; SINGH, A.K. Attenuation of ischemia/reperfusion induced MAP kinases by $\mathrm{N}$ acetylcysteine, sodium nitroprusside and phosphoramidon. Moll Cell Biochem., v.240 (1-2), p.19-29, 2002.

23. SOUTHRN, P. A.; POWIS, G. - Free radicals in medicine. Chemical nature and biologic reactions. Mayo Clin Proc., v.63. p.381-389, 1988.

24. ZATZ, R. - Série Fisiopatologia Clínica - Fisiopatologia renal -São Paulo, Editora Atheneu. p.21-23-26-28-29-283, 2000.

25. TOUYZ, R.M.; SCHIFFRIN, E.L. Reactive oxygen species in vascular biology: implications in hypertension. Histochem Cell Biol., v.122, 
p.339-352, 2004.

26. BREWSTER, U; PERAZELLA, M.A. The renin-angiotensin-aldosterone system and the kidney: Effects on kidney disease. Am J Med., v.116, p.263-272, 2004.

27. TEPEL, M.; GIET M, V.D.; STATZ, M.; JANKOWSKI, J.; ZIDEK, W. The antioxidant acetylcysteine reduces cardiovascular events in patients with end-stage renal failure: a randomized, controlled trial. Circulation, v.107, p.992-995, 2003.

28. GREENE, E.L.; KREN, S., AND HOSTETTER, T.H. Role of Aldosterone in the Remnant Kidney Model in the Rat. J.Clin. Invest. v.98 (4), p.1063-1068, 1996.

29. HOSTETTER, T.H. and IBRAHIM, N. - Aldosterone in chronic kidney and cardiac disease. J Am Soc Nephrol., v.14. p.2395-2401, 2003.

30. ZATZ, R.; NUCCI, G. Effects of acute nitric oxide on rat glomerular microcirculation. Am. J. Physiol., v.30, p. F360-F363, 1991.

31. POLLOCK, D.M. Endothelin, angiotensin, and oxidative stress in hypertension. Hypertension, v.45, p.477-480, 2005.

32. NATH, K.A.; SALAHUDEEN, A.K. Induction of renal growth and injury in the intact rat kidney by dietary deficiency of antioxidants. J. Clin. Invest., v.86, p.1179-1192, 1990.

33. SUN, Y.; ZHANG, J.; LU, L.; CHEN, S.S.; QUINN, M.T.; WEBER, K.T. Aldosterone-induced inflammation in the rat heart: role of oxidative stress. Am J Pathol., v.161, p.1773-1781, 2002.

34. NATH, K.A., CRAOTT, A.J.; HOSTETTER, T.H. Oxygen consumption and oxidant stress in surviving nephrons. Am J Physiol., v.258, p.F1354-F1362, 1990. 
35. AGOSTINO, VIRDIS.; Spironolactone Improves Angiotensin-Induced Vascular Changes and Oxidative Stress. - Hypertension, v.40, p.504$510,2002$.

36. ROBERT, V.; HEYMES, C.; SILVESTRE, J.B.; SABRI, A .; SWYNGHEDAUW, B.; DELCAYRE, C. Angiotensin AT1 receptor subtype as a cardiac target of aldosterone - Role in aldosterone-saltinduced fibrosis. Hypertension, v.33, p.981-986, 1999.

37. LARAGH, J.H.; SEALEY, J.E.: $\mathrm{K}(+)$ depletion and the progression of hypertensive disease on heart failure. The pathogenic role of diureticinduced aldosterone secretion. Hypertension, v.37, p.806-810, 2001.

38. WEHLING, M.; CHRIST, M.; THEISEN, K Membrane receptors for aldosterone: a novel pathway for mineralocorticoid action. Am $\mathbf{J}$ Physiol., v.263, p. E974-E979, 1992.

39. AGARWAL, R Proinflammatory effects of oxidative stress in chronic kidney disease: role of angiotensin II blockade. Am J Physiol., v.284, p.F863-F869, 2003.

40. FUHR, J.; KACZMARCZYK, F.J.; KRUTTGEN, C.D. Eine einfache colorimetrische Methode zur Inulinbestimmung für Nieren-Clearance Untersuchungen bei Stoffwechselgesunden und Diabetikern. Klin Wochenschr, v. 33, p.729-730, 1955.

41. WALKER, P.D. AND SHAH, S. Reactive oxygen metabolites in endotoxin-induced acute renal failure in rats. Kidney International. , v.38, p.1125-1132, 1990.

42. ROMERO, F.; RODRIGUEZ-ITURBE, B.; PARRA, G.; GONZALEZ, L.; HERRERA-ACOSTA, J.; TAPIA, E. Mycophenolate mofetil prevents the progressive renal failure induced by $5 / 6$ renal ablation in rats. Kidney International, v.55, p.945-955, 1999. 
43. OHKAWA, H; OHISHI, N.; YAGI, K - Assay for lipid peroxides in animal tissues by thiobarbituric acid reaction. Anal. Biochem., v.71, p.952-958.

44. VOLPINI, R.A.; COSTA, R.S.; DA SILVA, C.G.A.; \& COIMBRA, T.M. Inhibition of nuclear factor- $\mathrm{kB} \quad(\mathrm{NF}-\mathrm{\kappa} B)$ activation attenuates tubulointerstitial nephritis induced by gentamicin. Nephron, v.98, p.97106, 2004.

45. ANNUK, M.; ZILMER, M.; LIND, L.; Oxidative stress and endothelial function in chronic renal failure. J Am Soc Nephrol., v.12 (12), p.27472752, 2001.

46. VAZIRI, N.D.; DICUS, M.; HO, N.D.; BOROUJERDI-RAD, L.; SINDHU, R.K. Oxidative Stress and dysregulation of superoxide dismutase and NADPH oxidase in insufficiency. Kidney Int., v. 63(1), p.179-185, 2003.

47. SIEMS W., QUAST S., CARLUCCIO F.; WISWEDEL, I.; HIRSCH, D.; AUGUSTIN, W.; HAMPI, H.; RIEHLE, M.; SOMMERBURG, $\mathrm{O}$. Oxidative stress in chronic renal failure as a cardiovascular risk factor. Clin. Nephrol., v.58 (1), p.12-9, 2002.

48. OZDEN M. ERYTHROCYTE GLUTATHIONE PEROXIDASE ACTIVITIES, plasma malondialdehyde and erythrocyte glutathione levels in hemodialysis and CAPD patients. Clin Biochem.,v.35(4), p.269-73, 2002.

49. ERDOGAN, C.; UNLUCERCI, Y.; TURKMEN, A .; KURU, A .; CETIN, $\mathrm{O}$.; BEKPINAR, S. The evaluation of oxidative stress in patients with chronic renal failure. Clin. Chim Acta. v.322(1-2), p.157-61, 2002.

50. ANDERSON, S.; MEYER, T.W.; RENNKE, H.G.; BRENNER, B.M. Control of glomerular hypertension limits glomerular injury in rats with 
reduced renal mass. J Cli Invest., v.76, p.612-619, 1985.

51. HAHN, S.; KUEMMERLE, N.B.; CHAN, W. HISANO, S.; SABORIO, P.; KRIEG JR.; CHAN, J.C.M. Glomerulosclerosis in the remmant kidney rat is modulated by dietary $\alpha$-tocopherol. J Am Soc Nephrol., v.9, p.2089-2095, 1998.

52. ATTIA, D.M.; VERHAGEN, A.M.G.; STROES, E.S.G. VAN FAASSEN, E.E.; GRÖNE, H.J.; DE KIMPE, S.J.; KOOMANS, H.A .; BRAAM, B.; JOLES, J. - Vitamin E alleviates renal injury, but not hipertension, during chronic nitric oxide synthase inhibition in rats. $\mathbf{J}$ Am Soc Nephrol., v.12, p.2585-2593, 2001.

53. FUJIHARA, C.K.; MALHEIROS, D.M.A.C.; ZATS, R.; NORONHA, I.L. Mycophenolate mofetil attenuates renal injury in the remmant kidney. Kidney Intern., v.54, p.1510-1519, 1998.

54. HASDAN, G.H.; BENCHETRIT, S.; RASHID, G. GREEN, J.; BERNHEIM, J.; RATHAUS, M. Endothelial dysfunction and hypertension in 5/6 nephrectomized rats are mediated by vascular superoxide. Kidney International, v.61, p.586-590, 2002.

55. WANG, Y.; RANGAN, G.K.; TAY, Induction of monocyte chemoattractant protein-1 by albumin is mediated by nuclear factor kappaB in proximal tubule cells. J Am Soc Nephrol., v.10, p.12041213, 1999.

56. AGARWAL, R. Chronic kidney disease is associated with oxidative stress independent of hypertension. Clin Nephrol., v.61, p.377-383, 2004.

57. AGARWAL, R. On the nature of proteinuria with acute renal injury in patients with chronic kidney disease. - Am J Physiol Renal Physiol., v.288, p.F265-F271, 2005. 
58. HEYMAN, S.N., GOLDFARB, M. N- acetylcysteine ameliorates renal microcirculation: Studies in rats. Kidney Int., v.63(2), p.634-641, 2003.

59. PALMER, R.M.J.; ASHTON, D.S.; MONCADA, S. Vascular endothelial cells synthesize nitric oxide from L-arginine. Nature, v.333, p.664-666, 1998.

60. CHENG, Z.J.; VASKONEN, T.; TIKKANEN, I. Endothelial dysfunction and salt-sensitive hypertension in spontaneously diabetic GotoKakizaki rats. Hypertension, v.37, p.433-439, 2001.

61. BRIGUORI, C. Acetylcysteine and contrast agent-associated nephrotoxicity. J Am Coll Cardiol., v.17, 40(2), p.298-303, 2002.

62. PITT, B.; ZANNAD, F.; REMME, J.; CODY, R.; CASTAIGNE, A.; PERZ, A; PALENSKY, J.; WITTES, J. The effect of spironolactone on morbidity and mortality in patients with severe heart failure. Randomized Aldactone Evaluation Study Investigators. N. Engl. J. Med., v.341 (10), p.709-17, 1999.

63. TODD-TURLA, K.M.; SCHNERMANN, J; FEJES-TOTH, G. Distribution of mineralocorticoid and glucocorticoid receptors mRNA along the nephrons. Am J Physiol., v.264, p.F781-F791, 1993.

64. FRIDOVICH, I. - The biology of oxygen radicals. Science, (Wash. DC), v.201, p.875-880, 1978.

65. BLACK, H.R. Evolving role of aldosterone blockers alone and in combination with angiotensin-converting enzyme inhibitors or angiotensin II receptor blockers in hypertension management: A review of mechanistic and clinical data. Am Heart J., v.147, p.564-72, 2004.

66. OBERLEITHNER, H.; LUDWIG, T.; RIETHMÜLLER, C.; HILLEBRAND, U.; ALBERMANN, L.; SCHÄFER, C.; SHAHIN, V.; SCHILLERS, H. Human Endothelium: Target for Aldosterone. 
Hypertension, v.43, p.952-956, 2004.

67. ARAUJO, M.; HELOU, C.M.B.; SEGURO, A.C. Renal potassium handling in aging rat. Kidney Blood Press Res., v.21(6), p.425-431, 1998.

68. WAKISAKA, M.; SPIRO, M.J.; SPIRO, R.G. Syntesis of type IV collagen by cultured glomerular cells and comparison of its regulation by glucose and other factors with that of type IV collagen. Diabetes, v.43, p.95-103, 1994.

69. MA, L-J.; NAKAMURA, S.; ALDIGIER, J.C.; ROSSINI, M.; YANG, H.; LIANG, X.; NAKAMURA, I.; MARCANTONI, C.; FOGO, A. .Regression of glomerulosclerosis with high-dose angiotensin inhibition is linked to decreased plasminogen activator inhibitor-1. J Am Soc Nephrol., v.16, p.966-976, 2005.

70. MURPHY, T.J.; ALEXANDER, R.W.; GRINDLING, K.K.; RUNGE, M.S.; BERNSTEIN, K.E. Isolation of a cDNA encoding the vascular type-1 angiotensin II receptor. Nature, v.351, p.233-236,1991.

71. OHYAMA, K.; OHYAMA, Y.; SANO, T.; NAKAGOMI, Y.; HAMAKUBO, T.; MORISHIMA, I.; INAGAMI, T. Disulfide bridges in extracellular domains of angiotensin II receptor type $1^{\text {a }}$. Regul Pept., v.57, p.141147, 1995.

72. ULLIAN, M.E.; GELASCO, A.K.; FITZGIBBON, W.R.; BECK, C.N.; MORINELLI, T.A. N-acetylcysteine decreases angiotensin II receptor binding in vascular smooth muscle cells. J. Am. Soc. Nephrol., v.16, p.2346-2353, 2005. 
De: pmorriss@im.wustl.edu [mailto:pmorriss@im.wustl.edu]

Enviada em: terça-feira, 28 de junho de 2005 17:06

Para: trulu@usp.br; mhmshimizu@uol.com.br

Assunto:

RE: KI-00513-2005.R1 - N-Acetylcysteine attenuates the progression of chronic renal failure

Dear Prof. Seguro:

The file on your revised manuscript is now complete. Therefore, your manuscript is accepted for publication in Kidney International and will be scheduled for publication in the next available issue.

You should receive the page proofs for your article within approximately 3 months. Please correct the proofs and return them per instructions that will accompany the proofs. Otherwise, it will be necessary to return the proofs to the printer with only those corrections made by the editorial office.

My thanks for having submitted your work to Kidney International.

Sincerely yours,

Saulo Klahr, M.D.

For the Editors 
De: Meiser,Rebecca [mailto:RMEISER@im.wustl.edu]

Enviada em: quarta-feira, 13 de julho de 2005 11:55

Para: mhmshimizu@uol.com.br

Cc: MStone@bos.blackwellpublishing.com

Assunto: KI 05-0513.R1 color letter

July 13,2005

Dear Dr. Seguro,

I have begun processing your manuscript entitled "N-Acetylcysteine attenuates the progression of chronic renal failure" (KI 05-0513.R1, \#677), scheduled for publication in the November 2005 issue of Kidney International. As was indicated in our earlier correspondence with you, the author is required to pay the cost of reproducing any color illustrations that accompany your manuscript. The established cost is $\$ 1500$ US per page or any portion thereof. Your paper includes 2 color figures (Figures 3 and 5), which will require 2 pages of color, for a cost of $\$ 3000$.

Many authors choose to solicit corporate sponsorship to pay for all or part of these charges. If you do obtain sponsorship, please supply the name, address, telephone number, and fax number of the person who is to be billed for this charge.

To meet our production schedule, I must receive a reply no later than August 5, 2005. You may mail, fax, or email to me your commitment to one of the following conditions:

1. You agree to pay $\$ 3000$ for 2 pages of color;

2. You arrange for a sponsor to pay all or part of the charge and you accept responsibility for any amount not covered by the sponsor; or

3. You agree to publish some of the figures in color and some of the figures in black and white.

If we do not hear from you by the above-indicated deadline, we will assume that black and white reproduction of your color figures is satisfactory to you.

Thank you for your contribution to Kidney International. If you have any additional questions or concerns, please let me know.

Sincerely,

Rebecca Meiser

Editorial Assistant, Kidney International

The materials in the e-mail are private and may contain Protected Health

Information. If you are not the intended recipient be advised that any unauthorized use, disclosure, copying, distribution or the taking of any action in reliance on the contents of this information is strictly prohibited. If you have received this e-mail in error, please immediately notify the sender via telephone at 314 454-8916 or by return e-mail. 


\section{$\mathrm{N}$-Acetylcysteine attenuates the progression of chronic renal} failure

Maria Heloisa Massola Shimizu*; Terezila Machado Coimbra*, Magali de Araujo*; Luis Fernando Menezes*; Antonio Carlos Seguro*.

*LIM/12 - Nephrology Department - University of São Paulo School of Medicine \#Physiology Department - University of São Paulo School of Medicine at Ribeirão Preto

Corresponding author: Antonio Carlos Seguro

Laboratório Pesquisa Basica LIM/12

Faculdade de Medicina USP

Av. Dr. Arnaldo, 455 3o. andar, sala 3310

CEP: 01246-000 São Paulo, SP

Brazil

Phone/Fax: 5511 3088-2267

E-mail: trulu@usp.br 
Short title: NAC attenuates CRF progression 


\section{ABSTRACT}

Background. Lipid peroxidation impairs renal function. Aldosterone contributes to renal injury in the remnant kidney model. This study aimed to determine the effects of the antioxidant $\mathrm{N}$-acetylcysteine (NAC) on renal function and aldosterone levels in chronic renal failure.

Methods. Adult male Wistar rats were submitted to 5/6 nephrectomy or laparotomy (sham-operated) and received NAC (600 $\mathrm{mg} / \mathrm{L}$ in drinking water, initiated on postoperative day 7 or 60), spironolactone (1.5 g/kg of diet initiated on postoperative day 7), the NAC-spironolactone combination or no treatment. Clearance studies were performed on postoperative days 21,60 and 120.

Results. Mean daily NAC and spironolactone ingestion was comparable among the treated groups. Mean weight gain was higher in NAC-treated rats than in untreated rats. A significant decrease in urinary thiobarbituric acid reactive substances (TBARS) concentrations, a lipid peroxidation marker, was observed in NAC-treated rats. By day 120, glomerular filtration rate (GFR), which dropped dramatically in untreated rats, was stable (albeit below normal) in NAC-treated rats, which also presented lower proteinuria, glomerulosclerosis index and blood pressure, together with attenuated cardiac and adrenal hypertrophy. These beneficial effects, observed even when NAC was initiated on postnephrectomy day 60 , were accompanied by a significant reduction in plasma aldosterone and urinary sodium/potassium ratio. The NAC-spironolactone combination lowered blood pressure and improved GFR protection.

Conclusion. The NAC-spironolactone combination improves renal function more than does NAC alone. In the remnant kidney model, early or late NAC administration has a protective effect attributable to decreased plasma aldosterone and lower levels of lipid peroxidation.

Key words: Acetylcysteine; Kidney Failure, Chronic; Lipid peroxidation; TBARS; Kidney Function Tests; Inulin; Aldosterone; Spironolactone 


\section{INTRODUCTION}

Oxidative stress, resulting from the imbalance between reactive oxygen species (ROS) and the antioxidant system, contributes to the pathogenesis of different diseases. Several studies have demonstrated that chronic renal failure $(\mathrm{CRF})$ is associated with oxidative stress $(1,2)$. An antioxidant deficient diet increased the progression of renal disease in animals with nephrectomy (3). However, the pathogenesis of oxidative stress in CRF patients remains poorly defined (4). Levels of malondialdehyde (MDA), a product of lipid peroxidation, have been shown to increase after $5 / 6$ nephrectomy in rats. The antioxidant $\mathrm{N}$-acetylcysteine (NAC) is a source of sulfhydryl groups in cells and, due to its interaction with ROS, is a scavenger of free radicals (5). It has been shown that NAC administration improves endothelial function while reducing inflammation, fibrosis, cartilage explants and acetaminophen liver metal toxicity (5). In addition, NAC decreases MDA levels in chronic hemodialysis patients (6) and ameliorates ischemic renal failure (7). It has also been used in the prevention of radiocontrast-induced renal failure (8). The effect of NAC on progressive renal disease has not been previously evaluated.

Aldosterone contributes to renal injury in the remnant kidney model (9). In the heart, aldosterone-induced inflammation is also mediated by oxidative stress and attenuated by NAC (10). Aldosterone, partly via increased oxidative stress, may mediate some of the angiotensin II-induced vascular effects seen in hypertension (11). Treatment with NAC reduces composite endpoints of cardiovascular events in patients with end-stage renal failure (12).

This study was carried out in order to determine the effects of NAC on kidney function and aldosterone production in the remnant kidney model.

\section{MATERIALS AND METHODS}

A total of 70 adult male Wistar rats $(150-200 \mathrm{~g})$ were provided by the University of São Paulo School of Medicine for use in this study. All rats were anesthetized with $50 \mathrm{mg} / \mathrm{kg}$ of body weight (BW) of sodium pentobarbital, administered intraperitoneally, and were subjected to either $5 / 6$ nephrectomy, induced by right nephrectomy and ligation of two branches of the renal artery, or laparotomy (sham operation). After recovering from the anesthesia, the animals were returned to their original cages and given free access to water and standard rat chow (Nuvilab ${ }^{\circledR}$, Curitiba, Brazil). Clearance studies were performed, variously, on postoperative days 21,60 , and 120 . One 
day prior to each clearance study, rats were housed in metabolic cages without food or water. The Ethics in Research Committee of the University of São Paulo School of Medicine approved the study design.

\section{Early $\mathrm{N}$-acetylcysteine administration after 5/6-nephrectomy or sham operation}

In order to assess the effect of NAC administration in the early stages of nephrectomyinduced renal failure, animals were assigned to one of various groups, some receiving NAC (600 $\mathrm{mg} / \mathrm{L}$ in drinking water), initiated on postoperative day 7 , and some receiving no treatment. The groups were defined as follows: Sham/EV21 (Sham operated and evaluated on postoperative day 21, $n=6$ ); Nx/EV21 (nephrectomized and evaluated on day 21, $n=6$ ); Nx/EV60 (nephrectomized and evaluated on day 60, $n=6$ ); Nx/EV120 (nephrectomized and evaluated on day 120, $n=6$ ); Sham+NAC-IN7/EV21 (Sham operated, treated with NAC from day 7 and evaluated on day 21, $n=$ 6); Nx+NAC-IN7/EV21 (nephrectomized, treated with NAC from day 7 and evaluated on day 21, $n=$ 6); Nx+NAC-IN7/EV60 (nephrectomized, treated with NAC from day 7 and evaluated on day $60, n=$ 6); Nx+NAC-IN7/EV120 (nephrectomized, treated with NAC from day 7 and evaluated on day 120, $n=6)$.

$\mathrm{N}$-acetylcysteine administration in the later stages of renal failure

To evaluate the effect of NAC on end-stage renal failure, another group was created, composed of nephrectomized rats receiving NAC $(600 \mathrm{mg} / \mathrm{L}$ in drinking water) initiated on postoperative day 60 . These rats were evaluated on postoperative day 120 , and the group was designated NX+NAC-IN60/EV120 $(n=6)$.

\section{Early administration of spironolactone and the $\mathrm{N}$-acetylcysteine-spironolactone combination}

Two additional groups were created, both composed of nephrectomized rats. The animals in one group received spironolactone $(1.5 \mathrm{~g} / \mathrm{kg}$ of diet, initiated on postoperative day 7) and were evaluated on postoperative day 60 . This group was designated Nx+SPI-IN7/EV60 $(n=8)$. Animals in the other group, designated $\mathrm{Nx}+\mathrm{SPI}+\mathrm{NAC}-\mathrm{IN7/EV60}(n=8)$ also received spironolactone (in the same quantity), together with NAC (600 mg/L in drinking water), both initiated on postoperative day 7 , and were also evaluated on postoperative day 60.

Urinary protein excretion and urinary levels of TBARS

As previously mentioned, rats were housed in metabolic cages without food or water before each clearance study, and a 24-h urine sample was collected in order to determine urinary protein excretion and levels of TBARS. Urinary protein excretion was determined using the Sensiprot kit, (Labtest, São Paulo, Brazil). Urinary TBARS levels were assessed using the thiobarbituric acid 
method, diluting a $0.2-\mathrm{mL}$ urine sample in $0.8 \mathrm{~mL}$ of distilled water, to which $1 \mathrm{~mL}$ of $17.5 \%$ trichloroacetic acid was immediately added. Subsequently, $1 \mathrm{~mL}$ of $0.6 \%$ thiobarbituric acid, $\mathrm{pH} 2$, was added. The sample was then placed in a boiling water bath for $15 \mathrm{~min}$. After the sample had cooled, $1 \mathrm{~mL}$ of $70 \%$ trichloroacetic acid was added, and the mixture was allowed to incubate for 20 min. The sample was then centrifuged for $15 \mathrm{~min}$ at $2000 \mathrm{rpm}$. The optical density of the supernatant was read at $534 \mathrm{~nm}$ against a reagent blank using a spectrophotometer. The concentration of lipid peroxidation products was calculated as malondialdehyde- equivalent using a molar extinction coefficient for the malondialdehyde-thiobarbituric acid complex of $1.56 \times 10^{5} \mathrm{~mol}^{-}$ $1 / \mathrm{cm}^{-1}$. Urinary levels of TBARS were expressed as $\mathrm{nmol} / 24 \mathrm{~h}(3)$.

\section{Clearance studies}

Prior to the performance of the clearance studies, each designated animal was anesthetized intraperitoneally with sodium thiopental $(50 \mathrm{mg} / \mathrm{kg} \mathrm{BW})$. The trachea was cannulated with a PE-240 catheter, and spontaneous breathing was maintained. To control mean arterial pressure and allow blood sampling, the right carotid artery was catheterized with a PE-60 catheter. For infusion of inulin and fluids, the left jugular vein was cannulated with a PE-60 catheter. In order to collect urine samples, a suprapubic incision was made, and the urinary bladder was cannulated with a PE-240 catheter. Following the surgical procedure, a loading dose of inulin $(100 \mathrm{mg} / \mathrm{kg} \mathrm{BW}$ diluted in $0.9 \%$ saline) was administered through the jugular vein. A constant infusion of inulin (10 $\mathrm{mg} / \mathrm{kg}$ BW in $0.9 \%$ saline) was then started and continued at $0.04 \mathrm{ml} / \mathrm{min}$ throughout the experiment. A total of 3 urine samples were collected at 30-min intervals. Blood samples were obtained at the beginning and end of the experiment. At the clearance study endpoint, the kidneys were flushed with saline and perfused with Dubosq-Brazil (modified Bouin) fixative in situ at the measured arterial pressure. The renal tissue was then weighed, and two sections were postfixed in buffered $10 \%$ formaldehyde solution. The material was embedded in paraffin for later assessment of glomerular and renal cortical interstitial injury. Hearts and adrenal glands were also removed and weighed. 
Blood and urine inulin were determined by the anthrone method, and sodium and potassium concentrations were measured using a flame photometer (model 143; Instrumentation Laboratory, Lexington, MA, USA). Glomerular filtration rate (GFR) and urinary sodium/potassium $(\mathrm{UK} / \mathrm{UNa}$ ) ratio was calculated. Serum aldosterone in blood samples obtained at the end of the clearance study was determined by radioimmunoassay (Coat-A-Count, DPC, Los Angeles, CA, USA). 


\section{Histomorphometric analysis}

Paraffin-embedded renal tissue was deparaffinized using standard techniques, and 2- to 3$\mathrm{m}$ thick sections were stained with periodic acid-Schiff and Masson trichrome technique. A single blinded observer performed all histomorphometric measurements. The extent of glomerular sclerosis was evaluated in four animals on postnephrectomy day 60 and in six animals on postnephrectomy day 120. A score was attributed to each glomerulus according to the extent of sclerotic injury: $0=$ intact; $1=$ up to $10 \%$ damaged; $2=11-20 \%$ damaged; $3=21-30 \%$ damaged; 4 $=31-40 \%$ damaged $5=41-50 \%$ damaged $; 6=51-60 \%$ damaged $;=61-70 \%$ damaged $; 8=71-$ $80 \%$ damaged; $9=81-90 \%$ damaged; $10=91-100 \%$ damaged. For each rat, the glomerulosclerosis index (GSI) was calculated. The GSI is a weighted average, multiplied by 100 , of all individual glomeruli thus obtained. At least 50 glomeruli per rat were examined.

\section{Fractional interstitial area}

In kidneys obtained from Nx/EV120 and Nx+NAC-IN7/EV120 group animals, the fractional interstitial area of the renal cortex was determined by morphometry with a light camera connected to an image analyzer (KS300; Kontron, Munich, Germany) (13). Twenty $0.174-\mathrm{mm}^{2}$-grid fields were evaluated in the renal cortex of each kidney. Interstitial areas were first manually encircled on a video screen and then determined by computerized morphometry. 
Immunohistochemical analysis

Immunohistochemical analysis was performed for kidneys obtained from animals in the Nx/EV120 and Nx+NAC-IN7/EV120 groups. The primary antibodies used were a monoclonal anti rat ED1 antibody to a cytoplasmic antigen present in macrophages and monocytes (Serotec Product Datasheet, Oxford, UK) and a monoclonal IgG antibody to rat lymphocytes (CD3; Harlan Sera-Lab, Loughborough, England). The sections were incubated for $1 \mathrm{~h}$ with anti-ED1 antibodies (macrophages, 1:1000) or CD3 antibodies (lymphocytes, 1:1000). The reaction product was detected with an avidin-biotin-peroxidase complex (Vector Laboratories, Burlingame, CA, USA). The color reaction was developed with 3,3'-diaminobenzidine (Sigma Chemical Company, St. Louis, MO, USA), and the material was counterstained (with methyl green for ED1 or hematoxylin for ED3), then dehydrated and mounted. Nonspecific protein binding was blocked by incubation with $20 \%$ goat serum in PBS for 20 min. Replacing the primary antibody with mouse $\lg$, at an equivalent concentration, created a negative control.

Infiltrating macrophages/monocytes and lymphocytes in the renal cortex were counted in the tubulointerstitium and in the glomeruli using a $0.245-\mathrm{mm}^{2}$ grid field or 30 glomeruli, respectively.

\section{Statistical analysis}

Data were analyzes using one-way analysis of variance (ANOVA) and Bonferroni's post test using GraphPad Prism (version 3.0) and Stata (version 8.0) statistical software.

Data are mean \pm SEM, a $p$ value $<0.05$ was considered to be significant at a two-tailed level. The ANOVA and Bonferroni's post test were used to analyze the GSI. Analysis of the immunohistochemistry was performed using $t$ test with Welch's correction. Statistical significance was established at $p<0.05$.

\section{RESULTS}

Early $\mathrm{N}$-acetylcysteine administration after 5/6 nephrectomy or sham operation 
There was a significant and progressive increase in the BW of all rats submitted to $5 / 6$ nephrectomy. However, Nx+NAC-IN7/EV60 and Nx+NAC-IN7/EV120 rats presented significantly higher mean BW gain than did untreated nephrectomized rats (Table 1).

As illustrated in Table 1, NAC ingestion was similar in all NAC-IN7-treated groups. Urinary protein was significantly higher in nephrectomized rats than in sham-operated rats. However, $\mathrm{Nx}+\mathrm{NAC}-\mathrm{IN7/EV60}$ and Nx+NAC-IN7/EV120 rats presented lower levels of protein excretion than did untreated nephrectomized rats.

Urinary TBARS excretion was also lower in $\mathrm{Nx}+\mathrm{NAC}$-IN7 group rats than in untreated nephrectomized rats. In Nx+NAC-IN7/EV21 rats, levels of TBARS were comparable to those observed in sham-operated rats, whereas there was a significant increase in this parameter in untreated nephrectomized rats. In Nx+NAC-IN7/EV60 and Nx+NAC-IN7/EV120 rats, respectively, TBARS levels were approximately $40 \%$ and $60 \%$ lower than in untreated nephrectomized rats (Table 1). These data suggest that NAC reduces lipid peroxidation and attenuates the renal injury responsible for the high protein excretion in the 5/6 nephrectomy model.

Table 2 shows that inulin clearance (and therefore GFR) fell progressively in nephrectomy rats in comparison to sham-operated rats $(p<0.001)$. Nevertheless, rats in all Nx+NAC-IN7 groups presented less dramatic drops in GFR than did sham-operated rats, with values almost $50 \%$ higher than those seen in untreated nephrectomized rats.

Serum aldosterone increased significantly and progressively in nephrectomized rats compared with Sham rats. However, rats in all Nx+NAC-IN7 groups presented significantly lower serum levels of this hormone, approximately 5 times lower in Nx+NAC-IN7/EV21 rats and 2.5 times lower in Nx+NAC-IN7/EV60 rats than those seen in untreated nephrectomized rats. On postoperative day 120 , all nephrectomized rats presented lower serum aldosterone levels, although rats in the $\mathrm{Nx}+\mathrm{NAC}-\mathrm{IN7}$ groups continued to present considerably lower values than did untreated nephrectomized rats (Table 2).

On postoperative days 60 and 120, fractional excretion of potassium was significantly lower in Nx+NAC-IN7 group rats compared with untreated nephrectomized rats. On postoperative day 
120 , the UK/UNa ratio was significantly lower in all $N x+N A C-I N 7$ rats than in untreated nephrectomized rats (Table 2).

Heart and adrenal weights also increased significantly and progressively in nephrectomized rats (Table 2). By postoperative day 21, the weights of these organs remained unchanged. However, Nx+NAC-IN7/EV60 and Nx+NAC-IN7/EV120 rats presented significantly lower heart and adrenal weights, indicating that NAC might have attenuated the hypertrophy of these organs during the progression of CRF.

There were no differences in blood pressure (BP) between $\mathrm{Nx}+\mathrm{NAC}$-IN7-treated and untreated nephrectomized rats evaluated at 21 and 60 days. Nevertheless, a significant lower BP was observed in Nx+NAC-IN7/EV120 rats (Table 2).

As illustrated in Figure 1, the relative interstitial area in Nx/EV120 rats was $22.47 \pm 3.66 \%$, compared with $10.17 \pm 0.66 \%$ for Nx+NAC-IN7/EV120 rats $(p<0.03)$.

As can be seen in Figures 2 and 3, the number of cells demonstrating ED1 staining for macrophages/monocytes was significantly lower in Nx+NAC-IN7/EV120 rats than in Nx/EV120 rats, both in the glomeruli $(1.46 \pm 0.25$ vs. $4.16 \pm 0.70, p<0.02)$ and in the tubulointerstitium $(13.26 \pm$ 1.80 vs. $34.59 \pm 6.16, p<0.02)$.

The immunohistochemical analysis also showed significantly lower numbers of infiltrating lymphocytes in Nx+NAC-IN7/EV120 rats than in Nx/EV120 rats, both in glomeruli $(1.19 \pm 0.26$ vs. $2.10 \pm 0.30, p<0.05)$ and in the tubulointerstitium (10.45 \pm 0.61 vs. $27.12 \pm 2.93, p<0.05)$ (Figures 4 and 5).

$\mathrm{N}$-acetylcysteine administration in the later stages of renal failure

In Nx+NAC-IN60/EV120 rats, a protective effect similar to that seen in Nx+NAC-IN7/EV120 rats was observed. Inulin clearance was $0.51 \pm 0.03 \mathrm{ml} / \mathrm{min} / 100 \mathrm{~g} \mathrm{BW}$; mean arterial pressure was $159 \pm 8 \mathrm{mmHg}$; proteinuria was $134 \pm 22 \mathrm{mg} /$ day; urinary TBARS excretion was $127 \pm 15 \mathrm{nmol} /$ day; aldosterone $31 \pm 4 \mathrm{ng} / \mathrm{dl}$, Uk/UNa was $1.3 \pm 0.1$, heart weight was $1.42 \pm 0.07 \mathrm{~g}$ and adrenal weight was $43 \pm 3 \mathrm{mg}$. Mean body weight gain in the Nx+NAC-IN60/EV120 group (336.7 $\pm 10.1 \mathrm{~g})$ was comparable to that of the Nx+NAC-IN7/EV120 group. These results indicate that NAC is protective even in end-stage renal failure 
As illustrated in Figure 6A, the GFR was higher in Nx+NAC-IN7/EV120 rats and in $\mathrm{Nx}+\mathrm{NAC}-\mathrm{IN60/EV120}$ rats than in Nx/EV120 rats, whereas the GSI after nephectomy was considerably lower in Nx+NAC-IN7/EV120 rats and in Nx+NAC-IN60/EV120 rats than in Nx/EV120 rats (Fig. 6B)

The clearance data are from the surviving animals. In Nx/EV120 we started with 9 rats, one of which died on day 78 , another one on day 98 , and one on day 103 , as a result, we performed clearance studies in 6 animals (33\%). In the Nx+NAC-IN7/EV 120 group, we started with 8 rats: one died on day 96 and another one on day 110 , so 6 animals were studied $(25 \%)$. In the Nx+NACIN60/EV 120 group, we started with 7 animals and only one died on day 97 (14.3\%).

\section{Spironolactone and the $\mathrm{N}$-acetylcysteine-spironolactone combination}

Mean daily spironolactone ingestion was comparable between the two groups ( $\mathrm{Nx}+\mathrm{SPI}$ IN7/EV60 = $134 \pm 7 \mathrm{mg} / \mathrm{kg} /$ day; Nx+SPI+NAC-IN7/EV60 = $126 \pm 5 \mathrm{mg} / \mathrm{kg} /$ day, (not significant).

In the $\mathrm{Nx}+\mathrm{SPI}-\mathrm{IN} 7 / \mathrm{EV} 60$ group, urinary protein excretion was lower than in the Nx/EV60 group (18 $\pm 1 \mathrm{mg} / 24 \mathrm{~h}$ vs. $27 \pm 2 \mathrm{mg} / 24 \mathrm{~h}, p<0.001)$; as was the UK/UNa ratio $(0.90 \pm 0.10$ vs. $5.90 \pm 2.0, p<0.001)$. The inulin clearance was greater in Nx+SPI-IN7/EV60 than in the Nx/EV60 group $(0.28 \pm 0.04$ vs. $0.21 \pm 0.06 \mathrm{ml} / \mathrm{min} / 100 \mathrm{~g} \mathrm{BW}, p<0.05)$. The same was observed in the case of arterial pressure (155 \pm 3 vs. $158 \pm 3 \mathrm{mmHg}, p<0.05$ ), whereas no differences were observed in aldosterone, TBARS levels, heart and adrenal weight.

The NAC-spironolactone combination resulted in lower mean blood pressure than did spironolactone only $(\mathrm{Nx}+\mathrm{SPI}+\mathrm{NAC}-\mathrm{IN7/EV60}=136 \pm 2 \mathrm{mmHg} ; \mathrm{Nx}+\mathrm{SPI}-\mathrm{IN7} / \mathrm{EV} 60=155 \pm 3$ $\mathrm{mmHg}, \mathrm{p}<0.001$. In addition, inulin clearance in the $\mathrm{Nx}+\mathrm{SPI}+\mathrm{NAC}-\mathrm{IN7} / \mathrm{EV} 60$ group was $0.59 \pm 0.04$ $\mathrm{ml} / \mathrm{min} / 100 \mathrm{~g} \mathrm{BW}$, demonstrating an additive effect in comparison to treatment with NAC alone $(\mathrm{Nx}+\mathrm{NAC}-\mathrm{IN7} / \mathrm{EV} 60=0.47 \pm 0.05, p<0.001 ;$ Fig. $7 \mathrm{~A})$.

Mean GSI was significantly higher in the Nx/EV60 group than in any of the other groups evaluated on postoperative day 60 , the lowest GSI being observed in the $\mathrm{Nx}+\mathrm{SPI}+\mathrm{NAC}-\mathrm{IN} 7 / \mathrm{EV} 60$ group (Fig. 7B). 
If we plot the rate of urinary excretion of protein/inulin clearance with the respective glomerulosclerosis index of animals, we obtain a positive correlation (Figure $8, r=0.161 p<0.008$ ).

\section{DISCUSSION}

Our data demonstrate that TBARS urinary excretion increases progressively in the remnant kidney model, indicating that lipid peroxidation plays an important role in the progression of CRF. Nath et al. showed that MDA per nephron increases in a model of subtotal nephrectomy and is accompanied by an increase in fractional and absolute urinary excretion of MDA (14). A recent study showed that, in evaluating patients with chronic kidney disease, the measurement of oxidative damage markers (such as MDA) in urine is a more sensitive method than the measurement of such markers in plasma (15).

In the present study, we showed that NAC lowers lipid peroxidation significantly and consistently for a period of at least 120 days after subtotal nephrectomy. This was accompanied by a significant protective effect on GFR and renal inflammation, as well as by significant decreases in aldosterone levels.

Subtotal (5/6) nephrectomy is widely used to create experimental models of progressive nephropathy. Renal inflammation is prominent in such models. Various methods of reducing renal injury in nephrectomized rats, such as the administration of angiotensin-converting enzyme inhibitors, angiotensin II antagonists or immunosuppressive agents (such as mycophenolate mofetil), have been employed (16-17-18-19). All of these agents decreased proteinuria and reduced renal inflammation, as evaluated by the GSI and tubulointerstitial injury scores. However, significant protection of GFR, as determined by inulin clearance, has not been reported.

The major new finding of the present study is that NAC administration to $5 / 6$ nephrectomized rats produced significant protection against a decrease in GFR, maintaining a mean inulin clearance of $0.45 \mathrm{ml} / \mathrm{min}(50 \%$ of normal) that remained stable at 120 days after nephrectomy. In contrast, GFR decreased progressively in the untreated rats. Reductions in inflammation and in fractional interstitial volume were observed in NAC-treated rats at 120 days 
after nephrectomy. Although reductions in proteinuria and BP were also observed in these rats, the protective effect that NAC had on GFR was more impressive than the reduced proteinuria.

The data regarding GFR and glomerulosclerosis are quite interesting. However, the antiproteinuric effect of NAC at 120 days appears quite modest. Nevertheless, if we correct the mean daily proteinuria by the respective mean inulin clearance, $\mathrm{Nx} / \mathrm{EV} 120$ rats presented a four to five times greater protein excretion/inulin clearance when compared to Nx+NAC-IN7/EV120 rats and $\mathrm{Nx}+\mathrm{NAC}-\mathrm{IN60/EV} 120$ rats. The same is true if we compare urinary excretion of protein/inulin clearance in $\mathrm{Nx} / \mathrm{EV} 60$ rats to that observed in $\mathrm{Nx}+\mathrm{NAC}-\mathrm{IN7/EV60}$ rats and $\mathrm{Nx}+\mathrm{SPI}+\mathrm{NAC}-\mathrm{IN7/EV60}$ rats.

In addition, a significant reduction in BP was not observed in NAC-treated rats until day 120. Similar results have been obtained with administration of the antioxidant vitamin $E$ in a rat model of chronic nitric oxide synthase inhibition (20) in which renal injury was reduced, but there was no concomitant improvement in hypertension. In spontaneously diabetic rats fed a high-sodium diet, treatment with angiotensin II receptor blockers has been shown to improve parameters without affecting blood pressure (21).

Proteinuria and elevated BP are predictors of progressive kidney injury. Some studies suggest that albumin can stimulate the production of proinflammatory cytokines in proximal tubule cells by NF- $\kappa B$ activation $(22,23)$. It is not known whether the proinflammatory state and oxidative stress in the kidney can be reduced without a significant reduction in proteinuria and BP.

A recent study was conducted involving patients with chronic kidney disease who were being treated with an angiotensin-converting enzyme inhibitor in combination with other antihypertensive agents (15). The authors submitted the patients to additional angiotensin II blockade with losartan and observed improvement in GFR with no effect on BP or proteinuria. The additional angiotensin II blockade induced a $35 \%$ reduction in oxidized albumin and a reduction in urinary excretion of monocyte chemotactic protein-1, corresponding to the degree of renal inflammation. In another study of chronic kidney disease patients, angiotensin II blockade also induced a $38 \%$ reduction in urinary excretion of the fibrogenic cytokine TGF- $\beta$ (24). Therefore, as previously demonstrated, 
treatment with angiotensin II receptor blockers improves oxidative stress parameters in proteinuric patients with chronic kidney disease without affecting blood pressure (25).

In our study, the combination of NAC and spironolactone (Nx+SPI+NAC5IN7/EV60 rats) was found to lower BP and reduce oxidative stress, thereby conferring additive protection of GFR. This finding suggests a need for further studies evaluating the effectiveness of treatment with antioxidant-antihypertensives combinations in models of CRF.

Administration of NAC has been shown to be protective in several types of organ injury. This is due to the fact that NAC inhibits the activation of some protein kinases and of NF- $\mathrm{KB}$, which is an important transcription factor for a number of cytokine genes that may be activated as a result of endothelial shear stress $(5,26,27)$. The expression of NF- $\mathrm{kB}$-dependent genes may be important in inducing endothelial cell death, as well as in generating a local inflammatory reaction characterized by the release of endothelial-derived cytokines (28).

Based on our data, we can conclude that NAC directly regulates the proinflammatory effects of oxidative stress in chronic kidney disease. These data may be significant since current strategies for treating chronic kidney disease address the reduction of BP and proteinuria. Therefore, the addition of NAC to these treatment regimens could be promising as a means of preventing the oxidative stress complications of chronic kidney disease.

It is remarkable that aldosterone levels remained elevated on day 120 after $5 / 6$ nephrectomy, albeit to a lesser degree than on day 60. A previous study carried out in our laboratory showed that aldosterone levels were lower in 8-month-old rats than in younger rats (29). In the present study, the lower aldosterone levels seen at 120 days are probably attributable to the aging of the animals and are consistent with the lower fractional excretion of potassium seen in these rats.

Rats treated with NAC presented noticeable decreases in aldosterone levels as early as 21 days after nephrectomy. Our data suggest that aldosterone makes only a modest contribution to the induction of arterial hypertension in the remnant kidney model since the marked decrease in aldosterone levels in NAC-treated rats 21 and 60 days following nephrectomy was accompanied by only a slight decrease in BP. 
Since high levels of aldosterone are necessary to maintain potassium balance in CRF, we can hypothesize that the lower levels of aldosterone seen in NAC-treated animals are a consequence of a lesser degree of renal injury.

Nonhemodynamic effects of aldosterone may contribute to glomerulosclerosis. Studies in vitro have shown that production of type-IV collagen increased in mesangial cells incubated with aldosterone (30). Transcripts for the mineralocorticoid receptor have been detected in the glomeruli, which may mediate the action of this hormone at this site (31). It is possible that the beneficial effect of NAC on GFR and glomerulosclerosis is at least partly mediated by aldosterone.

Sun et al. demonstrated aldosterone-induced inflammation in the rat heart $(10,32)$. The authors found this effect to be mediated by oxidative stress and attenuated by NAC. In our study, cardiac hypertrophy, indirectly evaluated by determining heart weight, increased progressively following nephrectomy. Heart weights at 60 and 120 days after nephrectomy were significantly higher in NAC-treated rats than in untreated animals. It is possible that the lower levels of aldosterone in NAC-treated rats are responsible for this effect.

In summary, our data demonstrate that NAC attenuates drops in GFR, as well as lowering proteinuria and BP in nephrectomized rats. This is accompanied by a significant reduction in aldosterone levels. Our results indicate that ROS play an important role in the progression of CRF. It is evident that NAC has potential utility in preventing glomerulosclerosis and loss of kidney function in patients with CRF. The findings that NAC attenuated GFR drop and lowered proteinuria, even in end-stage CRF, and that the combination of NAC and spironolactone improves renal function more than does NAC alone have significant clinical implications. 
Acknowledgments: This research is supported by FAPESP (Fundação de Amparo à Pesquisa do Estado de São Paulo); LIM (Laboratório de Investigação Médica). Dr. Antonio C. Seguro is supported by CNPq (Conselho Nacional de Pesquisa). The authors thank Jefferson D. Boyles for editorial assistance and Ivaldo Olimpio da Silva for statistical advice.

Reprint requests to Dr. Antonio Carlos Seguro

Laboratorio Pesquisa Basica LIM/12

Faculdade de Medicina USP

Av. Dr. Arnaldo, 455 3o. andar, sala 3310

CEP: 01246-000 São Paulo, SP

Brazil

Phone/Fax: 5511 3088-2267

E-mail: trulu@usp.br 


\section{REFERENCES}

1- Annuk M, Zilmer M, Lind L, et al: Oxidative stress and endothelial function in chronic renal failure. J Am Soc Nephrol 12(12):2747-2752, 2001.

2- Vaziri ND, Dicus M, Ho ND, et al: Oxidative Stress and dysregulation of superoxide dismutase and NADPH oxidase in renal insufficiency. Kidney Int 63(1):179-185, 2003.

3- Nath KA, Salahudeen AK: Induction of renal growth and injury in the intact rat kidney by dietary deficiency of antioxidants. J.Clin. Invest. 86:1179-1192, 1990.

4- Massy ZA, Nguyen-Khoa T: Oxidative stress and chronic renal failure: markers and management. J Nephrol 15(4):336-341, 2002.

5- Zafarullah M, Li WQ, Sylvester J, Ahmad M: Molecular mechanisms of N-acetylcysteine actions. Cell Mol Life Sci 610:6-20, 2003

6 Trimarchi $\mathrm{T}$, Mongitore MR, Baglioni $\mathrm{P}$, et al: $\mathrm{N}$-acetylcysteine reduces malondialdehyde levels in chronic hemodialysis patients- a pilot study. Clin Nephrol 59:441-446, 2003.

7- Di Mari J, Megyesi J, Udvarhelyi $\mathrm{N}$, et al: $\mathrm{N}$-acetylcysteine ameliorates ischemic renal failure. Am J Physiol 272:F292-F298, 1997.

8- Tepel M, van der Giet M, Schwarzfeld C, et al: Prevention of radiographic-contrast-agentinduced reductions in renal function by n-acetylcysteine. N Engl J Med 343:180-184, 2000.

9- Greene EL, Kren S, Hostetter TH: Role of aldosterone in the remnant kidney model in the rat. $J$ Clin Invest 98:1063-1068, 1996.

10 Sun Y, Zhang J, Lu L, et al: Aldosterone-induced inflammation in the rat heart: role of oxidative stress. Am J Pathol 161:1773-1781, 2002.

11- Virdis A, Neves MF, Amiri F, et al: Spironolactone improves angiotensin-induced vascular changes and oxidative stress. Hypertension 40:504-510, 2002.

12- Tepel M, van der Giet M, Statz M, et al: The antioxidant acetylcysteine reduces cardiovascular events in patients with end-stage renal failure: a randomized, controlled trial. Circulation 107:992-995, 2003. 
13- Volpini RA, Costa RS, da Silva CGA \& Coimbra TM: Inhibition of nuclear factor-kB (NF-kB) activation attenuates tubulointerstitial nephritis induced by gentamicin. Nephron 98: 97-106, 2004.

14- Nath KA, Craott AJ, Hostetter TH: Oxygen consumption and oxidant stress in surviving nephrons. Am J Physiol 258:F1354-F1362, 1990.

15- Agarwal R: Proinflammatory effects of oxidative stress in chronic kidney disease: role of additional angiotensin II blockade. Am J Physiol 284:F863-F869, 2003.

16- Anderson S, Meyer TW, Rennke HG, Brenner BM: Control of glomerular hypertension limits glomerular injury in rats with reduced renal mass. J Clin Invest 76:612-619, 1985.

17- Meyer T, Anderson S, Rennke HG, Brenner BM: Reversing glomerular hypertension stabilizes established renal injury. Kidney Int 31:752-759, 1987.

18- Fujihara CK, Malheiros DMAC, Zatz R, Noronha IL: Mycophenolate mofetil attenuates renal injury in the remnant kidney. Kidney Int 54:1510-1519, 1998.

19- Ots M, Mackenzie HS, Troy JL: Effects of combination therapy with enalapril and losartan on the rate of progression of renal injury in rats with $5 / 6$ renal mass ablation. $J$ Am Soc Nephrol 9:224-230, 1998.

20- Attia DM, Verhagen AM, Stroes ES, et al: Vitamin E alleviates renal injury, but not hypertension, during chronic oxide synthase inhibition in rats. J Am Soc Nephrol 12:2585-2593, 2001.

21- Cheng ZJ, Vaskonen T, Tikkanen I, et al: Endothelial dysfunction and salt-sensitive hypertension in spontaneously diabetic Goto-Kakizaki rats. Hypertension 37:433-439, 2001.

22- Wang $\mathrm{Y}$, Chen J, Chen L, et al: Induction of monocyte chemoattractant protein-1 in proximal tubule cells by urinary protein. J Am Soc Nephrol 8:1537-1545, 1997.

23- Wang Y, Rangan GK, Tay YC, et al: Induction of monocyte chemoattractant protein-1 by albumin is mediated by nuclear factor kappaB in proximal tubule cells. J Am Soc Nephrol 10:1204-1213, 1999.

24- Agarwal R, Siva S, Dunn SR, Sharma K: Add-on angiotensin II receptor blockade lowers urinary transforming growth factor-beta levels. Am J Kidney Dis 39:486-492, 2002. 
25- Agarwal R: Chronic kidney disease is associated with oxidative stress independent of hypertension. Clin Nephrol 61:377-383, 2004.

26- Kim HJ, Jung KJ, Yu BP, et al: Influence of age and calorie restriction on MAPKs activity in rats kidney. Exp Gerontol 37:1041-1053, 2002.

27- Mehta A, Sekhon CP, Giri S, et al: Attenuation of ischemia/reperfusion induced MAP kinases by $\mathrm{N}$-acetyl cysteine, sodium nitroprusside and phosphoramidon. Mol Cell Biochem 240(1-2):19$29,2002$.

28- Atkins KB, Lodhi IJ, Hurley LL, Hinshaw DB: N-acetylcysteine and endothelial cell injury by sulfur mustard. J Appl Toxicol 20(Suppl 1): S125-S128, 2000.

29- Araujo M, Helou CMB, Seguro AC: Renal potassium handling in aging rat. Kidney Blood Press Res 21(6): 425-431, 1998.

30- Wakisaka M, Spiro MJ, Spiro RG: Synthesis of type IV collagen by cultured glomerular cells and comparison of its regulation by glucose and other factors with that of type IV collagen. Diabetes 43:95-103, 1994.

31- Todd-Turla KM, Schnermann J, Fejes-Toth G, et al: Distribution of mineralocorticoid and glucocorticoid receptors mRNA along the nephron. Am J Physiol 264:F781-F791, 1993.

32- Sarnak MJ: cardiovascular complications in chronic kidney disease. Am J Kidney Dis 41 (5 Suppl):11-17, 2003. 
TABLE 1. Mean body weight gain, daily N-acetylcysteine ingestion and 24-hour urinary excretion of protein and TBARS on postoperative days 21,60 and 120 in untreated rats and in rats receiving $\mathrm{N}$-acetylcysteine initiated on postoperative day 7

\begin{tabular}{|c|c|c|c|c|}
\hline Group & $\begin{array}{c}\Delta \text { BW } \\
(\text { g) }\end{array}$ & $\begin{array}{c}\text { NAC ingestion } \\
\text { (mg/100 g BW/day) }\end{array}$ & $\begin{array}{l}\text { Urinary protein } \\
\qquad(\mathrm{mg} / 24 \mathrm{~h})\end{array}$ & $\begin{array}{c}\text { Urinary TBARS } \\
\text { (nmol/24 h) }\end{array}$ \\
\hline Sham/EV21 & $106 \pm 10$ & - & $4.74 \pm 1.02$ & $18.22 \pm 2.41$ \\
\hline Nx/EV21 & $133 \pm 14$ & - & $21.46 \pm 2.71^{\star *}$ & $28.83 \pm 3.22$ \\
\hline Nx/EV60 & $141 \pm 11$ & - & $26.57 \pm 2.99^{\star *}$ & $109.0 \pm 17.95^{*}$ \\
\hline Nx/EV120 & $248 \pm 20$ & - & $207.5 \pm 9.50$ * & $254.0 \pm 51.51^{*}$ \\
\hline Sham+NAC-IN7/EV21 & $98 \pm 9$ & $14.0 \pm 0.5$ & $3.41 \pm 0.45$ & $14.85 \pm 1.64$ \\
\hline Nx+NAC-IN7/EV21 & $146 \pm 16$ & $13.7 \pm 0.6$ & $14.78 \pm 1.93$ & $15.50 \pm 0.89^{b}$ \\
\hline Nx+NAC-IN7/EV60 & $188 \pm 13^{\mathrm{a}}$ & $14.5 \pm 0.3$ & $15.62 \pm 2.64$ & $63.21 \pm 6.32^{c}$ * \\
\hline Nx+NAC-IN7/EV120 & $308 \pm 16^{b}$ & $15.7 \pm 0.8$ & $158.6 \pm 9.82^{b_{*}}$ & $91.69 \pm 6.03^{c}$ * \\
\hline
\end{tabular}


Data expressed as mean \pm SEM;

$\Delta \mathrm{BW}=$ variation (increase) in body weight; NAC, N-acetylcysteine, TBARS, thiobarbituric acid reactive substances; Sham, sham operated; Nx, nephrectomized; IN7, initiated (treatment) on postoperative day 7; EV21, evaluated on postoperative day 21; EV60, evaluated on postoperative day 60;

EV120, evaluated on postoperative day 120

${ }^{\mathrm{a}} p<0.01,{ }^{\mathrm{b}} p<0.005,{ }^{\mathrm{c}} p<0.02$; comparison between treated and untreated groups

${ }^{*} p<0.001,{ }^{* *} p<0.05$, vs. Sham

one way NOVA - Bonferroni's post test 
TABLE 2. Renal and systemic functional parameters on postoperative days 21,60 and 120 in untreated rats and in rats receiving $\mathrm{N}$-acetylcysteine initiated on postoperative day 7

\begin{tabular}{|c|c|c|c|c|c|c|c|}
\hline Group & $\begin{array}{c}\text { Serum } \\
\text { aldosterone } \\
(\mathrm{ng} / \mathrm{dL})\end{array}$ & $\begin{array}{c}\text { GFR } \\
(\mathrm{mL} / \mathrm{min} / \\
100 \mathrm{~g} \mathrm{BW})\end{array}$ & $\begin{array}{c}\text { BP } \\
(\mathrm{mmHg})\end{array}$ & $\begin{array}{l}\text { FEK } \\
(\%)\end{array}$ & $\begin{array}{c}\text { UK/UNa } \\
\text { ratio }\end{array}$ & $\begin{array}{c}\text { Heart } \\
\text { weight } \\
(g)\end{array}$ & $\begin{array}{l}\text { Adrenal } \\
\text { weight } \\
\text { (mg) }\end{array}$ \\
\hline Sham/EV21 & $11 \pm 2$ & $0.83 \pm 0.05$ & $109 \pm 3$ & $28.4 \pm 1.6$ & $0.87 \pm 0.03$ & $0.85 \pm 0.03$ & $29 \pm 0.25$ \\
\hline Nx/EV21 & $288 \pm 34^{*}$ & $0.25 \pm 0.06^{\star}$ & $138 \pm 4^{*}$ & $34.0 \pm 4.7$ & $4.74 \pm 1.61^{\star *}$ & $1.04 \pm 0.03^{* *}$ & $41 \pm 2.70^{\star}$ \\
\hline Nx/EV120 & $134 \pm 12^{\star *}$ & $0.16 \pm 0.03^{*}$ & $174 \pm 5^{\star}$ & $100.1 \pm 22.1^{\mathrm{a}}$ & $5.13 \pm 0.69^{* *}$ & $1.51 \cdot 0.07^{\star}$ & $59 \pm 2.02^{*}$ \\
\hline Sham+NAC-IN7/EV21 & $15 \pm 2$ & $0.93 \pm 0.02$ & $103 \pm 1$ & $24.0 \pm 1.6$ & $1.76 \pm 0.32$ & $0.81 \pm 0.05$ & $27 \pm 0.88$ \\
\hline Nx+NAC-IN7/EV120 & $59 \pm 2^{c * *}$ & $0.45 \pm 0.04^{b *}$ & $150 \pm 7^{b *}$ & $18.24 \pm 2.2^{d}$ & $2.23 \pm 0.72^{d}$ & $1.35 \pm 0.05^{\star}$ & $42 \pm 1.7^{c *}$ \\
\hline
\end{tabular}


Data expressed as mean \pm SEM; GFR, glomerular filtration rate (inulin clearance); BP, blood pressure; FEK, fractional excretion of potassium; UK/UNa,

urinary sodium/potassium ratio; NAC, N-acetylcysteine; Sham, sham operated; Nx, nephrectomized; IN7, initiated (treatment) on postoperative day 7 ;

EV21, evaluated on postoperative day 21; EV60, evaluated on postoperative day 60; EV120, evaluated on postoperative day 120

${ }^{a} p<0.0001,{ }^{b} p<0.005,{ }^{c} p<0.01,{ }^{d} p<0.05$, comparison between treated and untreated groups

${ }^{*} p<0.001,{ }^{* *} p<0.05$, vs. Sham

By one way ANOVA - Bonferroni's post-test 
TABLE 3. Renal and systemic functional parameters on postoperative day 120 in nephrectomized rats receiving spironolactone alone or the combination of spironolactone and $\mathrm{N}$-acetylcysteine initiated on postoperative day 60

\begin{tabular}{|c|c|c|c|c|c|c|c|c|}
\hline Group & $\begin{array}{c}\text { BP } \\
(\mathrm{mmHg})\end{array}$ & $\begin{array}{c}\text { GFR } \\
(\mathrm{mL} / \mathrm{min} / \\
100 \mathrm{~g} \mathrm{BW})\end{array}$ & $\begin{array}{l}\text { Proteinuria } \\
\text { (mg/24 h) }\end{array}$ & $\begin{array}{c}\text { UK/UNa } \\
\text { ratio }\end{array}$ & $\begin{array}{c}\text { Aldosterone } \\
\text { (ng/dl) }\end{array}$ & $\begin{array}{c}\text { TBARS } \\
\text { (nmol/24 h) }\end{array}$ & $\begin{array}{c}\text { Heart } \\
\text { weight } \\
\text { (g) }\end{array}$ & $\begin{array}{c}\text { Adrenal } \\
\text { weight } \\
\text { (mg) }\end{array}$ \\
\hline Nx+SPI-IN7/EV60 & $155 \pm 3$ & $0.28 \pm 0.04$ & $18 \pm 1$ & $0.90 \pm 0.1$ & $325 \pm 77$ & $118 \pm 14$ & $1.38 \pm 0.03$ & $57 \pm 1.5$ \\
\hline Nx+SPI+NAC-IN7/EV60 & $136 \pm 2^{a}$ & $0.59 \pm 0.04^{a}$ & $14 \pm 1^{b}$ & $0.66 \pm 0.1$ & $183 \pm 20$ & $81 \pm 5^{b}$ & $1.31 \pm 0.03$ & $41 \pm 1.4^{\mathrm{a}}$ \\
\hline
\end{tabular}

Data expressed as mean \pm SEM; BP, blood pressure; GFR, glomerular filtration rate (inulin clearance); UK/UNa, urinary sodium/potassium ratio; TBARS; SPI, spironolactone; NAC, N-acetylcysteine; IN7, initiated (treatment) on postoperative day 7; EV60, evaluated on postoperative day 60

${ }^{\mathrm{a}} \mathrm{p}<0.0001$ vs. $\mathrm{Nx}+\mathrm{SPI}$ only; ${ }^{\mathrm{b}} \mathrm{p}<0.03 \mathrm{vs}$. Nx+SPI only, by unpaired t-test 


\section{Figure Legends}

Figure 1. Fractional interstitial area in glomeruli of Nx/EV120 and Nx+NAC-IN7/EV120 rats. Data are expressed as mean \pm SEM (Unpaired $t$-test with Welch's correction at $p<0.03$ ).

Figure 2. Number of ED1-positive cells $/ \mathrm{mm}^{2}$ in the glomeruli and tubulointerstitium of $\mathrm{Nx} / \mathrm{EV} 120$ and Nx+NAC-IN7/EV120 rats. Data are expressed as mean \pm SEM. (Unpaired $t$ test with Welch's correction at $p<0.02)$.

Figure 3. Immunostaining for ED1 (monocytes/macrophages) in the renal cortices from $\mathrm{Nx} / \mathrm{EV} 120$ rats $(\mathrm{A})$ and Nx+NAC-IN7/EV120 rats (B). Note that the number of ED1-positive cells is higher in $(A)$.

Figure 4. Number of CD3-positive cells $/ \mathrm{mm}^{2}$ in the glomeruli and tubulointerstitium of $\mathrm{Nx} / \mathrm{EV} 120$ and Nx+NAC-IN7/EV120 rats. Data are expressed as mean \pm SEM. (Unpaired $t$ test with Welch's correction at $p<0.05)$.

Figure 5. Immunostaining for CD3 (T-lymphocytes) in renal cortices from Nx/EV120 rats (A) and $\mathrm{Nx}+\mathrm{NAC}-\mathrm{IN7/EV120}$ rats (B). Note that the number of CD3-positive cells is higher in (A).

Figure 6. (A) Inulin clearance and (B) glomerulosclerosis index in Nx/EV120, Nx+NACIN7/EV120 and Nx+NAC-IN60/EV120 groups. Data are expressed as mean \pm SEM (ANOVA-Bonferroni's post-test, $p<0.05$ )

Figure 7. (A) Inulin clearance and (B) glomerulosclerosis index in the $\mathrm{Nx} / \mathrm{EV} 60, \mathrm{Nx}+\mathrm{SPI}-$ IN7/EV60, Nx+NAC-IN7/EV60 and Nx+SPI+NAC-IN7/EV60 groups. Data are expressed as mean \pm SEM (ANOVA-Bonferroni's post-test, $p<0.05$ )

Figure 8. Correlation between proteinuria - corrected by inulin clearance (UV prot./Cin) and the respective glomerulosclerosis index (GSI). Data are from $\mathrm{Nx} / \mathrm{EV} 60, \mathrm{Nx}+\mathrm{SPI}-$ 
IN7/EV60, Nx+NAC-IN7/EV60, Nx+SPI+NAC-IN7/EV60, Nx/EV120, Nx+NAC-IN7/EV120 and Nx+NAC-IN60/EV120 groups. 
FIGURE 1

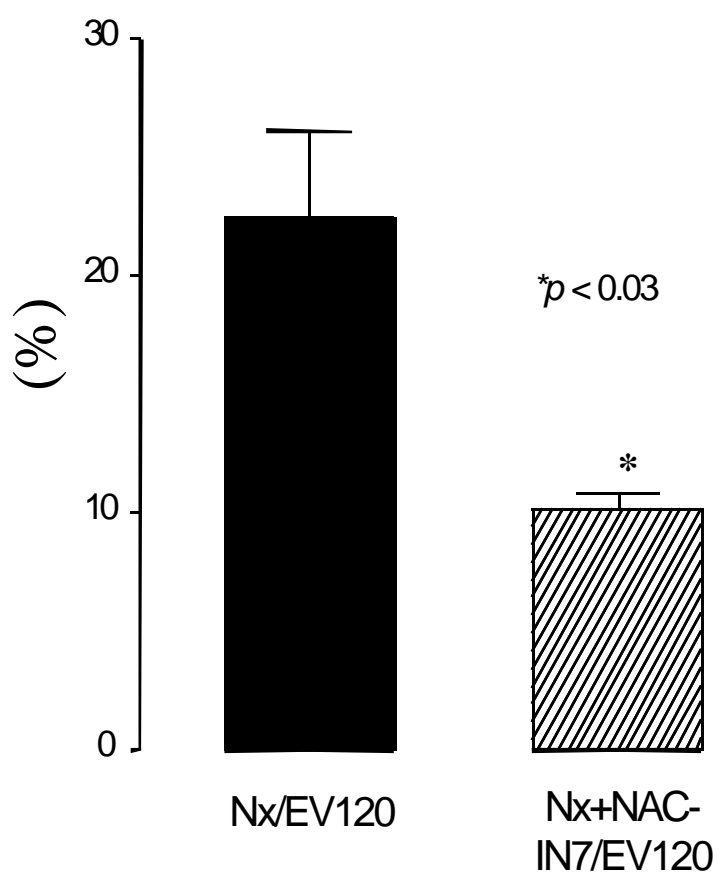




\section{FIGURE 2}

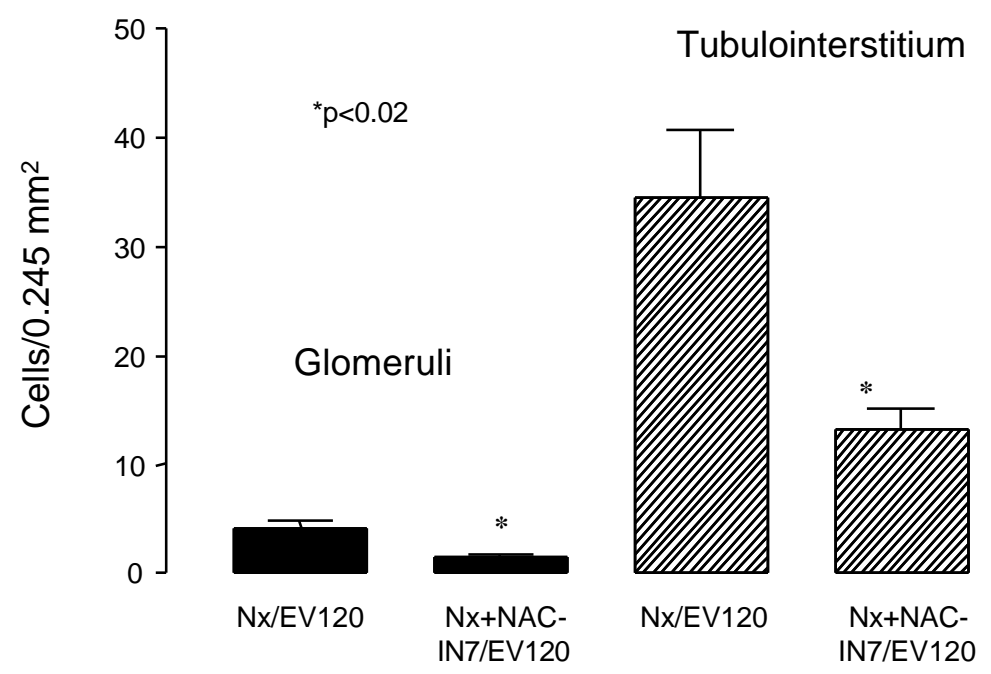


FIGURE 3

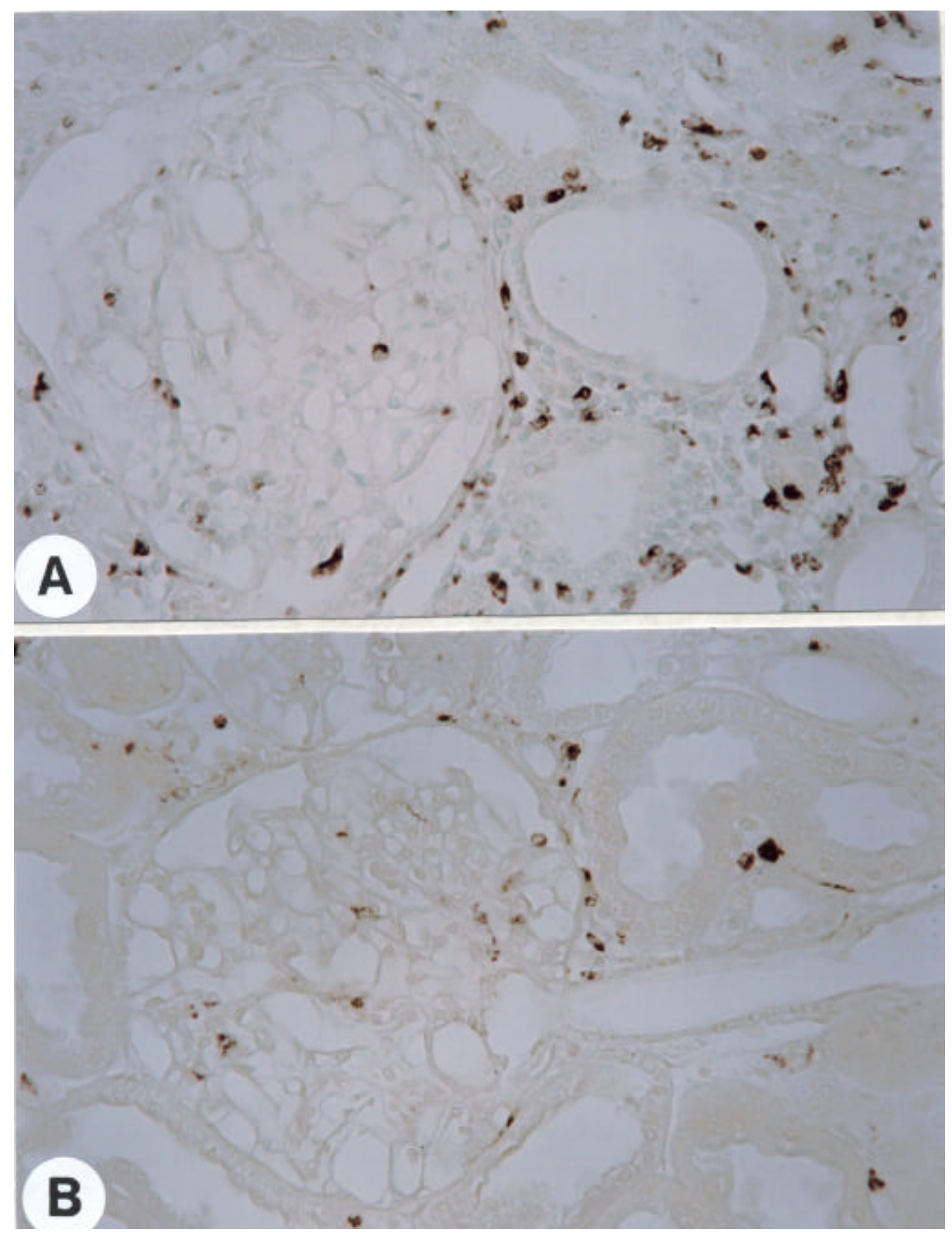




\section{FIGURE 4}

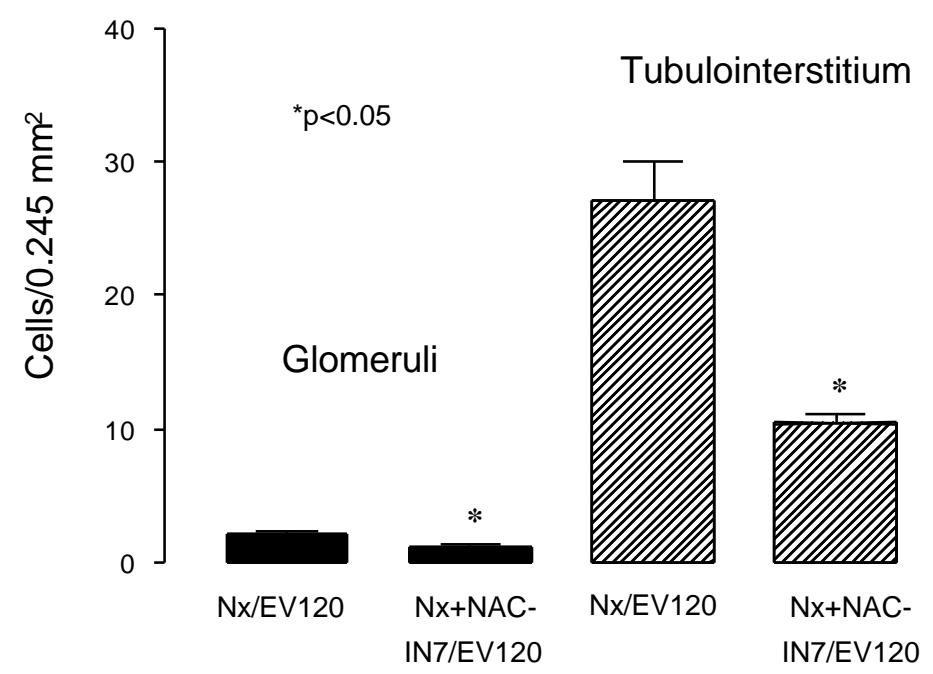




\section{FIGURE 5}

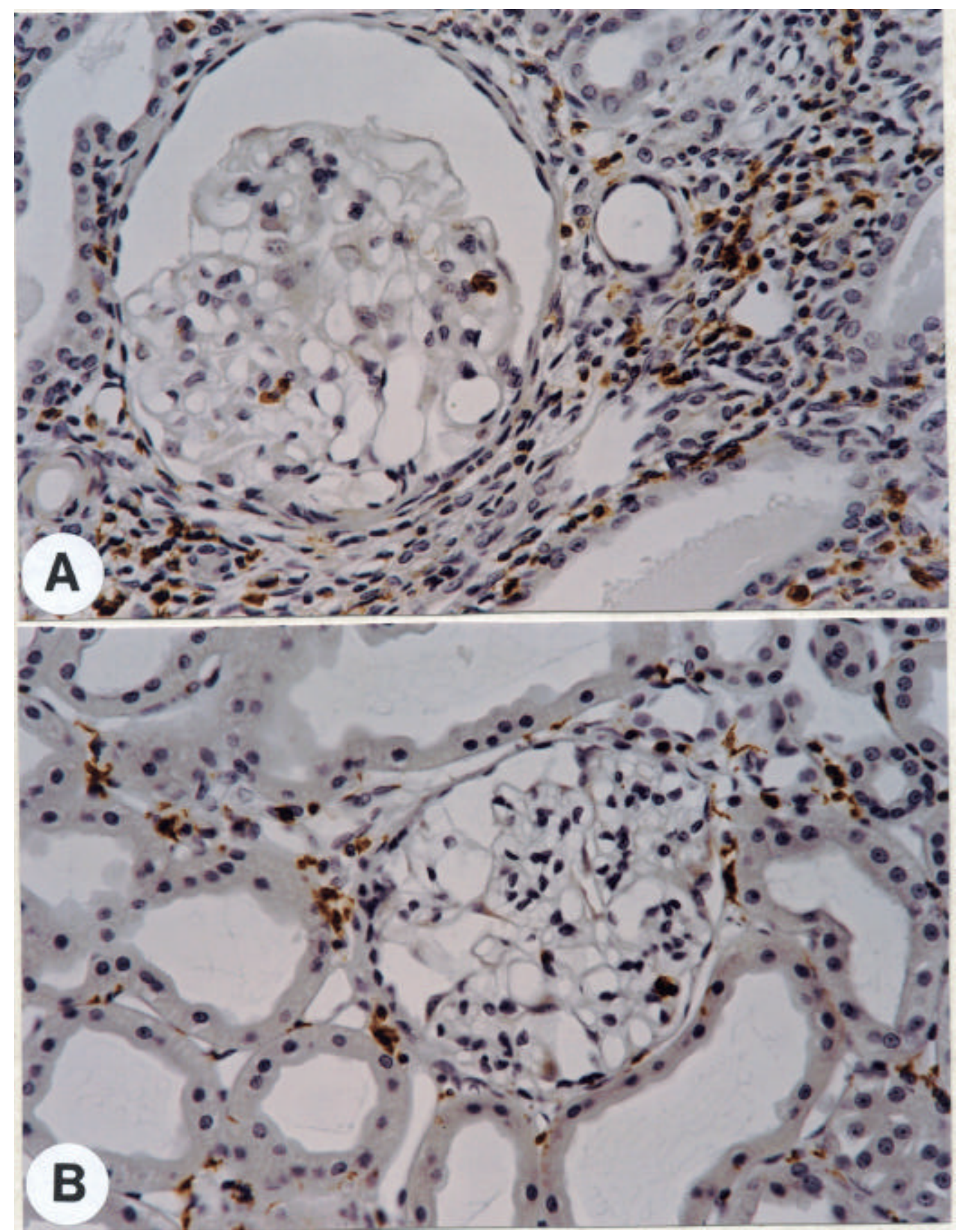


FIGURE 6
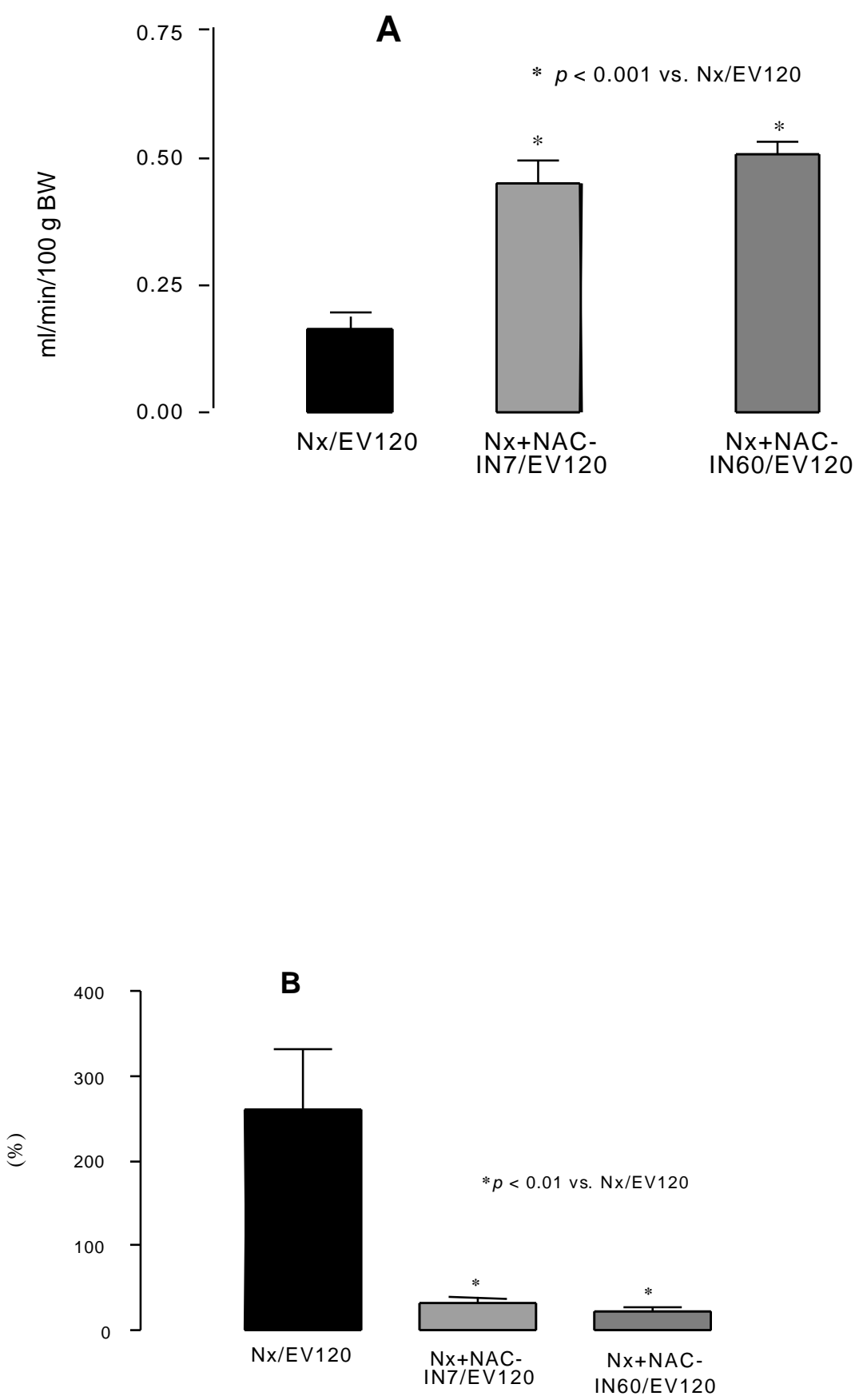


\section{FIGURE 7}

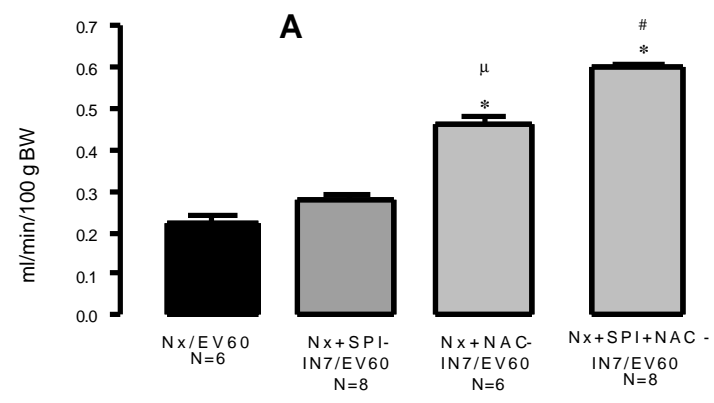

${ }^{*} p<0.001$ vs. $\mathrm{Nx} / \mathrm{EV} 60 \# p<0.001$ vs. $\mathrm{Nx}+\mathrm{SPI}-\mathrm{IN} 7 / \mathrm{EV} 60 \mu p<0.05$ vs. $\mathrm{N} x+\mathrm{SP}+\| \mathrm{N} 7 / \mathrm{EV} 60$

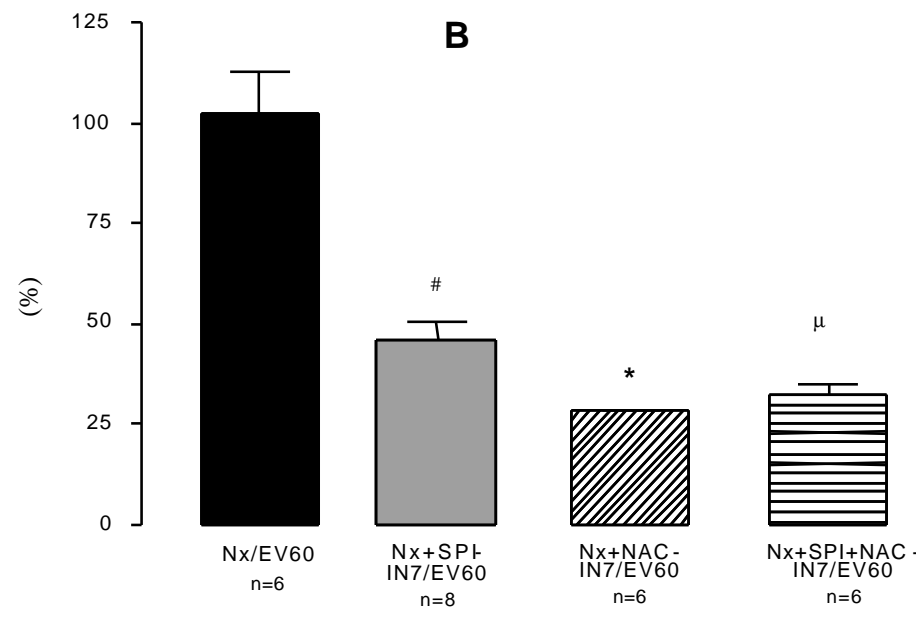

$* p<0.001$ vs. Nx/EV60 $\# p<0.01$ vs. Nx/EV60 $\mu p<0.05$ vs. Nx/EV60 
FIGURE 8

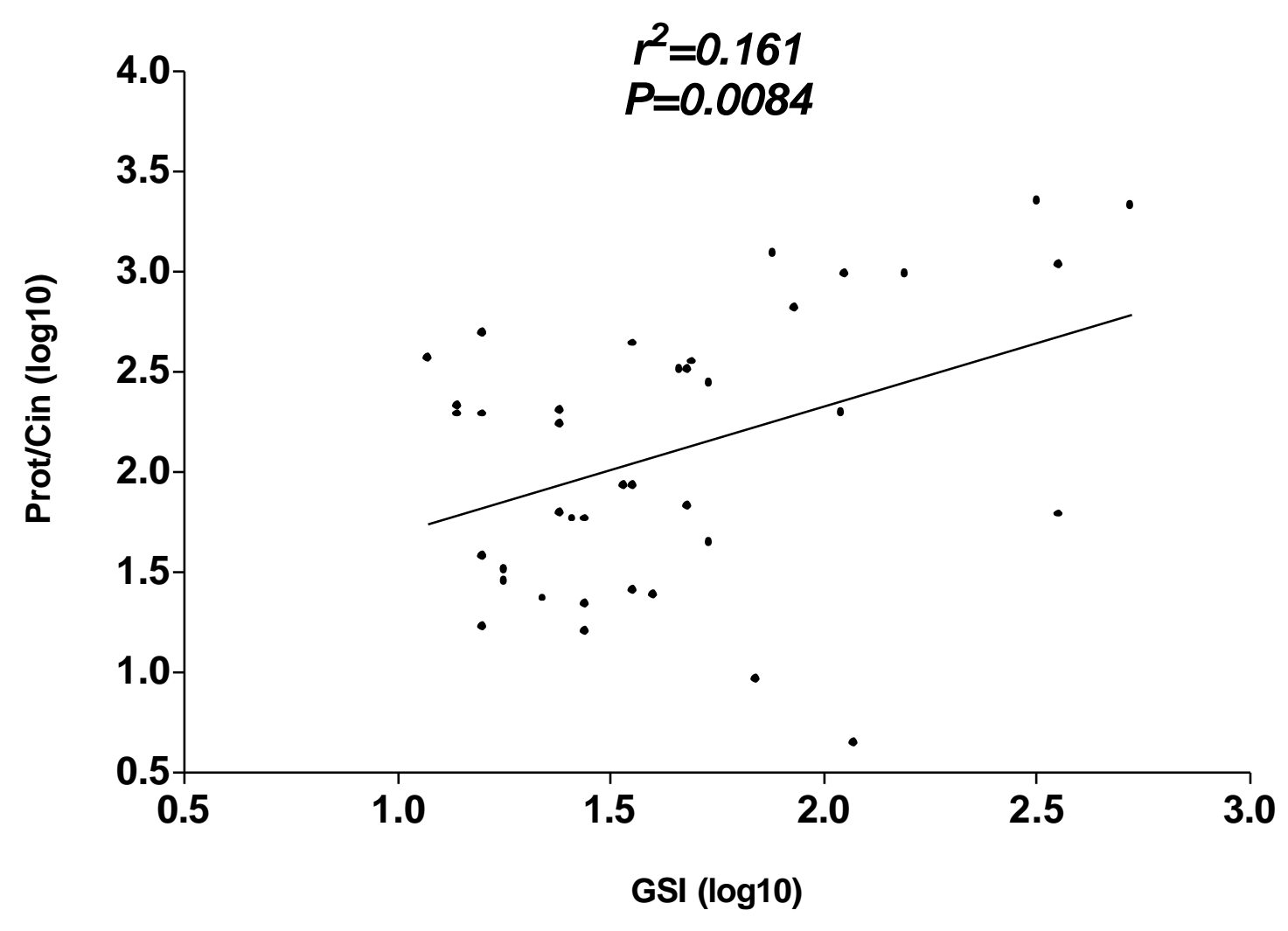

